LUÍS ANTONIO RODRIGUES QUADRANTE

\title{
DESENVOLVIMENTO DE UM SIMULADOR SIMPLIFICADO PARA ESTUDO DE GERAÇÃO DE ONDAS EM TANQUES DOTADOS DE GERADORES SEGMENTADOS.
}

Dissertação apresentada à Escola

Politécnica da Universidade de São Paulo para obtenção do Título de Mestre em Engenharia 


\title{
DESENVOLVIMENTO DE UM SIMULADOR SIMPLIFICADO PARA ESTUDO DE GERAÇÃO DE ONDAS EM TANQUES DOTADOS DE GERADORES SEGMENTADOS.
}

\author{
Dissertação apresentada à Escola \\ Politécnica da Universidade de São \\ Paulo para obtenção do Título de \\ Mestre em Engenharia \\ Área de Concentração: \\ Engenharia Naval e Oceânica
}

Orientador:

Prof. Dr. Alexandre Nicolaos Simos 
Este exemplar foi revisado e alterado em relação à versão original, sob responsabilidade única do autor e com a anuência de seu orientador.

São Paulo, de julho de 2011.

Assinatura do autor

Assinatura do orientador

FICHA CATALOGRÁFICA

Quadrante, Luís Antonio Rodrigues

Desenvolvimento de um simulador simplificado para estudo de geração de ondas em tanques dotados de geradores segmen-

tados / L.A.R. Quadrante. -- ed.rev. -- São Paulo, 2011.

p.

Dissertação (Mestrado) - Escola Politécnica da Universidade de São Paulo. Departamento de Engenharia Naval e Oceânica.

1. Tanque de provas 2. Ondas (Geração) 3. Simulação I. Universidade de São Paulo. Escola Politécnica. Departamento de Engenharia Naval e Oceânica II. t. 
Dedico este trabalho à minha esposa Minako e aos meus pais por sempre me apoiarem. 


\section{Agradecimentos}

Ao meu orientador, Prof. Dr. Alexandre Nicolaos Simos, por todo o apoio, encorajamento e orientação durante o mestrado.

Ao Prof. Dr. Kazuo Nishimoto, pela idealização do projeto e pelos anos de aprendizado no TPN.

Ao Prof. Dr. Celso Pupo Pesce, por todos os comentários e sugestões feitos no texto da qualificação.

À Minako, pelo apoio e carinho.

Ao Pedro e ao Mário, pela ajuda nas discussões sobre a geração de ondas e por fornecer os dados dos ensaios de geração que fizeram, utilizados neste trabalho para validação.

Aos amigos do laboratório do Departamento de Engenharia Naval e Oceânica, Carlos, João e Marlei, pela ajuda com os meus primeiros ensaios de geração de onda.

Ao André, pela ajuda durante o período no Japão e à todo pessoal do TPN, onde comecei este trabalho.

À Escola Politécnica da USP pela oportunidade na realização deste trabalho.

E, finalmente, a todos que contribuíram direta ou indiretamente para a realização deste trabalho 


\section{Resumo}

Este trabalho trata do desenvolvimento de um simulador simplificado para auxiliar no estudo da geração de ondas regulares em tanques de provas dotados de geradores segmentados, com foco em estudos sobre o Calibrador Hidrodinâmico, tanque de provas inaugurado na Universidade de São Paulo no ano de 2010.

Este simulador simplificado utiliza fontes de onda pontuais para representar cada gerador e tem como sua principal vantagem, a economia de tempo em comparação a análises do problema de contorno potencial realizadas no domínio da freqüência utilizando, por exemplo, o método dos elementos de contorno.

A verificação da validade da ferramenta desenvolvida foi feita através de comparações do caso bidimensional com ensaios realizados em um canal de ondas e, no caso tridimensional, com resultados fornecidos pelo programa Wamit, o qual resolve o problema de contorno potencial. Nestas comparações, o simulador demonstrou seu potencial, atingindo bons resultados.

Uma vez validada, a ferramenta foi utilizada para analisar três diferentes configurações de operação do Calibrador Hidrodinâmico que podem vir a ser implementadas no futuro. As análises mostram que nenhuma das configurações é a melhor para todas as combinações de períodos e direções de propagação nas quais o tanque pode operar e podem servir como base para a definição de um procedimento de operação que vise garantir maior flexibilidade na utilização do tanque de provas mantendo a qualidade do campo de ondas gerado para os ensaios. 


\begin{abstract}
This work aims the development of a simplified simulator to assist the study about regular waves generation in test tanks equipped with segmented type wavemakers, focusing on the study about the Calibrador Hidrodinâmico (Hydrodynamics Calibrator), test tank inaugurated in 2010 at University of São Paulo.

This simplified simulator uses punctual wave sources to represents each wavemaker end its main advantage is the computational time economy in comparison with analysis of the potential boundary problem made on frequency domain using, as example, the boundary elements method (BEM).

To verify the developed tool validity, comparisons with bi-dimensional wave generation tests carried out on a flume were made. In three dimensional case, the comparisons were made with results provided by the program Wamit, which one solves the potential boundary problem. In all comparisons the results achieved were very good.

Once proved the validity of simulator results, it was applied to analyze three different operational configurations of the Calibrador Hidrodinâmico, which can be implemented in future. The analysis showed that there is not a configuration with best results for all periods and propagation angles inside the tank operational limits and these results can be used to define a operation procedure that aims to ensure more flexibility on wavemakers operation to obtain the best possible wave field quality for all periods and propagation angles.
\end{abstract}




\section{Sumário}

\section{Lista de figuras}

\section{Lista de Tabelas}

\section{Lista de Abreviaturas}

\section{Lista de Símbolos}

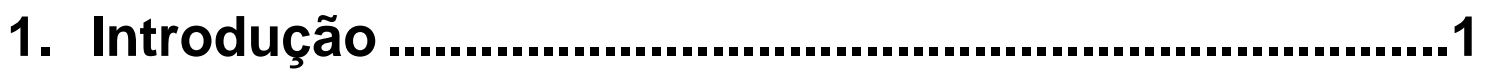

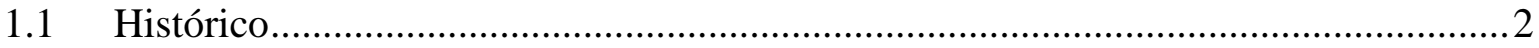

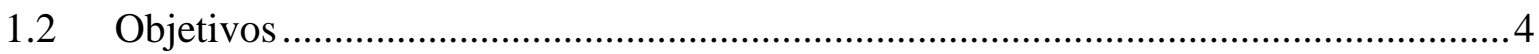

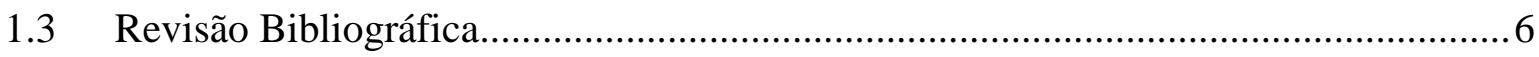

2. Teoria de geração e absorção de ondas ......................9

2.1 Teoria linear de ondas de gravidade ................................................................ 10

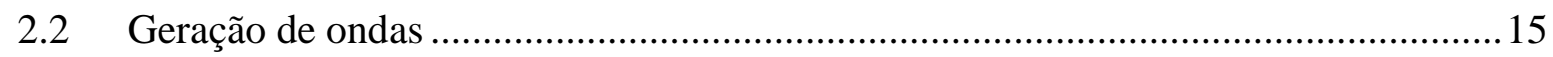

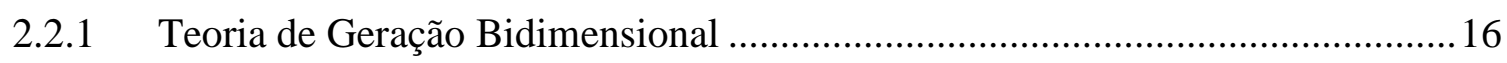

2.3 Função de Transferência - Flap ....................................................................... 21

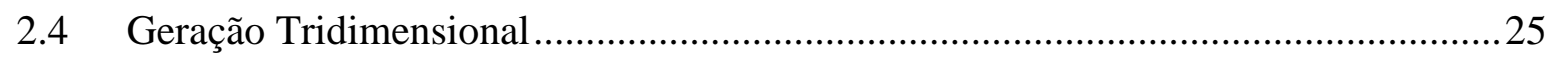

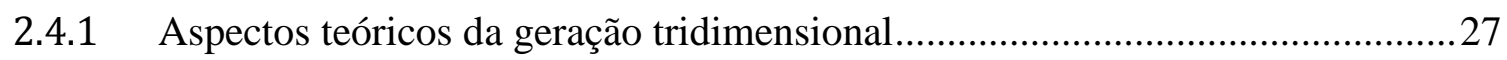

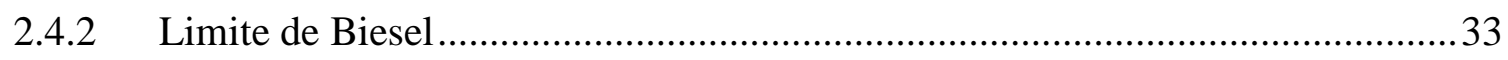

\section{Simulador Numérico ................................................37}

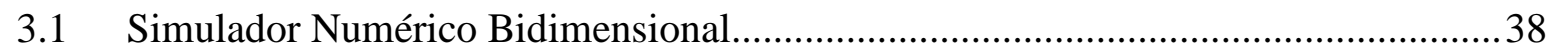

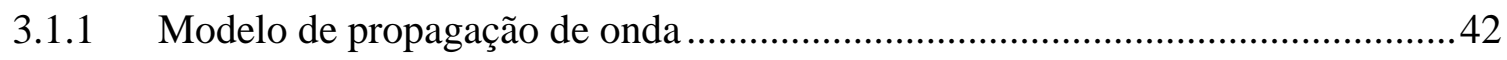

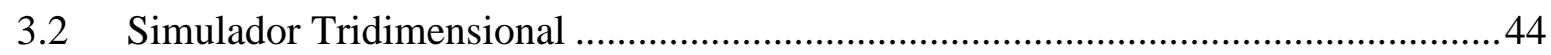

3.2.1 Representação dos Geradores: Fontes .......................................................... 45

3.2.2 Representação da reflexão e da absorção ......................................................... 46

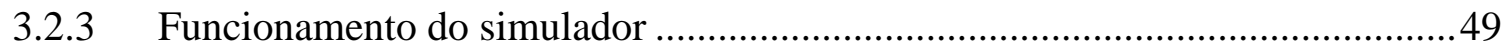

4. Validação do Simulador ............................................54 


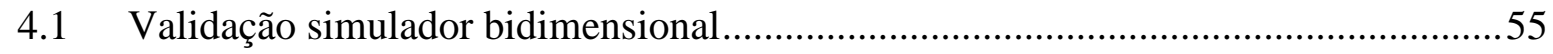

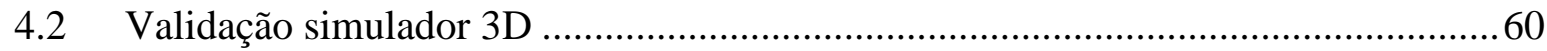

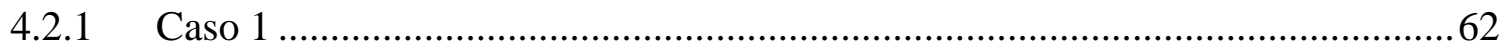

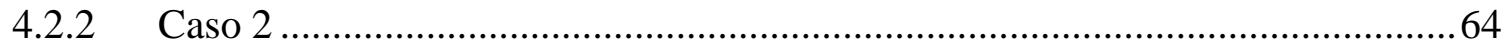

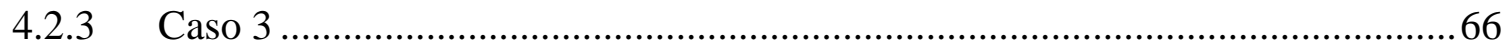

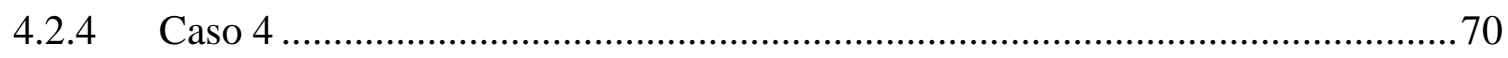

5. Análises Calibrador Hidrodinâmico..........................73

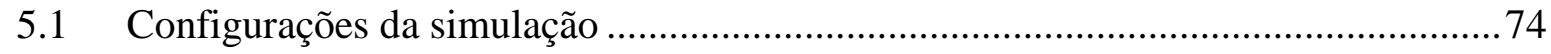

5.2 Metodologia de análise e comparações.................................................................. 77

5.3 Análise dos cantos arredondados na geração de ondas perpendiculares à parede .....79

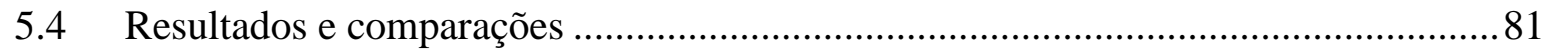

5.4.1 Configuração ideal - Todos os flaps operando .............................................. 81

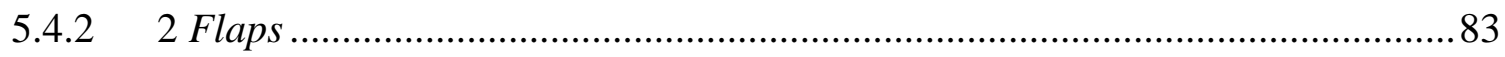

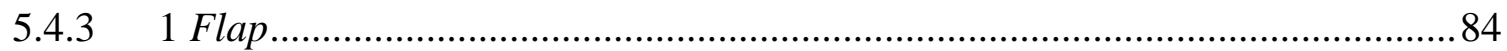

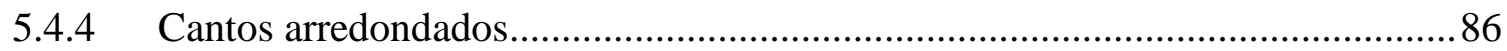

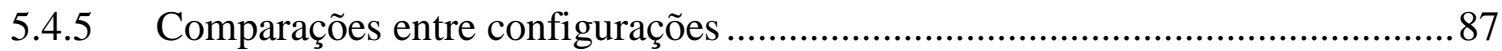

6. Conclusões e Recomendações de Trabalhos Futuros .96

6.1 Recomendações para futuras pesquisas ................................................................ 98

7. Referências ...........................................................100

\section{Apêndice A - Dispositivos de Geração}




\section{Lista de Figuras}

Figura 1.1: Calibrador Hidrodinâmico, tanque de provas construído na Universidade de São Paulo.

Figura 1.2: Novo tanque de provas localizado no NMRI, Japão. 4

Figura 2.1: Representação de uma onda progressiva. a) instante de tempo fixo. b) x fixo.

Figura 2.2: Representação do campo de velocidades para profundidade finita (fonte: Newman 1977)

Figura 2.3: Representação do campo de velocidades para profundidade infinita. (fonte: Newman 1977).

Figura 2.4: Eixo de coordenadas utilizado.

Figura 2.5: Flap Pivotado no fundo

Figura 2.6: Flap pivotado acima do fundo

Figura 2.7: Flaps em movimento para gerar onda obliqua.

Figura 2.8: Sistema de coordenadas.

Figura 2.9: Discretização do gerador de ondas.

Figura 2.10: Diferença de percurso entra ondas de flaps adjacentes.

Figura 3.1: Disposição do simulador bidimensional proposto.

Figura 3.2: Convergência da somatória de amplitude das (ondas evanescentes, para

o período de 2 segundos.

Figura 3.3: Modelo de propagação de onda.

Figura 3.4: Reflexão de onda em uma parede.

Figura 3.5: Método de representação de reflexão de ondas utilizando imagens dos geradores.

Figura 3.6: Sistema de coordenadas e definição de geradores e

Figura 3.7 Parede geradora

Figura 3.8: Sincronização entre as duas paredes geradoras... 52

Figura 4.1: Protótipo de gerador com quatro flaps montado em um canal. 54

Figura 4.2: Função de transferência do protótipo. (Carneiro, 2008) 
Figura 4.3: Comparação Protótipo e Simulador para onda 2 segundos.

Figura 4.4: Aproximação do sinal de leitura de onda $\mathrm{T}=2$ segundos.........................57

Figura 4.5: Comparação Protótipo X Simulador para onda de 0.5 segundos ..............58

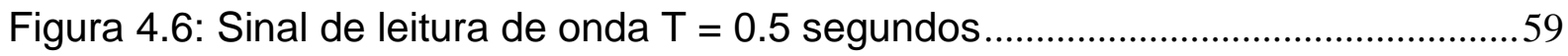

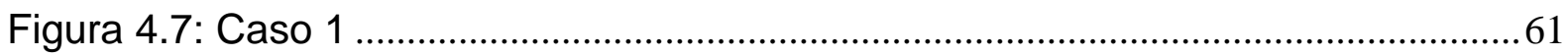

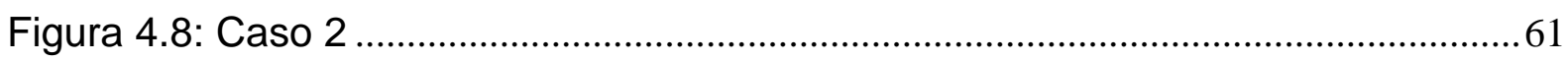

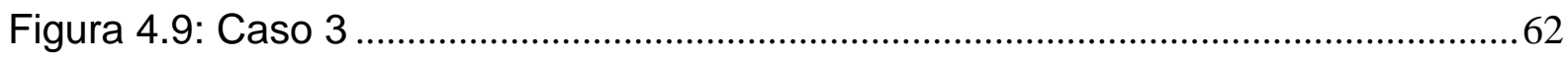

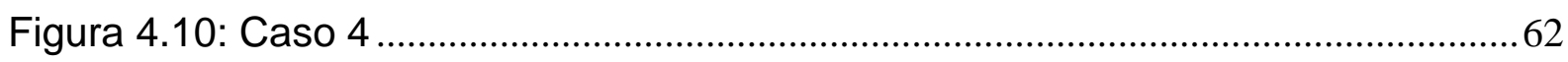

Figura 4.11: Caso 1 - Mapa da superfície livre para apenas um gerador, obtido com o Simulador.

Figura 4.12: Caso 1 - Mapa de superfície livre fornecido pelo Wamit .........................63

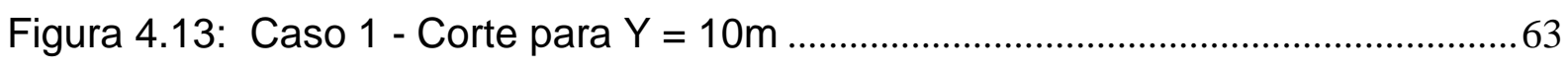

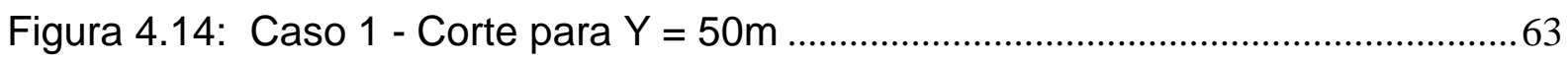

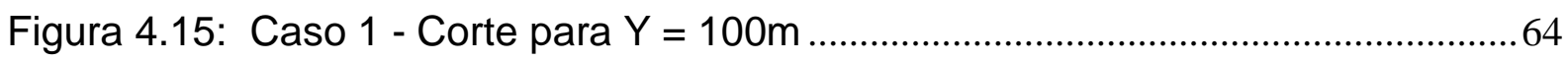

Figura 4.16: Caso 2 - Mapa da superfície livre para apenas um gerador, obtido com o Simulador, com reflexão......

Figura 4.17: Caso 2 - Mapa de superfície livre fornecido pelo Wamit .........................64

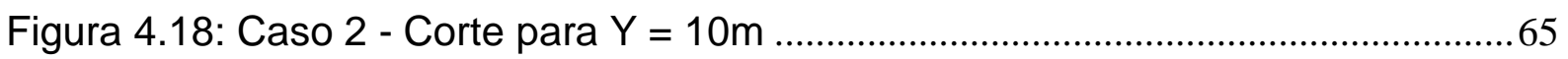

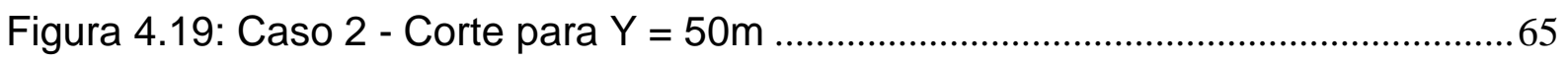

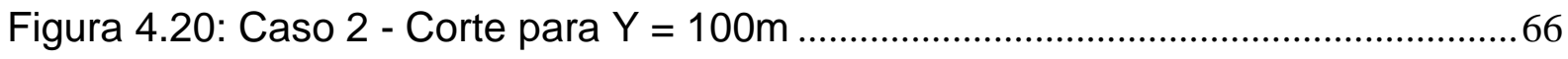

Figura 4.21: Caso 3 - Mapa da superfície livre obtido com o Simulador para direção de propagação igual a 0 graus, com reflexão.

Figura 4.22: Caso 3 - Mapa de superfície livre fornecido pelo Wamit para direção de propagação igual a 0 graus......

Figura 4.23: Caso 3 - Direção de propagação de 0 graus - Cortes para $X=35 m$........67

Figura 4.24: Caso 3 - Direção de propagação de 0 graus - Cortes para $Y=50$ m........68

4.25: Comparação da amplitude de onda obtida no simulado com a função de transferência teórica.

Figura 4.26: Caso 3 - Mapa da superfície livre obtido com o Simulador para direção de propagação igual a 22.5 graus, com reflexão. 
Figura 4.27: Caso 3 - Mapa de superfície livre fornecido pelo Wamit para direção de propagação igual a 22.5 graus.

Figura 4.28: Caso 3 - Direção de propagação de 22.5 graus - Cortes para $X=35$ m ..69

Figura 4.29: Caso 3 - Direção de propagação de 22.5 graus - Cortes para $Y=50 m$.. 70

Figura 4.30: Caso 4 - Mapa da superfície livre obtido pelo simulador, gerando onda em 67.5 graus.

Figura 4.31: Mapa de superfície livre fornecido pelo Wamit, , gerando onda em 67.5 graus

Figura 4.32: Caso 4 - Direção de propagação de 67.5 graus - Cortes para $Y=50 m$.. 71

Figura 4.33: Caso 4 - Cortes para $X=35 \mathrm{~m}$.

Figura 5.1: Nomenclatura das paredes e numeração dos flaps para o tanque quadrado

Figura 5.2: Nomenclatura das paredes e numeração dos flaps para o tanque com

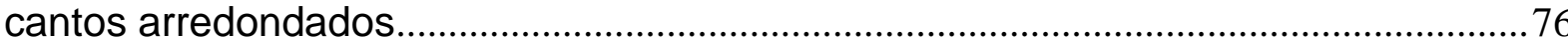

Figura 5.3: Área do tanque na qual serão realizadas as análises.................................77

Figura 5.4: Máximas amplitudes dentro de um período de onda obtidas para a análise.

Figura 5.5: Desvio padrão normalizado em função do período de onda para as cinco

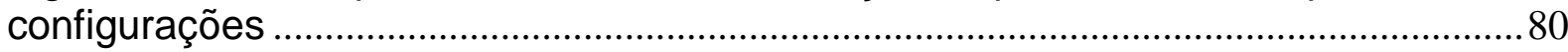

Figura 5.6: Desvio padrão em função do período para todos os flaps operando. .......82

Figura 5.7: Desvio padrão em função do período para o caso 2Flaps............................84

Figura 5.8: Desvio padrão em função do período para o caso 1Flap..............................85

Figura 5.9: Desvio padrão em função do período para o caso com cantos arredondados.

Figura 5.10: Comparação entre os quatro casos - Direção 0 graus. …………………....8

Figura 5.11: Desvio padrão Comparação entre os quatro casos - Direção 22.5 graus. 88

Figura 5.12: Comparação entre os quatro casos - Direção 45 graus..............................8

Figura 5.13: Comparação entre os quatro casos - Direção 67.5 graus..........................8 89

Figura 5.14: Desvio Comparação entre os quatro casos - Direção 90 graus...............90

Figura 5.15: Superfície livre para o caso 2Flaps, com direção 67.5 e período $0.7 s$ s. 92 
Figura 5.16: Superfície livre para o caso 1Flap, com direção 67.5 e período $0.7 \mathrm{~s}$....92 Figura 5.17: Superfície livre para o caso 2Flaps, com direção 67.5 e período 1.0s. .93 Figura 5.18: Superfície livre para o caso 1Flaps, com direção 67.5 e período 1.0s. .93 Figura 5.19: Onda do caso 2Flaps (esq.) e onda que seria gerada pelos flaps travados. 


\section{Lista de Tabelas}

Tabela 2.1: Relação entre amplitude da onda progressiva e das evanescentes.......24

Tabela 4.1: Características dos ensaios comparados......................................56

Tabela 4.2: Resumo das comparações para o simulador bidimensional. ................60

Tabela 5.1: Modos de utilização do tanque quadrado no simulador ........................74

Tabela 5.2: Períodos e ângulos de propagação para análise ..................................78

Tabela 5.3: Modo de operação das paredes do tanque para cada período e ângulo.

Tabela 5.4: Configurações escolhidas para análise ...................................... 80

Tabela 5.5: Resultados obtidos para o caso ideal, com todos os flaps operando.....82

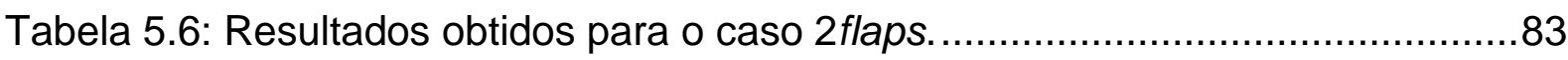

Tabela 5.7: Resultados obtidos para o caso 1Flap. ....................................... 85

Tabela 5.8: Resultados obtidos para o caso com cantos arredondados ..................86 


\section{Lista de Abreviaturas}

$\mathrm{CH}$-TPN Calibrador Hidrodinâmico do Tanque de Provas Numérico

NMRI National Maritime Research Institute

TPN Tanque de Provas Numérico

USP Universidade de São Paulo 


\section{Lista de Símbolos}

A amplitude de onda

$A_{p} \quad$ amplitude da onda progressiva

$A_{n} \quad$ amplitude dos modos evanescentes

$c_{g} \quad$ velocidade de grupo

$c_{p} \quad$ velocidade de fase

E função representando o movimento do flap

$F_{p} \quad$ função de transferência do flap

$g \quad$ aceleração da gravidade

$h \quad$ profundidade

$h^{\prime} \quad$ distância entre o ponto de pivotamento do flap e o fundo

$k \quad$ número de onda

$k_{p} \quad$ número de onda da onda progressiva

$k_{p} \quad$ número de onda da onda evanescente

$T \quad$ tempo

$\ell \quad$ largura do flap

L distância entre o ponto de pivotamento e acionamento do flap

S stroke na linha d'agua

$\mathrm{S}_{\mathrm{c}} \quad$ stroke de acionamento

$T \quad$ período de onda

$v_{x} \quad$ velocidade do fluido na direção $\mathrm{x}$

$v_{z} \quad$ velocidade do fluido na direção $\mathrm{z}$

$\alpha \quad$ ângulo de incidência da onda 
$\eta_{e} \quad$ elevação da onda evanescente

$\eta_{p} \quad$ elevação da onda progressiva

$\varepsilon$ função de forma do flap

$\Phi$ potencial real do escoamento

$\varphi \quad$ potencial de velocidades

$\theta \quad$ ângulo de propagação da onda

$\omega$ freqüência angular da onda

$\zeta \quad$ superfície livre

$\lambda$ comprimento de onda 


\section{Introdução}

A indústria naval e de petróleo está em constante crescimento e desenvolvimento, sempre em busca de embarcações e plataformas melhores e mais seguras para as atividades de exploração e produção de óleo e gás. Os principais fatores a serem considerados durante a fase de projeto destes sistemas navais e oceânicos são os fatores ambientais, como vento, ondas e correntes oceânicas, que interagem diretamente com a unidade flutuante.

Em todo novo projeto são previstos ensaios com modelos em escala reduzida, conduzidos em tanques de provas que visam reproduzir as condições ambientais nas quais a estrutura desenvolvida irá operar. Com o avanço computacional ocorrido nas ultimas décadas, existe uma clara tendência de transferir parte dos testes realizados em tanques de provas para simuladores numéricos, podendo ser citado, como exemplo, o Tanque de Provas Numérico (TPN), desenvolvido na Universidade de São Paulo.

Apesar desta tendência, no presente momento, nenhum modelo numérico criado é capaz de prever, de forma autônoma, todas as forças de origem hidrodinâmica atuantes sobre estes sistemas flutuantes, sendo sempre necessário aliar ensaios em tanques de provas com simuladores numéricos, para fins de calibração e verificação.

Com este objetivo, foi inaugurado no ano de 2010 nas dependências do TPN o Calibrador Hidrodinâmico (CH-TPN), um tanque de provas dotado de geradores segmentados capazes de gerar e absorver ondas de forma ativa, como pode ser verificado nos trabalhos de Maeda ${ }^{[10]}$ e Naito ${ }^{[12]}$. Ainda, de acordo com Naito e como discutido por Schaffer ${ }^{[16]}$, o sistema de absorção ativa permite a diminuição das dimensões dos tanques e, ao mesmo tempo, um aumento na duração dos ensaios antes que as reflexões que ocorrem nas paredes do tanque interfiram nos resultados. 
Tendo sido inaugurado há dois anos, o tanque está em fase de testes e ajustes de seus sistemas de geração e absorção de onda. Este é um processo demorado, como foi observado em outros tanques similares, podendo ser citado como exemplo - Deep Sea Basin, tanque de provas construído no National Maritime Research Institute, Japão, e que demorou anos para atingir plena operação (Maeda et. al. ${ }^{[10]}$ ).

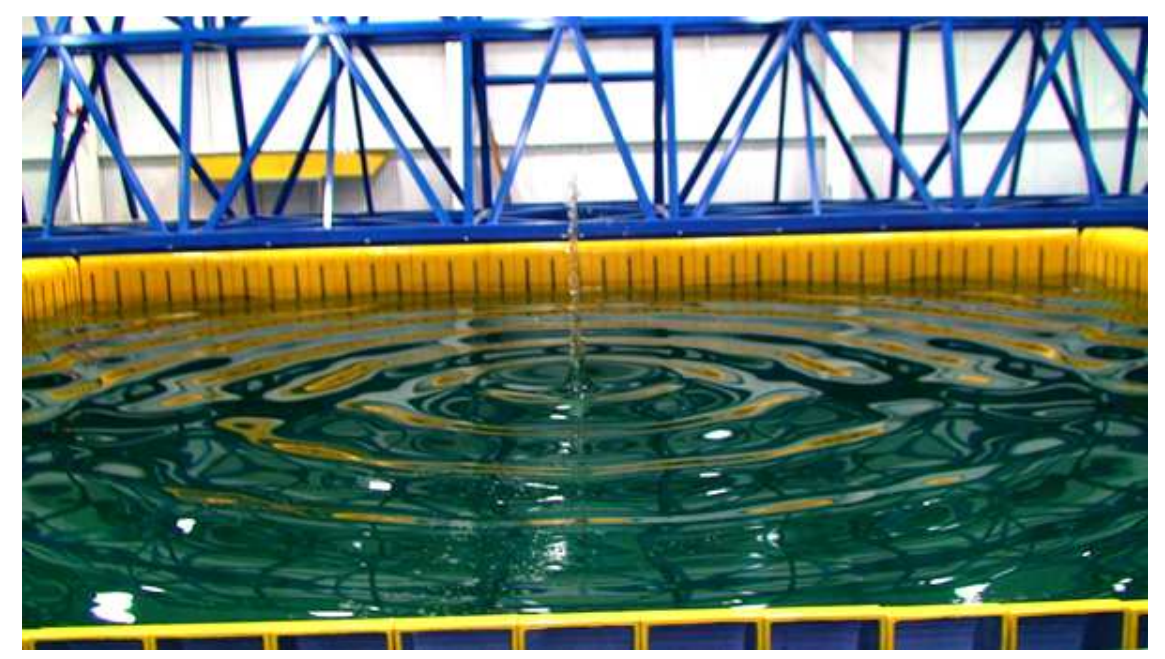

Figura 1.1: Calibrador Hidrodinâmico, tanque de provas construído na Universidade de São Paulo.

Visando auxiliar neste desenvolvimento e também estudar possíveis alterações na geometria e modo de operar do tanque, este trabalho tem como objetivo 0 desenvolvimento de um simulador simplificado capaz de emular a elevação da superfície livre do tanque, ao longo do tempo, utilizando para isso funções de singularidades do tipo fontes pontuais para representar os geradores de onda.

\subsection{Histórico}

O emprego de tanques de prova para obtenção de características hidrodinâmicas de sistemas flutuantes é realizado há centenas de anos. Como um dos pioneiros, podese citar o tanque de Willian Froude (1810-1879), no qual eram executados ensaios com embarcações em escala reduzida para, através de medidas de sua resistência 
ao avanço, estabelecer previsões para a força de resistência experimentada pelas embarcações reais.

Com o passar dos anos, o desenvolvimento tecnológico da indústria naval e a utilização de novos materiais e métodos de construção naval passaram a demandar testes de modelos em ondas, na tentativa de trazer para o ambiente de laboratório as mesmas condições ambientais enfrentadas pelas embarcações no oceano.

Os primeiros tanques com ondas não passavam de canais com um gerador em uma de suas extremidades e um absorvedor passivo (praia) na outra. Com o passar do tempo, os sistemas de geração passaram a ser segmentados, com acionamento independente, permitindo a geração de ondas obliquas à parede geradora.

Apesar do desenvolvimento dos dispositivos de geração, os dispositivos de absorção permaneceram praticamente inalterados, mantendo-se o emprego de sistemas passivos, até que em 1970 Milgram propôs o primeiro sistema de absorção ativa, restrito a ondas unidirecionais, utilizando um dispositivo antes usado apenas para a geração de ondas.

Com o passar dos anos, outros pesquisadores trabalharam sobre a absorção ativa de ondas, desenvolvendo teorias aplicáveis a casos tridimensionais, dando margem ao projeto de tanques compostos por dispositivos capazes de operar como gerador e absorvedor simultaneamente, dispostos ao longo das paredes do tanque. De acordo com a bibliografia e informações recentes, além do CH-TPN, existem apenas três tanques deste tipo em funcionamento no mundo, todos localizados no Japão.

Dentre estes três, o pioneiro é um tanque acadêmico com apenas 1.5 metros de diâmetro, desenvolvido e construído na Universidade de Osaka sob a supervisão do professor Naito (ver, por exemplo, Naito ${ }^{[12]}$ ). Este tanque serviu como base de testes para o sistema de absorção ativa e para estudos de diferentes geometrias de tanque.

Os outros dois tanques, mais modernos e com finalidades profissionais, encontram-se no National Maritime Research Institute (NMRI), centro de pesquisas 
localizado na região metropolitana de Tóquio. O primeiro deles foi inaugurado em 2002, é circular e dispõe de 128 flaps dispostos em sua volta, contanto com 14 metros de diâmetro e 5 metros de profundidade (ver, por exemplo, Maeda. ${ }^{[10]}$ ).

O segundo tanque é retangular, medindo $40 \times 80$ metros, com cantos arredondados, e 4.5 metros de profundidade. Ele dispõe de 382 flaps dispostos em toda sua volta e é utilizado para ensaios de manobra de embarcações.

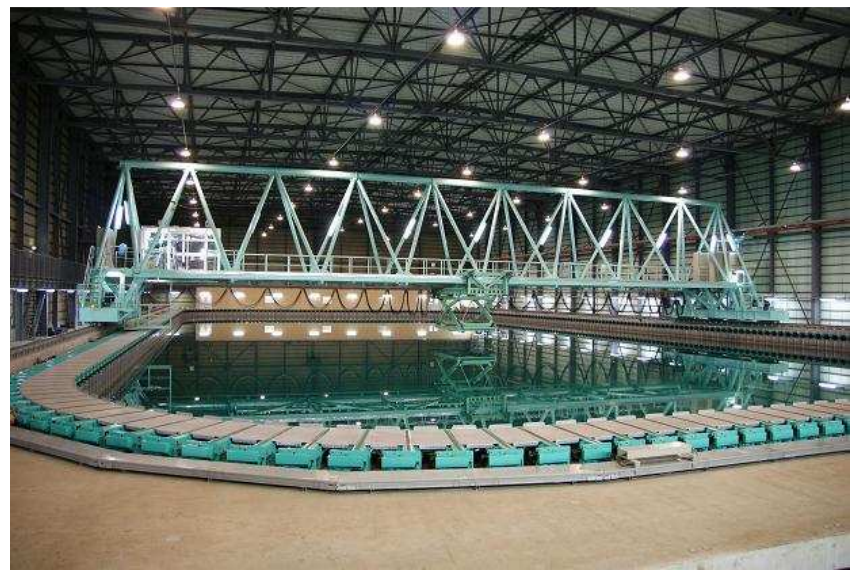

Figura 1.2: Novo tanque de provas localizado no NMRI, Japão

Seguindo esta tendência, entrou em operação, também em 2010, o Calibrador Hidrodinâmico, um tanque de provas medindo $14 \times 14$ metros e 4.1 de profundidade, dotado de 156 flaps capazes de realizar geração e absorção ativa de ondas.

O $\mathrm{CH}$-TPN é o primeiro tanque de provas deste tipo no Brasil e foi totalmente desenvolvido na Universidade de São Paulo, propiciando uma importante oportunidade para o desenvolvimento de tecnologia nacional no campo da geração e absorção de ondas.

\subsection{Objetivos}

O objetivo deste trabalho é o desenvolvimento de uma ferramenta simplificada que possibilite o estudo da geração de ondas regulares em tanques de prova que utilizem conjuntos de flaps com acionamento independente em todo o seu perímetro. 
Para desenvolver tal ferramenta, pretende-se representar os geradores como fontes de onda pontuais. Deve-se verificar se tal abordagem é capaz de reproduzir bem o padrão de ondas, sua transmissão no tempo e a reflexão em fronteiras fixas, se atribuídas a cada fonte amplitudes e fases diretamente relacionadas às amplitudes e fases de movimento dos flaps correspondentes no tanque real.

A vantagem deste método é, obviamente, a simplicidade de aplicação e a economia de tempo em comparação com análises do problema de contorno potencial realizadas no domínio da freqüência utilizando, por exemplo, o método dos elementos de contorno. Outra vantagem é a possibilidade de modelar a oscilação da superfície livre no tempo, desde o início da geração até que o regime de operação seja atingido, permitindo, assim, visualizar os efeitos transitórios envolvidos e também, se desejado, simular a ação dos flaps como absorvedores de onda, dado que os sistemas de controle adotados para tal função são descritos, em geral, no domínio do tempo.

A validação do simulador se dará em duas partes. Primeiro, será criado um simulador 2D e sua validação será feita através da comparação com resultados de ensaios em um canal de ondas, executados com auxílio de um gerador do tipo flap. Em seguida, será criado o simulador 3D e este terá seus resultados comparados àqueles fornecidos pelo código Wamit, programa que utiliza o método dos elementos de contorno para resolver o problema da geração de ondas.

Uma vez que o simulador esteja validado, este será aplicado para um estudo da geração de ondas no Calibrador Hidrodinâmico do TPN, com foco na análise da influência dos flaps travados junto às quinas do tanque na geração de ondas em diferentes freqüências e direções.

Também serão realizadas análises sobre alterações na configuração do tanque, como a alteração do conjunto de flaps que fica travado e, até mesmo, mudanças de geometria como troca das quinas por cantos arredondados (adaptação prevista quando da construção do tanque). 
Apesar de a principal vantagem do tipo de tanque que o simulador ora desenvolvido procura reproduzir consistir na absorção ativa de ondas, esta não será tratada neste estudo, mas pode ser bastante explorada com a utilização do simulador. Um dos principais pontos da absorção de onda é a estimativa de freqüência e amplitude das ondas incidentes através de medições de altura de onda realizadas na superfície dos flaps do tanque, conforme apresentado por Maeda ${ }^{[10]}$. Como mencionado acima, existe a possibilidade de tais medições serem emuladas no tempo com a utilização do simulador, o que constituiria um interessante desdobramento dos estudos aqui apresentados.

\subsection{Revisão Bibliográfica}

O trabalho de desenvolvimento de uma ferramenta capaz de simular a geração de ondas requer um bom entendimento da teoria de ondas. Diversas referências foram consultadas, dentre as quais, muitas trouxeram contribuições de grande relevância para o trabalho realizado.

A simulação da superfície livre de um tanque requer o estudo da física de ondas em meio fluido. Newman ${ }^{[13]}$ e Dean e Dalrymple ${ }^{[6]}$ abrangem a teoria de ondas, desde sua aproximação linear, base para o presente trabalho, até a modelagem de efeitos não-lineares e técnicas de abordagem para problemas específicos. Um destes problemas, ao qual é dedicado um capítulo no livro de Dean e Dalrymple ${ }^{[6]}$, corresponde ao problema bidimensional de geração de ondas por dispositivos mecânicos tipo pistão, cunha ou flap. Nele são discutidas as condições de contorno do problema e a técnica de solução do problema potencial, culminando na obtenção das chamadas funções de transferência de geração de ondas para os diferentes dispositivos.

Biesel $^{[1]}$ discute os principais dispositivos de geração de ondas bidimensionais, ressaltando as vantagens e desvantagens de cada um. No mesmo ano, publica um trabalho tratando da geração de ondas através de um sistema segmentado de geradores, trabalho este empregado como base para o cálculo de amplitudes e 
fases dos geradores no simulador ora apresentado. Outro ponto importante de seu trabalho são as discussões sobre os limites físicos da geração de ondas através deste tipo de sistema, estabelecendo limites de freqüência e direção que definem quando é possível ou não gerar uma determinada onda.

Apesar de Biesel ter apresentado a função de transferência para geradores tipo flap, ele o fez apenas para geradores pivotados no fundo do tanque. Hyun ${ }^{[8]}$ apresentou a função de um flap pivotado a certa altura do fundo, configuração esta adotada no Calibrador Hidrodinâmico do TPN e, por esta razão, implementada neste trabalho.

Ito $^{[9]}$, Maeda ${ }^{[10]}$ e Naito ${ }^{[12]}$ também abordam a teoria de geração com geradores segmentados, mas o foco de seus trabalhos está voltado para a absorção de ondas. Apesar de não haver aplicação direta da teoria de absorção discutida por eles neste trabalho, elas serviram de inspiração sobre como tratar a absorção de ondas e também propiciaram idéias de desenvolvimentos futuros para o simulador.

Hirayama ${ }^{[7]}$ discutiu a geração de ondas transientes multidirecionais e sua simulação no domínio do tempo, servindo como referência para ajustes na fonte utilizada para representar os geradores de onda na simulação.

Carneiro $^{[2]}$ realizou o desenvolvimento de um protótipo de geração e absorção ativa de ondas utilizando um gerador do tipo flap, o qual foi construído e testado em um canal de ondas. A parte mais importante é o levantamento da função de transferência do flap através de ensaios em ondas regulares, assim como a obtenção da leitura da altura de onda na face do gerador. Os resultados apresentados naquele trabalho serviram como paradigma para uma primeira validação do simulador, discutida mais adiante no Capítulo 4.

O'Dea e Newman ${ }^{[15]}$ e, novamente, Newman ${ }^{[13]}$ apresentaram estudos numéricos sobre a geração de ondas direcionais com geradores segmentados e bem como sobre a absorção de ondas com tais dispositivos em tanques de provas, utilizando o método dos elementos de contorno. Esses trabalhos divulgam as implementações incorporadas ao código comercial WAMIT® para a simulação da geração e absorção de ondas em tanques de provas. A solução numérica é obtida no domínio da 
freqüência, mediante o emprego de uma distribuição de fontes. Os resultados apresentados por O'Dea e Newman ${ }^{[15]}$ serviram como paradigma para validação dos efeitos de geração e reflexão modelados no simulador tridimensional.

Por fim, Carneiro et al. (2009) e de Mello et al. ${ }^{[5]}$ apresentam as características do Calibrador Hidrodinâmico, tanque de provas construído na Universidade de São Paulo e cujo projeto e construção motivaram o desenvolvimento de uma ferramenta capaz de simular a geração de ondas, permitindo o estudo de ajustes operacionais e trazendo a possibilidade de se avaliar eventuais variações futuras na geometria do tanque. 


\section{Teoria de geração e absorção de ondas}

Com base na teoria linear de ondas de gravidade, cujos resultados principais são apresentados na seção 2.1, foram desenvolvidas teorias de geração de ondas, tendo como principal objetivo estudar dispositivos mecânicos capazes de induzir ao fluido em repouso, ao menos idealmente, o mesmo perfil de velocidades do escoamento que se verifica sob uma onda que se propaga em sua superfície.

Algumas destas teorias foram apresentadas por Biese ${ }^{[1][2]}$ e abordam diversos tipos de dispositivos que podem ser utilizados para gerar ondas, dentre eles o gerador do tipo flap, mesmo tipo escolhido para a utilização no Calibrador Hidrodinâmico. Tais teorias envolvem tanto a geração perpendicular quanto a geração de ondas oblíquas e serão tratadas com cuidado nas seções 2.2 a 2.4 .

No caminho contrário ao da geração de ondas foram desenvolvidas teorias com o objetivo de, utilizando os mesmos dispositivos que geram ondas, eliminar as ondas presentes no meio fluido, ação que recebeu o nome de "absorção ativa de onda". Todas as teorias de absorção ativa de ondas partem do princípio que a absorção de uma onda se faz através da geração de uma onda com fase e sentido de propagação opostas à da onda incidente.

A dificuldade para a aplicação prática das teorias de absorção está em como realizar esta tarefa uma vez que é necessário detectar de algum modo a amplitude, frequência e também a direção e o sentido de propagação da onda incidente para então calcular a resposta necessária para absorvê-la. Dentre as várias teorias desenvolvidas, aquela apresentada por Maeda ${ }^{[10]}$ foi a primeira teoria testada para utilização no Calibrador Hidrodinâmico. 


\subsection{Teoria linear de ondas de gravidade}

A modelagem matemática que representa o escoamento do fluido sob ação de ondas de gravidade é de suma importância para o entendimento das discussões feitas ao longo deste trabalho. Dessa forma, cabe aqui uma breve revisão dos resultados mais relevantes no contexto do presente estudo.

O enfoque recairá sobre o problema de uma onda plana progressiva. Este problema está ilustrado de forma esquemática na figura 2.1.

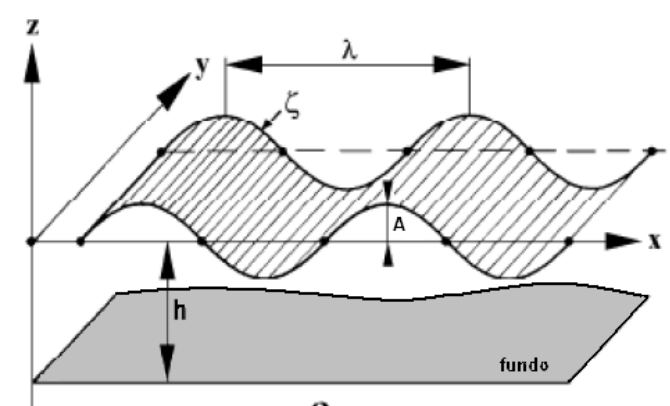

a

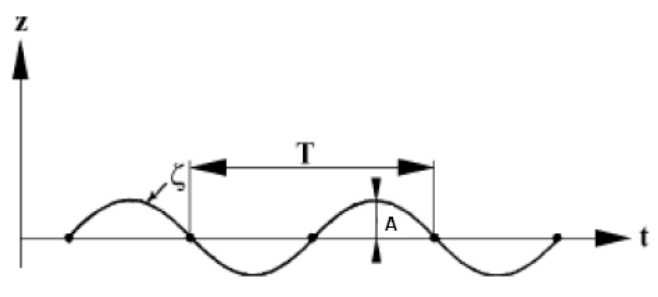

b

Figura 2.1: Representação de uma onda progressiva. a) instante de tempo fixo. b) x fixo.

A onda plana pode ser caracterizada pelos seguintes parâmetros:
A - Amplitude
$\mathrm{T}$ - Período de oscilação.
$\mathrm{h}$ - Profundidade.

A elevação da superfície livre, no caso bi-dimensional, é descrita pela relação $z=\zeta(x, t)$. A partir destes parâmetros, podemos definir outras relações importantes, como a freqüência angular da onda $(\omega=2 \pi / T)$ e o número de onda $(k=2 \pi / \lambda)$.

A solução do problema é buscada no contexto da teoria de escoamento potencial e, dessa forma, consiste em ncontrar um potencial de velocidades $\Phi(x, z, t)$ que represente o escoamento induzido por este campo ondulatório. A partir deste 
potencial determina-se o campo de velocidades do meio fluido, item importante no problema da geração de ondas, e seu campo de pressão.

O potencial de velocidades que buscamos é a solução da equação da continuidade para escoamentos potenciais, dada pela conhecida equação de Laplace (Eq. 2.1), e que expressa a condição de conservação de massa do escoamento. Esta é uma equação linear de segunda ordem a derivadas parciais cujas infinitas soluções, em seu conjunto, configuram a chamada classe de funções harmônicas.

$$
\Delta \varphi=\left(\frac{\partial^{2} \varphi}{\partial x^{2}}+\frac{\partial^{2} \varphi}{\partial z^{2}}\right)=0
$$

A particularização do problema requer, então, a consideração das condições de contorno do problema, sendo assim necessário defini-las. Para o problema esquematizado na figura 2.1, a maior dificuldade associada à solução do problema de contorno decorre da condição a ser satisfeita na superfície-livre, que é naturalmente uma condição não-linear. No contexto da chamada Teoria Linear de Ondas, uma simplificação do problema é proposta mediante a hipótese de pequenas amplitudes de onda e conseqüente linearização desta condição de contorno. Através do emprego de uma técnica de perturbação, transforma-se o problema não linear em um conjunto de problemas lineares sucessivos. O tratamento do problema é considerado clássico e pode ser facilmente encontrado nos livros de hidrodinâmica marítima e de teoria de ondas de superfície (ver, por exemplo, Newman ${ }^{[13]}$ ou Dean e Dalrymple $\left.{ }^{[6]}\right)$. Aqui, por brevidade, já serão apresentados os resultados da teoria linear, aproximação que estará sempre presente nos resultados derivados daqui por diante, mesmo que de maneira implícita.

No caso de uma onda plana progressiva são então definidas as seguintes condições de contorno:

1. Condição de contorno no fundo: Impermeabilidade do fundo plano 
$v_{z}=\frac{\partial \varphi}{\partial z}=0$, em $z=-h$

2. Condições de contorno na superfície livre.

Considerando-se ondas de pequenas amplitudes, pode-se trabalhar o problema utilizando as condições de contorno linearizadas.

2.1 - Condição Dinâmica: Impõe que a pressão na superfície livre deva ser igual à pressão atmosférica, suposta nula sem perda de generalidade no presente problema

$$
\zeta(x, t)=-\frac{1}{g} \cdot \frac{\partial \varphi}{\partial t}, \mathrm{em} z=0
$$

2.2 - Condição Cinemática: Garante a compatibilidade entre as velocidades das partículas fluidas na superfície e a velocidade de oscilação da própria fronteira, representada pela curva 2.3.

$$
\frac{\partial \varphi}{\partial z}=\frac{\partial \zeta}{\partial t}, \mathrm{em} \mathrm{z}=0
$$

É fácil perceber que as duas condições acima podem também ser combinadas em uma condição única, denominada de Condição de CauchyPoisson:

$$
\frac{\partial^{2} \varphi}{\partial t^{2}}+g \frac{\partial \varphi}{\partial z}=0, \text { em } \mathrm{z}=0
$$

O potencial de velocidades que satisfaz estas condições de contorno pode ser obtido, sem maiores dificuldades, a partir da aplicação da técnica de separação de variáveis. A dedução pode ser encontrada, por exemplo, no livro de Newman ${ }^{[13]}$. A 
técnica será também aplicada na seção 2.2.1, quando veremos que a solução da onda plana progressiva surge naturalmente como parte da solução mais geral do problema do gerador de ondas. Por ora, basta-nos reproduzir a expressão deste potencial:

$$
\varphi(x, z, t)=\frac{g A}{\omega} \frac{\cosh k(z+h)}{\cosh k h} \sin (k x-\omega t)
$$

Derivando este potencial em relação às coordenadas $x$ e $z$ obtemos o campo de velocidades associado ao escoamento em condição de profundidade finita.

$$
\begin{aligned}
& v_{x}=\frac{\partial \varphi}{\partial x}=\omega A \frac{\cosh k(z+h)}{\sinh k h} \cos (k x-\omega t) \\
& v_{z}=\frac{\partial \varphi}{\partial z}=\omega A \frac{\sinh k(z+h)}{\sinh k h} \sin (k x-\omega t)
\end{aligned}
$$

Uma representação do perfil de velocidades sob a onda pode ser observada na figura 2.2. Esta figura ilustra a velocidade das partículas fluidas em alguns pontos do escoamento, em um determinado instante de tempo.

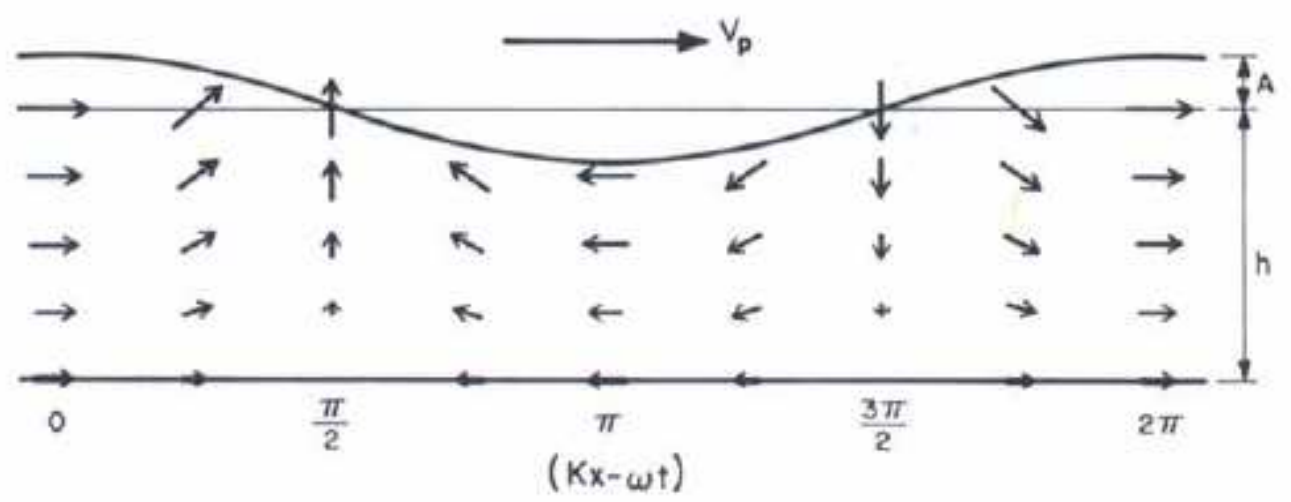

Figura 2.2: Representação do campo de velocidades para profundidade finita (fonte: Newman 1977)

As velocidades em $x$ e $z$ das partículas têm decaimento hiperbólico com a profundidade. Pela condição de contorno no fundo, temos que a velocidade normal 
ao fundo é nula quando $z=-h$, porém a velocidade horizontal não é nula pelo fato da solução não considerar viscosidade do fluido.

Com o aumento da profundidade, é de se esperar que a influência do fundo comece a desaparecer. Voltando às equações 2.7 e 2.8 e fazendo a relação $k h$ tender a infinito, obtemos um novo campo de velocidades, apresentado nas equações $2.9 \mathrm{e}$ 2.10 .

$v_{x}=\omega A e^{k z} \cos (k x-\omega t)$

$v_{z}=\omega A e^{k z} \sin (k x-\omega t)$

Nota-se, então, o decaimento exponencial das velocidades com a profundidade. Da mesma forma, a representação deste campo de velocidades pode ser feita fixandose um instante de tempo, conforme apresentado na figura 2.3.

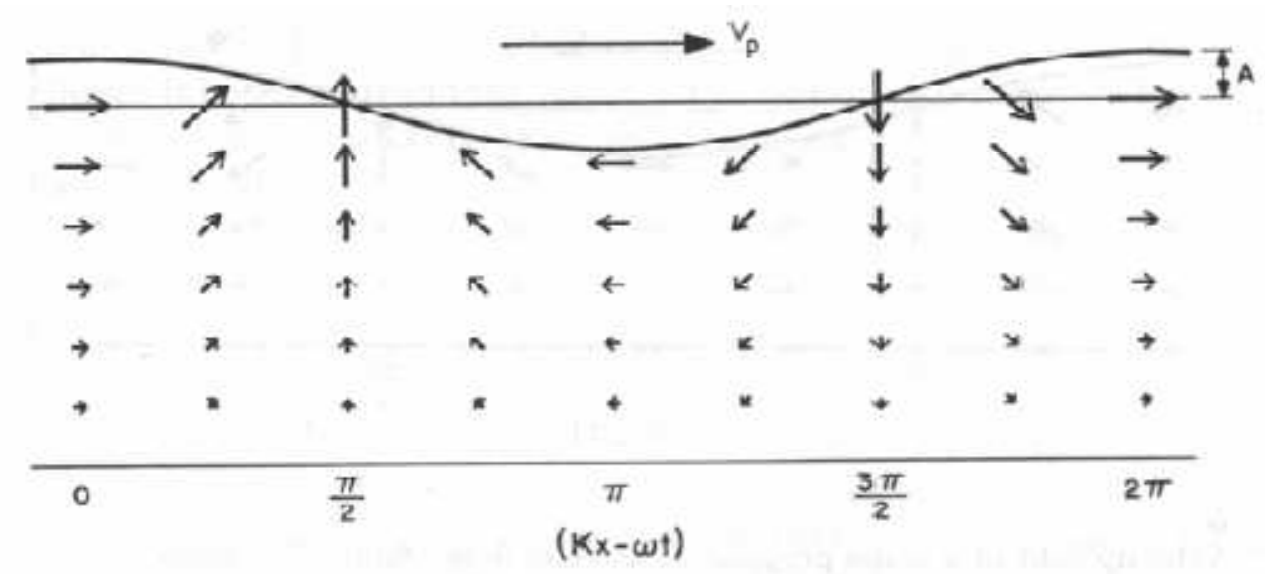

Figura 2.3: Representação do campo de velocidades para profundidade infinita. (fonte:

Newman 1977)

$\mathrm{Na}$ realidade, o equacionamento para águas profundas apresentado não é nada além de uma representação assintótica das equações 2.7 e 2.8 , as quais representam a solução mais geral do problema, e que, por essa razão, será adotada no desenvolvimento do simulador. 
A seguir discutiremos a importância desta solução no problema prático de geração de ondas. Como veremos, dependendo das características do tanque e do comprimento de onda a ser gerado, existem alguns tipos de dispositivos de geração de ondas que se mostram mais adequados para esta tarefa.

\subsection{Geração de ondas}

Em função das características do tanque de provas em desenvolvimento, doravante são considerados os dispositivos de geração do tipo "flap"1. A geração de ondas será tratada em duas partes:

- Geração bidimensional: Propagação perpendicular à parede do gerador

- Geração oblíqua: Propagação de onda em direção que forma um ângulo $\theta$ não nulo com a direção perpendicular à parede de geração

Na primeira parte será apresentada a teoria de geração bidimensional de ondas, a função de transferência do flap e os problemas decorrentes da incompatibilidade entre o perfil de velocidades desenvolvido pelo gerador de ondas e o perfil de velocidades sob uma onda plana progressiva.

Por haver apenas um sentido de propagação possível, perpendicular aos geradores, pode-se realizar uma abordagem considerando apenas duas dimensões no espaço, uma no sentido de propagação da onda e outra na profundidade $(x$ e $z$ ). Esta teoria de geração geralmente é utilizada em canais de ondas (ou, em inglês, "flumes"), tanques estreitos e muito longos nos quais existe somente um sentido de propagação de onda desejado.

$\mathrm{Na}$ segunda parte será introduzida a idéia dos geradores do tipo snake, que propiciam a geração de ondas com ângulo em relação à normal da parede geradora.

\footnotetext{
${ }^{1}$ Existem outros tipos de dispositivos capazes de gerar onda e alguns deles podem ser conferidos no apêndice A. O dispositivo tipo flap foi o escolhido para utilização no CH-TPN e, por isso, está no foco deste estudo.
} 
Nesta parte é necessário considerar uma parede de geração contínua que, teoricamente, através de seu movimento é capaz de gerar ondas com quaisquer direções de propagação. Sua utilização é feita em tanques oceânicos, onde a relação comprimento/largura é aproximadamente um, ou em canais que tenham largura suficiente para que sejam geradas ondas oblíquas.

Também serão discutidas as perturbações causadas pelo caráter discreto da parede geradora e conseqüentemente, os limites de geração, de modo a restringir estas perturbações às vizinhanças do gerador, assim evitando sua propagação e interferências na área de ensaio. Estes limites são muito importantes para o funcionamento do tanque, tanto na geração quanto na absorção de ondas, pois, como já mencionado anteriormente, umas das maneiras de encarar a absorção de ondas é entendê-la como a geração de uma onda com mesma amplitude da incidente, porém, com sentido e fase contrários.

\subsubsection{Teoria de Geração Bidimensional}

A teoria de geração bidimensional foi desenvolvida a partir da inclusão do dispositivo gerador no problema de contorno. A solução para o problema de onda plana progressiva não é mais solução deste problema, pois uma nova condição de contorno deve ser respeitada: a impermeabilidade da superfície geradora.

Esta nova condição de contorno impõe que a velocidade das partículas fluidas sobre a superfície, cuja posição é dada pela função $E(z, t)=\varepsilon(z) \cdot \sin (\omega t)$ e a velocidade desta superfície sejam iguais, respeitando assim a sua impermeabilidade. Deve-se encontrar, então, um potencial de velocidades que atenda não apenas as condições de fundo e superfície-livre, mas também as novas restrições impostas pela parede geradora. 


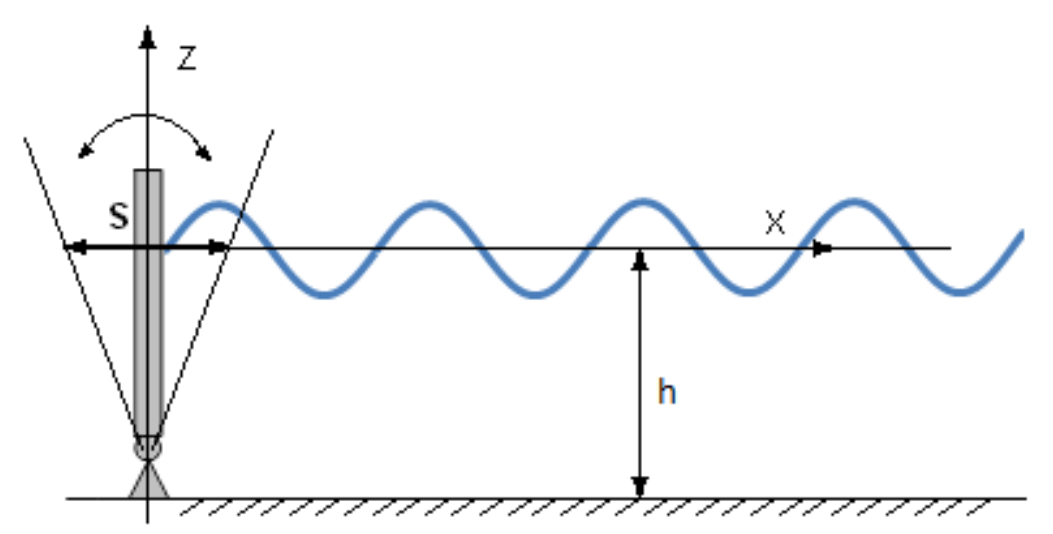

Figura 2.4: Eixo de coordenadas utilizado.

As condições de contorno do problema, considerando este eixo de coordenadas, são:

1. Impermeabilidade do fundo:

$v_{z}=\frac{\partial \varphi}{\partial z}=0$, em $z=-h$

2. Condição de contorno na superfície livre:

$\frac{\partial^{2} \varphi}{\partial t^{2}}+g \frac{\partial \varphi}{\partial z}=0$, em $z=0$

3. Condição de impermeabilidade da superfície do gerador:

É uma condição do tipo $\nabla \Phi \cdot \vec{n}=V(t) \cdot \vec{n}$ e deve ser válida na superfície que varia com $z$ e $t$. Contudo, na hipótese de pequenos deslocamentos do flap, a mesma pode ser simplificada impondo-se apenas a impermeabilidade na posição média $(x=0)$. Esta simplificação fornece bons resultados no contexto da teoria linear de ondas, já que pressupõe pequenas amplitudes na superfície livre. Finalmente, a condição é dada por:

$v_{x}=\frac{\partial \varphi}{\partial x}=\omega \varepsilon(z) \cos (\omega t)$, em $x=0$ 
4. Condição de radiação.

Além das condições acima, para se garantir a unicidade da solução deve-se impor uma condição adicional que garanta que quando $x$ tende a infinito, a onda represente de fato uma onda progressiva. Isso equivale a dizer, então, que não há ondas que se propagam do infinito para o batedor, ou que ondas estacionárias não podem se estender indefinidamente em $x$. Biesel denomina, assim, essa condição como condição de "total damping". É fácil notar, no entanto, que se trata de uma condição de radiação que garante que o potencial $\varphi(x, z, t)$ seja proporcional a $\sin (k x-\omega t)$ quando $x$ tende a infinito.

$\varphi(x, z, t) \alpha \sin (k x-\omega t)$, quando $\mathrm{x} \rightarrow \infty$

A solução deste problema de contorno pode ser obtida mediante emprego da técnica de separação de variáveis. Para o problema 2D, temos:

$\Phi(x, z, t)=\operatorname{Re}\left\{\varphi(x, z) e^{-i \omega t}\right\}$

O potencial pode ser escrito como duas funções distintas das variáveis x e $z$.

$\varphi(x, z)=\mathrm{X}(x) Z(z)$

Aplicando a condição de conservação de massa, dada pela equação 2.1:

$\nabla^{2} \varphi=\frac{1}{\mathrm{X}} \frac{d^{2} \mathrm{X}}{d x^{2}}+\frac{1}{Z} \frac{d^{2} Z}{d z^{2}}=0, \quad \forall(x, z)$

A solução geral desta equação pode ser obtida através da aplicação da técnica de expansão em autovetores, implicando em:

$\frac{1}{\mathrm{X}} \frac{d^{2} \mathrm{X}}{d x^{2}}=\alpha^{2} \Rightarrow \mathrm{X}=A_{n} e^{+\alpha_{n} x}+B e^{-\alpha_{n} x} \quad \forall(x, z)$ 
$\frac{1}{\mathrm{Z}} \frac{d^{2} \mathrm{Z}}{d z^{2}}=-\alpha^{2} \Rightarrow \mathrm{Z}=C \cos (\alpha z)+D \sin (\alpha z)$

Existem duas possibilidades. A variável $\alpha$ pode ser real ou imaginária. Considerando $\alpha$ real:

$\alpha^{2}>0$

Para encontrar a solução apropriada, é necessário aplicar as condições de contorno do problema. Iniciando pela condição de contorno do fundo apresentada na equação 2.11, a solução é:

$\mathrm{Z}(z)=C \cos \alpha(z+h) \quad(D=0)$

$E$, aplicando a condição de superfície livre, dada pela equação 2.12 , tem-se como solução:

$\frac{\partial^{2} \varphi}{\partial t^{2}}+g \frac{\partial \varphi}{\partial z}=0 \Rightarrow \alpha \tan (\alpha h)=-\frac{\omega^{2}}{g}$

Esta equação tem infinitas raízes reais $\alpha_{n} \operatorname{com} n=1,2,3 \ldots$

Portanto, a solução mais geral pode ser procurada como a soma de todas as autofunções

$$
\varphi(x, z)=\sum_{n}\left(A e^{+\alpha x}+B e^{-\alpha x}\right) C \cos \alpha_{n}(z+h)
$$

Do fenômeno da geração de ondas, é conhecido que a perturbação não se propaga, devendo ser nula no infinito, portando $A=0$, restando apenas: 
$\varphi(x, z)=\sum_{n=1}^{\infty} C_{n} e^{-\alpha_{n} x} \cos \alpha_{n}(z+h)$

Esta parcela do potencial representa as ondas evanescentes.

Considerando agora a possibilidade de $\alpha$ imaginário:

$\alpha^{2}<0 \Rightarrow \alpha=i \alpha_{0}$

Então:

$\mathrm{X}(x)=A_{p} e^{+i \alpha_{0} x}+B_{p} e^{-i \alpha_{0} x}$

Da condição de radiação (eq. 2.14), conclui-se que $B_{p}=0$ e, portanto:

$\mathrm{X}(x)=A_{p} e^{+i \alpha_{0} x}$

Faltando agora analisar em termos da variável $z$ :

$\frac{1}{\mathrm{Z}} \frac{d^{2} \mathrm{Z}}{d z^{2}}=-\left(i \alpha_{0}\right)^{2} \Rightarrow \frac{d^{2} \mathrm{Z}}{d z^{2}}-i \alpha_{0}^{2}=0$

Que tem como solução:

$\mathrm{Z}(z)=C_{p} e^{\alpha_{0} z}+D_{p} e^{-\alpha_{0} z}$

Da condição de contorno do fundo, vem:

$\mathrm{Z}(z)=C_{p} \cosh \alpha_{0}(z+h)$

E da condição de superfície livre: 
$\alpha_{0} \tanh \left(\alpha_{0} h\right)=-\frac{\omega^{2}}{g}$

Então, se $\alpha$ imaginário puro:

$$
\begin{aligned}
& \varphi(x, z)=A_{p} e^{i-\alpha_{0} x}\left[C_{p} \cosh \alpha_{0}(z+h)\right] \\
& \text { e, } \\
& \Phi(x, z)=A_{p} \cosh \alpha_{0}(z+h) \sin \left(\alpha_{0} x-\omega t\right)
\end{aligned}
$$

A solução completa é dada pela combinação das duas soluções apresentadas:

$$
\begin{aligned}
\Phi(x, z)= & A_{p} \cosh \alpha_{0}(z+h) \sin \left(\alpha_{0} x-\omega t\right)+ \\
& +\sum_{n=1}^{\infty} C_{n} e^{-\alpha_{n} x} \cos \alpha_{n}(z+h) \cos \omega t
\end{aligned}
$$

Nesta equação, $\alpha_{0}$ representa o número de onda da onda progressiva e os $\alpha_{n}$ representam o número de onda das componentes evanescentes. A partir de agora, estas variáveis serão substituídas, respectivamente, por $k_{p}$ e $k_{n}$.

Os valores de $A_{p}$ e $C_{n}$ são encontrados através da imposição da impermeabilidade no gerador, em $x=0$, assunto tratado na próxima seção.

\subsection{Função de Transferência - Flap}

Para cada tipo de gerador de ondas é possível a obtenção de uma função de transferência que relacione a amplitude de seu movimento com a onda gerada. Também é possível obter as amplitudes dos vários modos da onda evanescente nas 
proximidades do flap e assim ter noção quantitativa de sua influência na leitura de onda na proximidade do gerador.

As funções de transferência de dois sistemas utilizando geradores tipo flap serão obtidas nesta seção. O primeiro sistema, apresentado na figura 2.5, é o flap pivotado no fundo do tanque. Esta função de transferência será empregada no simulador para efetuar as comparações com os ensaios realizados com o protótipo construído no canal de ondas. O segundo sistema, que pode ser conferido na figura 2.6, consiste em um flap que pivota em torno de um ponto localizado a certa distância do fundo. A função de transferência deste caso será aplicada no simulador tridimensional, pois no Calibrador Hidrodinâmico, este é o sistema utilizado.

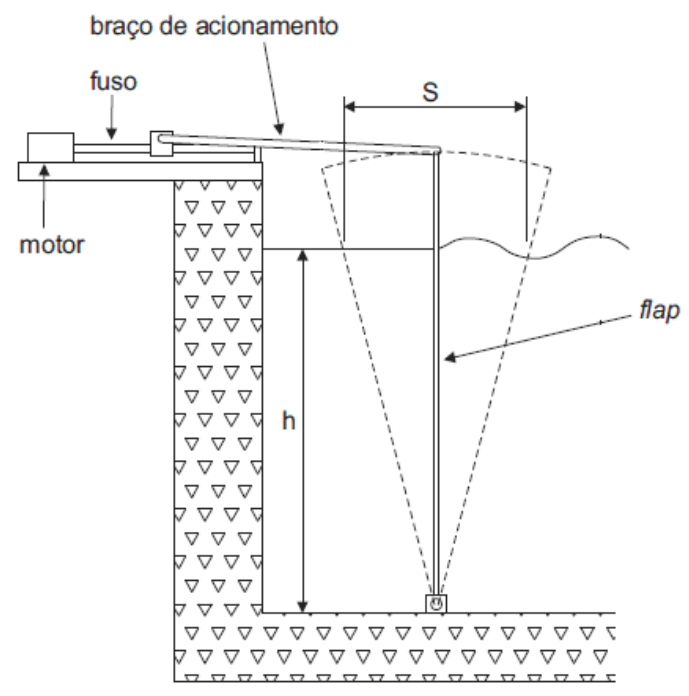

Figura 2.5: Flap Pivotado no fundo

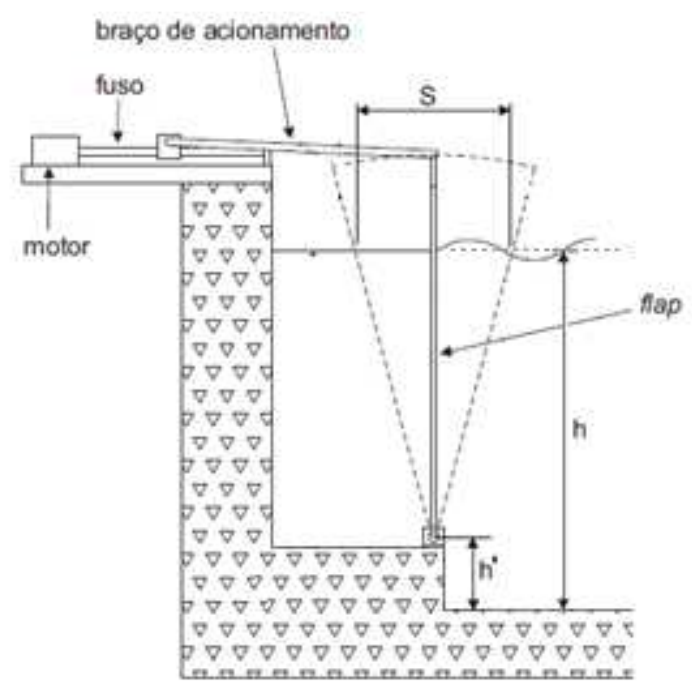

Figura 2.6: Flap pivotado acima do fundo

Para encontrar a função de transferência do flap pivotado no fundo, vamos partir da função que representa seu movimento.

$$
E(z, t)=\varepsilon(z) \sin (\omega t)=\frac{(S / 2)}{h} z \sin (\omega t)
$$

Aplicando a condição de impermeabilidade na superfície do flap, em $x=0$ : 
$\frac{\partial E}{\partial t}=-\frac{\partial \Phi}{\partial x}$

Resultando em:

$\frac{\varepsilon(z)}{2} \omega=-A_{p} k_{p} \cosh k_{p}(z+h)+\sum_{n=1}^{\infty} C_{n} k_{n} \cos k_{n}(z+h)$

A equação 2.37 tem uma função de $\mathrm{z}$ igualada a uma série de funções trigonométricas em z, similar a situação da série de Fourier. De fato, o conjunto de funções $\left\{\cosh k_{p}(z+h), \cos k_{n}(z+h)\right\}$ forma uma série harmônica de funções ortogonais e, portanto, qualquer função contínua par pode ser expandida em função delas.

Para encontrar $A_{p}$ a equação 2.37 é multiplicada por $\cosh k_{p}(z+h)$ e integrada de $-h$ até 0 , resultando em:

$$
A_{p}=\frac{-\int_{-h}^{0} \frac{\varepsilon(z)}{2} \omega \cosh k_{p}(z+h) d z}{k_{p} \int_{-h}^{0} \cosh ^{2} k_{p}(z+h) d z}
$$

De forma análoga, multiplicando 2.37 por $\cos k_{n}(z+h)$ :

$$
C_{n}=\frac{-\int_{-h}^{0} \frac{\varepsilon(z)}{2} \omega \cos k_{n}(z+h) d z}{k_{n} \int_{-h}^{0} \cos ^{2} k_{n}(z+h) d z}
$$

E, para finalizar, basta substituir a equação 2.35 em 2.38 e integrar, resultando na função de transferência do flap, para ondas propagantes 
$F_{p}=\frac{A_{p}}{S}=\frac{\operatorname{senh}\left(k_{0} h\right)}{k_{0} h} \cdot \frac{1-\cosh \left(k_{0} h\right)+k_{0} h \cdot \operatorname{senh}\left(k_{0} h\right)}{\operatorname{senh}\left(k_{0} h\right) \cosh \left(k_{0} h\right)+k_{0} h}$

O próximo passo é avaliar a perturbação causada pelas ondas evanescentes. Sua amplitude pode ser obtida por:

$$
A_{n}=\sum_{n=1}^{\infty} 2 k_{n} \cdot \sin \left(k_{n} h\right) C_{n}=S \cdot \sin \left(k_{n} h\right) \frac{\left(k_{n} h\right) \cdot \sin \left(k_{n} h\right)+\cos \left(k_{n} h\right)-1}{k_{n} h\left(\operatorname{sen}\left(k_{n} h\right) \cos \left(k_{n} h\right)+k_{n} h\right)} \cdot e^{-k_{n} x}
$$

A máxima elevação de cada componente da onda evanescente ocorre em $x=0$ e será dada por:

$$
\eta_{n}=\operatorname{S} \cdot \operatorname{sen}\left(k_{n} h\right) \cdot \frac{\left(k_{n} h\right) \cdot \sin \left(k_{n} h\right)+\cos \left(k_{n} h\right)-1}{k_{n} h\left(\operatorname{sen}\left(k_{n} h\right) \cos \left(k_{n} h\right)+k_{n} h\right)}
$$

Para se obter uma noção de como se comporta o gerador tipo flap gerando ondas muito longas (por exemplo, $\lambda / h=8$ ), para as quais vale a teoria de águas rasas, e ondas curtas $(\lambda / h=0.5)$, nos limites da teoria de águas profundas, pode ser feita a comparação entre a amplitude da onda evanescente e a amplitude da onda progressiva. Esta comparação é apresentada na tabela 2.1, através da relação entre a soma das amplitudes dos três primeiros e mais significativos modos evanescentes e a amplitude da onda progressiva.

Tabela 2.1: Relação entre amplitude da onda progressiva e das evanescentes.

\begin{tabular}{|l|cl|l|cl|}
\hline \multicolumn{3}{|c|}{$(\lambda / h)=8$} & \multicolumn{3}{c|}{$(\lambda / h)=0.5$} \\
\hline$\eta_{1}$ & -0.061 & $s$ & $\eta_{1}$ & 0.41 & $s$ \\
\hline$\eta_{2}$ & 0.0022 & $S$ & $\eta_{2}$ & 0.412 & $s$ \\
\hline$\eta_{3}$ & -0.0019 & $S$ & $\eta_{3}$ & 0.133 & $s$ \\
\hline$\eta_{1+} \eta_{2+} \eta_{3}$ & -0.0607 & $S$ & $\eta_{1+} \eta_{2+} \eta_{3}$ & 0.955 & $s$ \\
\hline$A_{p}$ & 0.408 & $S$ & $A_{p}$ & 1.84 & $s$ \\
\hline$\left(\eta_{1+} \eta_{2+} \eta_{3}\right) / A_{p}$ & $14.9 \%$ & & $\left(\eta_{1+} \eta_{2+} \eta_{3}\right) / A_{p}$ & $51.9 \%$ & \\
\hline
\end{tabular}

Desta comparação podemos notar que, quando o flap está gerando ondas longas, as componentes evanescentes não têm muita interferência na leitura de um sensor 
colocado sobre a parede do flap, enquanto, por outro lado, para as freqüências mais altas, a amplitude das evanescentes passa a ter a mesma ordem de magnitude da amplitude da onda progressiva. Deve-se ficar alerta, pois, dependendo da condição de operação do batedor, a desconsideração destas ondas pode implicar em grandes erros.

De forma análoga ao caso do flap pivotado no fundo, podemos encontrar a função de transferência para o flap pivotado a uma altura $h^{\prime}$ do fundo. Para isso, basta efetuar os cálculos anteriores alterando a condição de contorno que representa o flap para:

$$
\left\{\begin{array}{cl}
E(z, t)=\varepsilon(z) \operatorname{sen}(\omega t)=\frac{S\left(z-h^{\prime}\right)}{h-h^{\prime}} \operatorname{sen}(\omega t) & , \text { para } h^{\prime} \leq z \leq h \\
e & , \text { para } z \leq h^{\prime} \\
E(z, t)=\varepsilon(z) \operatorname{sen}(\omega t)=0 &
\end{array}\right.
$$

Como já mostrara, por exemplo, Hyun (1976), a função de transferência neste caso é dada por:

$$
\frac{A_{p}}{S}=\frac{k_{0}\left(h-h^{\prime}\right) \sinh \left(k_{0} h\right)-\cosh \left(k_{0} h\right)+\cosh \left(k_{0} h^{\prime}\right)}{k_{0}\left(h-h^{\prime}\right)\left[\sinh \left(k_{0} h\right) \cosh \left(k_{0} h\right)+k_{0} h\right]}
$$

E, para as ondas evanescentes:

$$
\frac{A_{n}}{S}=\frac{k_{n}\left(h-h^{\prime}\right) \sin \left(k_{n} h\right)+\cos \left(k_{n} h\right)-\cosh \left(k_{n} h^{\prime}\right)}{k_{n}\left(h-h^{\prime}\right)\left[\sin \left(k_{n} h\right) \cos \left(k_{n} h\right)+k_{n} h\right]}
$$

Na próxima seção serão apresentados os principais aspectos da teoria de geração de ondas tridimensionais que serão aplicadas no simulador.

\subsection{Geração Tridimensional}

A geração de ondas é caracterizada como tridimensional quando a direção da onda progressiva gerada passa a fazer um ângulo $\theta$ diferente de zero em relação à 
perpendicular da superfície geradora. Os geradores desenvolvidos para efetuar tal função são conhecidos como snake. Estes dispositivos são compostos por um conjunto de flaps posicionados lado a lado e com acionamento independente, formando uma parede de geração.

Através de uma defasagem controlada entre o movimento dos flaps adjacentes é possível gerar ondas com diferentes ângulos de propagação, com o conjunto de flaps se movimentando na forma de uma senóide, conforme pode ser visto na figura 2.7. Este movimento lembra o movimento de uma cobra rastejando, vindo daí seu nome snake.

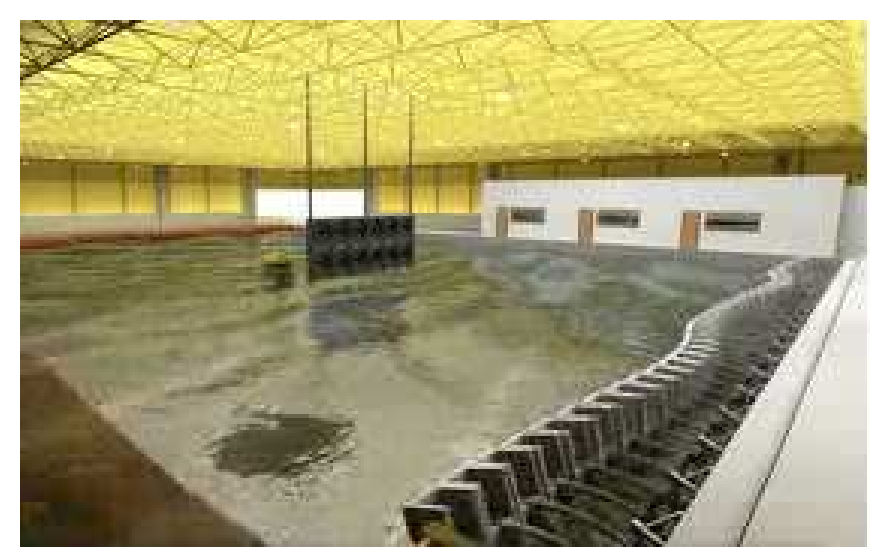

Figura 2.7: Flaps em movimento para gerar onda obliqua.

Deve-se ressaltar, porém, que não é possível gerar ondas com combinações quaisquer de freqüência e direção, já que existem limitações físicas envolvidas neste processo de geração. Além dos óbvios limites dos dispositivos mecânicos, com o aumento da defasagem entre os flaps surgem perturbações indevidas, denominadas ondas espúrias, que distorcem o campo de ondas gerado.

A relação entre direção e freqüência que define os limites de geração para dada geometria dos batedores é conhecida na literatura como limite de Biesel, o qual será discutido em maiores detalhes na seção 2.4.2. Ele determina o ângulo máximo de geração até o qual as ondas espúrias ficam restritas às vizinhanças do gerador, assim não interferindo no campo de ondas progressivas. 
No entanto, para se apresentar e discutir o limite de Biesel é necessário, primeiramente, apresentar certos aspectos da teoria de geração de ondas oblíquas, da qual ele se origina.

\subsubsection{Aspectos teóricos da geração tridimensional}

A teoria linear para geração de ondas oblíquas pode ser estabelecida, de uma maneira geral, utilizando métodos similares àqueles utilizados na geração bidimensional. Agora, no entanto, a teoria trata a parede geradora como um corpo que se deforma ao longo do tempo mediante a consideração de um termo de defasagem entre os flaps, relacionado à direção de propagação da onda gerada.

Os aspectos aqui tratados estão baseados em um conjunto de flaps posicionados sobre o eixo $y$, se estendendo de $-\infty$ à $+\infty$, o eixo $x$ sendo perpendicular às superfícies dos flaps e o eixo $z$ posicionado na vertical e orientado para cima, com $\mathrm{z}=0$ no fundo do tanque. A figura 2.8 mostra uma visão superior deste sistema de coordenadas.

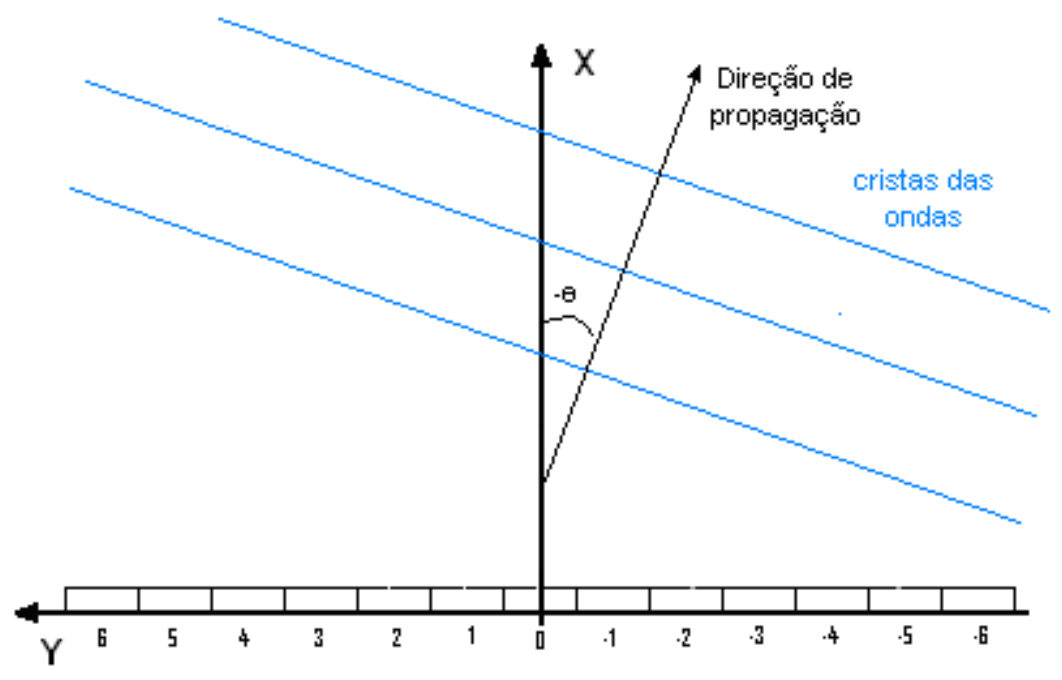

Figura 2.8: Sistema de coordenadas.

De maneira ideal, o sistema de geração deveria ser composto por uma parede contínua movendo-se na forma de uma senóide, não havendo, assim, o surgimento de ondas espúrias. Isto, contudo, é inviável de se obter na prática, sendo então 
necessárias aproximações. A aproximação mais utilizada, por sua simplicidade, é a divisão da superfície geradora em pequenos segmentos de largura constante (os flaps), cada um deles com sua superfície representada por um valor de $\mathrm{x}$ constante em cada instante de tempo, como apresentado na figura 2.9.

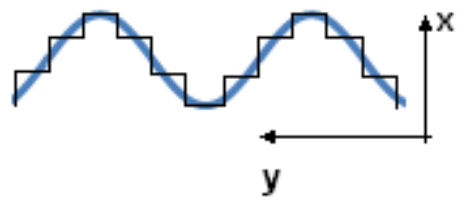

Figura 2.9: Discretização do gerador de ondas.

Para analisar as possíveis perturbações geradas por esta discretização e definir os limites de operação que delas decorrem, iremos seguir o trabalho feito por Biesel ${ }^{[2]}$ sobre geração oblíqua.

Vamos primeiramente tentar isolar o problema, desconsiderando as ondas evanescentes. Isto pode ser feito se considerarmos que o perfil de velocidade de cada flap é proporcional a $\cosh k(z+h)$, ou seja, são flaps ideais que reproduzem o decaimento do perfil de velocidades descrito pela teoria linear de ondas progressivas.

Supondo a geração de uma onda perpendicular aos flaps, todos devem ter movimento síncrono, e que pode ser descrito pela função:

$x_{n}(z, t)=S \cdot \cosh k \cdot(z+h) \cdot \operatorname{sen}(\omega \cdot t)$

Quando pensamos na geração em ângulo, queremos que as cristas de ondas se propaguem de acordo com a figura 2.8. Desta maneira, os flaps devem gerar ondas com defasagem entre si de modo que as cristas das ondas geradas por cada um dos flaps se encontrem sobre as linhas da figura. Sendo assim, em função da largura $\ell$ dos flaps, é possível calcular a diferença das distâncias percorridas por cada uma das cristas através da geometria apresentada na figura 2.10, e assim, calcular a defasagem necessária entre o movimento dos flaps. 


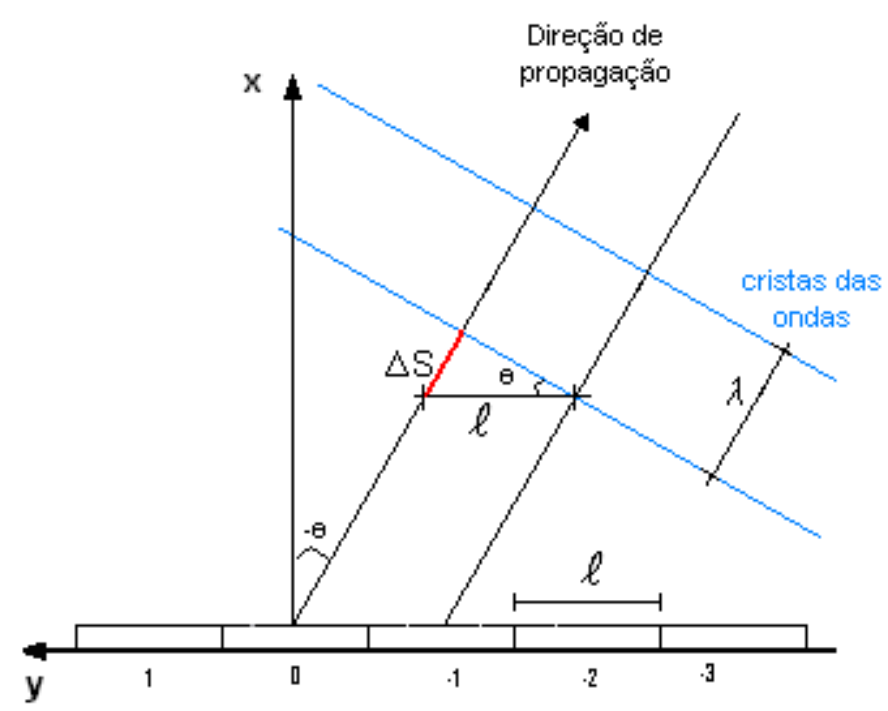

Figura 2.10: Diferença de percurso entra ondas de flaps adjacentes.

A diferença entre as distâncias percorridas pelas cristas das ondas geradas por dois flaps adjacentes, para compor a onda desejada, é obtida geometricamente e dada por:

$$
|\Delta S|=|\ell \cdot \operatorname{sen} \theta|
$$

Esta diferença pode ser incluída na fórmula 2.46, que representa o movimento de cada um dos flaps, como uma defasagem, na forma:

$x_{n}(z, t)=S \cdot \cosh (k \cdot z) \cdot \operatorname{sen}(\omega \cdot t-k . n \cdot \ell \cdot \operatorname{sen} \theta)$

A equação acima considera a defasagem de cada flap em relação ao flap posicionado em $y=0$, tomado como referência. Para analisar o problema da discretização da superfície geradora, vamos começar por definir uma função periódica em y dada por:

$f\left(\frac{y}{\ell}\right)=\frac{y}{\ell}-n$

Onde: 
$n-\frac{1}{2}<\frac{y}{\ell}<n+\frac{1}{2}$

Com o auxilio da função $f$, a equação de movimento do flap $n$ pode ser reescrita como:

$x_{n}=S \cdot \cosh (k \cdot z) \cdot \operatorname{sen}\left(\omega \cdot t-k \cdot y \cdot \operatorname{sen} \theta+f\left(\frac{y}{\ell}\right) \cdot k \cdot \ell \cdot \operatorname{sen} \theta\right)$

Derivando no tempo, temos a velocidade de cada flap:

$u_{n}=S \cdot \omega \cdot \cosh (k \cdot z) \cdot \cos \left(\omega \cdot t-k \cdot y \cdot \operatorname{sen} \theta+f\left(\frac{y}{\ell}\right) \cdot k \cdot \ell \cdot \operatorname{sen} \theta\right)$

Considerando o escoamento representado por um potencial $\Phi(x, y, z, t)$, onde:

$u=\frac{\partial \Phi}{\partial x} \quad v=\frac{\partial \Phi}{\partial y} \quad w=\frac{\partial \Phi}{\partial z}$

e que deve satisfazer a equação de Laplace:

$\frac{\partial^{2} \Phi}{\partial x^{2}}+\frac{\partial^{2} \Phi}{\partial y^{2}}+\frac{\partial^{2} \Phi}{\partial z^{2}}=0$

e a condição de contorno sobre a parede do flap, impondo a velocidade do fluido igual à velocidade desta parede:

$$
\frac{\partial \Phi}{\partial x}=S \cdot \omega \cdot \cosh (k \cdot z) \cdot \cos \left(\omega \cdot t-k \cdot y \cdot \operatorname{sen} \theta+f\left(\frac{y}{\ell}\right) \cdot k \cdot \ell \cdot \operatorname{sen} \theta\right), \text { em } x=0
$$


Reescrevendo a equação na forma complexa²:

$\frac{\partial \Phi}{\partial x}=\operatorname{Re}\left\{S \cdot \omega \cdot \cosh (k \cdot z) \cdot e^{i \omega t} \cdot e^{-i k y \operatorname{sen} \theta+i f\left(\frac{y}{\ell}\right) k \ell \operatorname{sen} \theta}\right\}$, em $x=0$

Como argumenta Biesel (1954), a função $e^{i f\left(\frac{y}{l}\right) k \ell \operatorname{sen} \theta}$ é periódica em y com período $\ell$ e, assim, pode ser desenvolvida em série de Fourier:

$e^{i f\left(\frac{y}{\ell}\right) k l \operatorname{sen} \theta}=e^{2 i \pi f\left(\frac{y}{\ell}\right)}=\sum_{j=-\infty}^{\infty}(-1)^{j} \frac{\operatorname{sen} \tau}{\tau-j \pi} e^{i j k^{\prime} y}$

Onde $\tau$ é dado por:

$\tau=\frac{1}{2}(k \cdot \ell \cdot \operatorname{sen} \theta)$

E $k^{\prime}$ é dado por:

$k^{\prime}=\frac{2 \pi}{\ell}$

Separando o termo j = 0 da somatória:

$e^{i f\left(\frac{y}{\ell}\right) k \ell \operatorname{sen} \theta}=\frac{\operatorname{sen} \tau}{\tau}+\sum_{j=-\infty}^{\infty}(-1)^{j} \frac{\operatorname{sen} \tau}{\tau-j \pi} e^{i j k^{\prime} y}, \quad \mathrm{j} \neq 0$

Substituindo a série na equação 2.56:

\footnotetext{
2 A partir daqui, de modo a simplificar as equações, quando se fala no potencial complexo deve-se considerar somente sua parte real.
} 
$\frac{\partial \Phi}{\partial x}=S . \omega \cdot \frac{\operatorname{sen} \tau}{\tau} \cosh (k . z) \cdot e^{i \omega t} \cdot e^{-i k y \operatorname{sen} \theta}+$
$+S . \omega \cdot \cosh (k . z) \sum_{j=-\infty}^{\infty}(-1)^{j} \frac{\operatorname{sen} \tau}{\tau-j \pi} e^{i \omega t} e^{i y\left(j k^{\prime}-k \operatorname{sen} \theta\right)}, \quad$ em $\mathrm{x}=0$

A partir deste ponto, a solução na forma complexa para este problema de contorno pode ser construída sem maiores dificuldades se nos remetermos à solução geral do problema 2D obtida via técnica de separação de variáveis (ver equação 2.26), incluirmos a correta forma da variação em $x$ do termo progressivo (lembrando de sua direção de propagação) e das componentes evanescentes e, por fim, impusermos a condição de impermeabilidade deste flap ideal (2.55):

$$
\begin{aligned}
& \Phi(x, y, z, t)=i \cdot \frac{S \cdot \omega}{k \cos \theta} \cdot \frac{\operatorname{sen} \tau}{\tau} \cosh (k \cdot z) \cdot e^{i \omega t} \cdot e^{-i k y \operatorname{sen} \theta} e^{-i k x \cos \theta}+ \\
& + \text { S. } \omega \sum_{j=-\infty}^{\infty} \frac{(-1)^{j}}{k_{j}} \frac{\operatorname{sen} \tau}{\tau-\pi} \cdot \cosh (k \cdot z) e^{i \omega t} \cdot e^{i\left(j k^{\prime}-k \operatorname{sen} \theta\right) y} \cdot e^{-k_{j} x}
\end{aligned}
$$

O primeiro termo da equação 2.62 representa a onda progressiva. Sua parcela real é dada por:

$$
\frac{S . \omega}{k \cos \theta} \cdot \frac{\operatorname{sen} \tau}{\tau} \cosh (k . z) \cdot \operatorname{sen}(k \cdot y \cdot \operatorname{sen} \theta+k \cdot x \cdot \cos \theta-\omega \cdot t)
$$

Da dedução apresentada acima, percebe-se que a razão dada por:

$$
\frac{\operatorname{sen} \tau}{\tau \cos \theta}
$$

representa a relação entre a amplitude de onda gerada no caso tridimensional e aquela que seria obtida caso os flaps estivessem gerando ondas em "canais separados" com amplitude de movimento $S$ (ou seja, se for ignorada a variação do movimento ao longo da direção y). Substituindo o valor de $\tau$ definido pela equação 2.58 na equação anterior temos: 
$\frac{\sin \tau}{\tau \cos \theta}=\frac{\sin \left[\frac{1}{2}(k \cdot \ell \cdot \sin \theta)\right]}{\frac{1}{2}(k \cdot \ell \cdot \sin \theta) \cos \theta}$

O limite da relação acima tende a um quando o ângulo de geração se aproxima de zero (direção de propagação perpendicular à parede). Conclui-se, também, que a amplitude da onda gerada no caso tridimensional é maior do que a da onda bidimensional que seria gerada caso os geradores estivem operando em canais separados.

A equação 2.65 deve ser utilizada para corrigir a amplitude dos geradores de onda sempre que uma onda obliqua for gerada.

Retornando à equação 2.62, seu segundo representa as perturbações, que decaem à medida que nos afastamos do gerador desde que os parâmetros $k_{j}$ sejam todos reais e positivos. As condições para isso serão discutidas a seguir e, como veremos, implicarão no chamado limite de Biesel.

\subsubsection{Limite de Biesel}

Como dito anteriormente, existe um limite para a geração de ondas oblíquas além do qual as perturbações criadas pelas descontinuidades da parede geradora, chamadas de ondas espúrias, perdem seu caráter evanescente e passam a distorcer o campo de ondas progressivas almejado. Este limite é conhecido como Limite de Biesel e esta seção tem como objetivo apresentar como ele foi originalmente definido. Para isso, retomemos a equação 2.62

O segundo termo da equação representa as ondas espúrias. Os termos $k_{j}$ representam o número de onda de cada componente da onda espúria e seus valores podem ser obtidos através da imposição da equação de Laplace (2.54), através da qual se depreende que: 
$\left(j k^{\prime}-k \cdot \operatorname{sen} \theta\right)^{2}-k^{2}-k_{j}^{2}=0$

Para garantir que estas ondas decaiam com a distância do gerador de ondas é necessário que o termo $e^{-k_{j} x}$ decaia e, portanto, os valores de $k_{j}$ devem ser reais e positivos. Manipulando a equação 2.66, temos que:

$k_{j}^{2}=\left(j k^{\prime}-k \cdot \operatorname{sen} \theta\right)^{2}-k^{2}$

E, portanto, devemos garantir que:

$\left(j k^{\prime}-k \cdot \operatorname{sen} \theta\right)^{2}-k^{2}>0$, para todos os valores de $j$ inteiros e diferentes de 2.68 zero.

Desta equação, como $k$ e $k^{\prime}$ são características fixas para cada onda a ser gerada, quanto maior o valor de $j$, mais rápido será o decréscimo das perturbações com a distância. Sendo assim, se considerarmos $0<\theta<\pi / 2$, é simples de demonstrar que a condição da equação 2.67 é atendida para todos os valores de $j$ se for atendida para $j=1$.

Como com o aumento de $j$, o termo $k_{j}$ aumenta, a perturbação correspondente a $j=$ 1 é aquela que demora mais para desaparecer e, portanto, esta pode ser considerada separadamente como a característica do quão rápido as perturbações deverão desaparecer completamente com a distância do gerador. Sendo assim, a equação 2.67 fica:

$\left(k^{\prime}-k \cdot \operatorname{sen} \theta\right)^{2}-k^{2}>0$

Ou: 
$\frac{k^{\prime}}{k}>1+\operatorname{sen} \theta$

Ou então, se substituirmos $k^{\prime}$ de acordo com 2.59 e $k$ pelo comprimento $\lambda$ da onda progressiva, teremos:

$$
\ell<\frac{\lambda}{1+\operatorname{sen} \theta}
$$

Desta formulação pode-se concluir que o máximo comprimento de cada flap é função do comprimento da onda a ser gerada e do ângulo de emissão, ou, alternativamente, através desta fórmula é possível determinar qual o máximo ângulo de emissão para cada freqüência possível de ser gerado com um conjunto de flaps com largura $\ell$.

Porém, Biesel sugeriu uma análise desta função de um ponto de vista prático. Segundo seus argumentos, ao se considerar $\theta$ igual a aproximadamente $\pi / 2$, de acordo com 2.71 o sistema deve ser capaz de gerar uma onda praticamente paralela ao gerador de ondas e o comprimento dessa onda é da ordem de $\lambda / 2$. Nesta situação, para gerar onda com este ângulo os flaps adjacentes estariam com movimento em contra fase. Com este tipo de movimento nenhum indicativo sobre o sentido de propagação da onda ser para a direita ou esquerda seria dado. De fato, ondas se propagando em ambas as direções seriam geradas, sendo uma destas direções indesejada.

Este exemplo mostra que trabalhar muito próximo do limite teórico pode não ser razoável em alguns casos. Vale lembrar que defasagens de movimento muito grandes entre dois flaps adjacentes causarão grandes descontinuidades e, portanto, causarão outras perturbações além daquelas previstas pela teoria.

Em resumo, é necessário definir um limite prático. Como esperado, este limite foi derivado a partir das considerações teóricas apresentadas acima e de observações em tanques de provas com geradores tipo snake. Segundo Biesel, é razoável considerar que $\mathrm{k}_{1}$, número de onda da primeira componente espúria, seja pelo 
menos tão grande quanto $k$, portanto a perturbação irá desaparecer quase completamente em uma fração do comprimento de onda distante do gerador. Substituindo na equação 2.66:

$\left(k^{\prime}-k \cdot \operatorname{sen} \theta\right)^{2}-2 k^{2}>0$

Finalmente, chegando à condição:

$\ell<\frac{\lambda}{\sqrt{2}+\operatorname{sen} \theta}$

Os limites definidos na equação 2.73 serão calculados de acordo com a largura de flap escolhida para o Calibrador Hidrodinâmico e serão adotados no simulador como limites de geração das ondas oblíquas. 


\section{Simulador Numérico}

O desenvolvimento do simulador numérico para o Calibrador Hidrodinâmico tem como principal objetivo a criação de uma ferramenta simplificada que emule a elevação da superfície livre presente em todo tanque sem ter que resolver, para isso, o problema de contorno para obtenção do potencial de velocidades. Os flaps do tanque são divididos entre geradores e absorvedores de onda, de acordo com a parede a que pertencem, reproduzindo a mesma forma de funcionamento do tanque real.

Os flaps geradores de onda são representados por fontes pulsantes que terão suas amplitudes e fases definidas pelos movimentos que seriam impostos aos flaps do tanque. O simulador prevê ainda a possibilidade de determinados flaps não atuarem, permitindo a reflexão do campo de ondas incidente sobre eles. A modelagem dos efeitos de reflexão é discutida em detalhes na seção 3.2.2. No presente estudo, a absorção de ondas pelos flaps é considerada ideal. Dessa forma, quando os flaps atuam como absorvedores, supõe-se que toda a energia de ondas é dissipada pelos absorvedores, não provocando qualquer distorção sobre o campo de ondas incidente. Obviamente, essa situação não é verificada em um tanque real, para o qual parte da energia será refletida nos absorvedores e parte se dissipará na forma de ondas evanescentes. A modelagem destes efeitos, contudo, não faz parte do escopo deste trabalho.

Para o desenvolvimento da ferramenta, a metodologia adotada consistiu em duas diferentes etapas. A primeira etapa de desenvolvimento envolveu a criação de um simulador de ondas bidimensional, representativo do campo de ondas gerado em um canal (flume), capaz de emular ondas geradas a partir dos movimentos de um flap atuante em uma de suas extremidades, com amplitude e freqüência de movimento pré-determinadas. A validade de seus resultados foi avaliada confrontando-os com um conjunto de resultados experimentais medidos no canal de ondas do Depto. de Engenharia Naval e Oceânica da EPUSP. Essa comparação será apresentada mais adiante, no Capítulo 4. 
Finalizada a fase de comparação e ajustes no simulador bidimensional, este foi estendido para o caso tridimensional, que permite a simulação de geradores do tipo snake (sucessão de geradores/absorvedores bidimensionais posicionados lado a lado), com geração de ondas em ângulos oblíquos com relação à parede de geração.

Para uma primeira validação dos resultados desta versão tridimensional, os campos de onda simulados foram confrontados com os resultados da literatura obtidos com a solução numérica do problema de contorno através do programa WAMIT, que recentemente incluiu uma opção que torna possível resolver o problema potencial da geração e absorção de ondas, como descrito nos trabalhos de Newman ${ }^{[14]}$ e $\mathrm{O}^{\prime} \mathrm{Dea}^{[12]}$.

A introdução ao simulador bidimensional será feita na próxima seção, apresentando as considerações feitas e o equacionamento utilizado. Em seguida, será apresentado o desenvolvimento do simulador tridimensional.

\subsection{Simulador Numérico Bidimensional}

A primeira meta do trabalho é desenvolver um simulador bidimensional que inclua a geração de ondas regulares utilizando a teoria de geração já apresentada. Este simulador consiste, então, em um flap localizado em $x=0$, responsável pela geração de ondas e serve para verificar se a onda simulada se aproxima da onda gerada nos ensaios. Além disso, é possível visualizar as ondas evanescentes na proximidade do gerador através da comparação da leitura de um sensor de ondas posicionado sobre a face do gerador e analisar se a reprodução destas ondas pelo modelo numérico é satisfatória. 


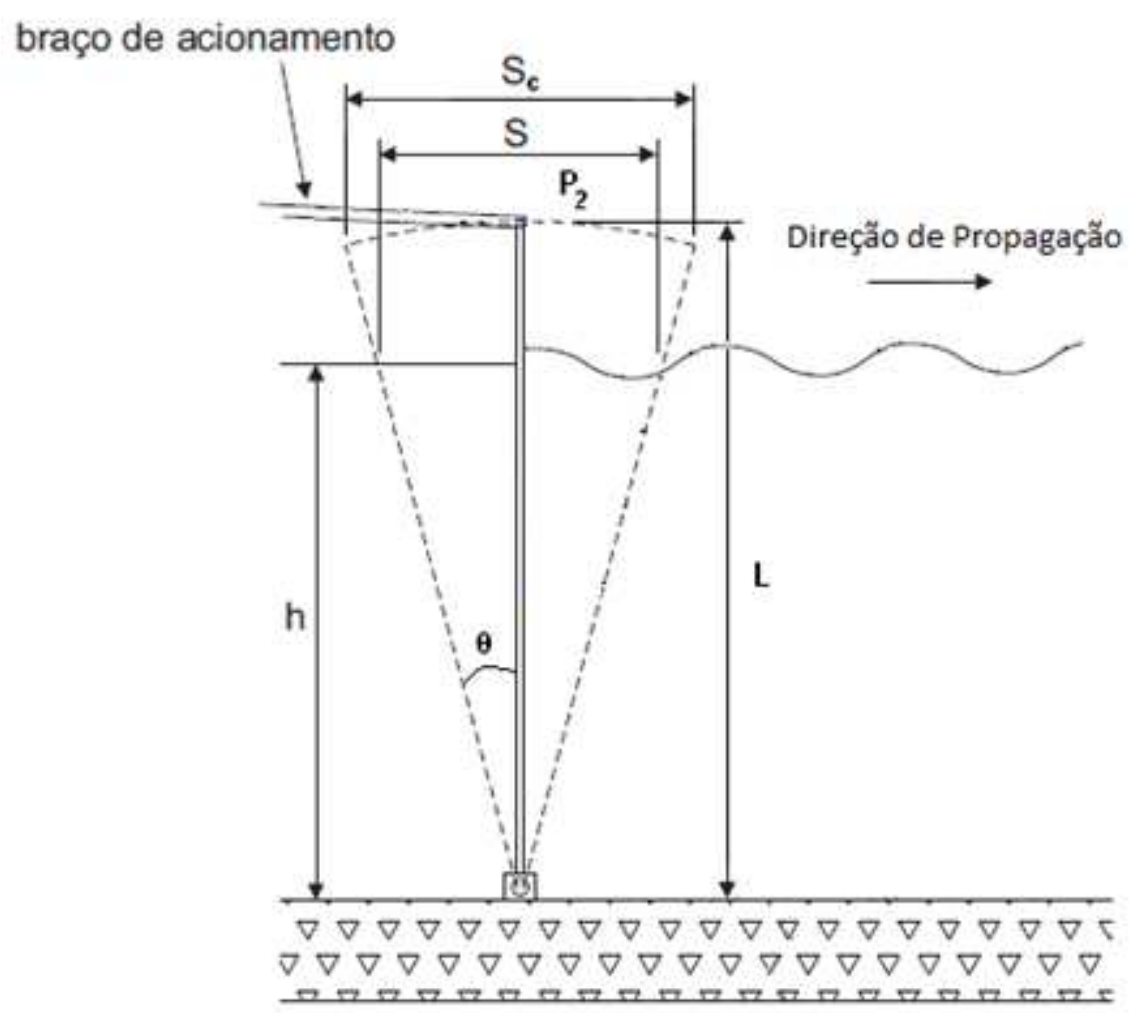

Figura 3.1: Disposição do simulador bidimensional proposto.

O simulador não encontra a solução do problema potencial para representar a elevação da superfície livre. Ele parte da solução de geração já proposta, que relaciona a amplitude do movimento com a amplitude da onda e também fornece a fase teórica entre a velocidade do flap e elevação da superfície livre. Da equação 2.13, que representa a velocidade do flap e da equação 2.8, que apresenta a velocidade em $z$ das partículas fluidas, é possível concluir que a velocidade do flap e a elevação da onda estão em contra fase, ou seja, quando a velocidade do flap é máxima, este se encontra na posição vertical e a crista da onda está localizada em $x=0$, onde a velocidade vertical é nula, definindo assim a fase entre posição e altura de onda gerada.

Considerando pequenos deslocamentos, a equação que representa o movimento no tempo de um ponto do flap localizado na altura da linha d'água em repouso pode ser escrita como:

$x_{\text {flap }}(t)=S \cdot \sin (\omega t)$ 
Observando a figura 3.1 nota-se que existe uma diferença entre o stroke fornecido pelo braço de acionamento, $S_{c}$, e o stroke na linha d'água, $S$. Foi definido que as entradas do simulador deverão ser feitas de acordo com a função de transferência do flap, que relaciona o stroke na linha d'água com a amplitude da onda gerada. No entanto, como veremos na seção 4.1, o sinal de referência de posição do flap obtido nos ensaios com o protótipo está localizado no braço de acionamento, sendo assim necessária uma correção para a comparação de posição entre os dois, dada por:

$S_{c}=S \cdot \frac{L}{h}$

Portanto, se quisermos a posição x do ponto de acionamento, localizado no topo do flap, devemos substituir $S$ por $S_{c}$ na equação 3.14. Então teremos:

$$
x_{c \text { flap }}(t)=S_{c} \cdot \operatorname{sen}(\omega t)=S \frac{L}{h} \cdot \operatorname{sen}(\omega t)
$$

De modo a adequar o gerador de ondas para uma possível junção com a teoria de absorção, é interessante trabalhar não com posição, e sim com velocidade do flap. Para isso, basta derivar no tempo a equação 3.3

$$
\dot{x}_{c \text { flap }}(t)=S \frac{L}{h} \omega \cdot \cos (\omega t)
$$

A elevação da superfície livre será representada pela sobreposição da onda progressiva com os vários modos evanescentes. Como citado anteriormente, a amplitude da componente progressiva está em fase com a velocidade do flap e pode ser definida como:

$\eta_{p}=A_{p} \cos (k x-\omega t)$

Onde a amplitude da onda progressiva $A_{p}$ é obtida através da função de transferência do flap, apresentada na equação 2.40 . 
De modo diferente da onda progressiva, as componentes evanescentes têm uma defasagem de 90 graus em relação à velocidade do flap e não se propagam, tendo sua influência sendo representada por:

$\eta_{e}=\sum_{n=1}^{\infty} A_{n} \sin (\omega t)$

A figura 3.2 apresenta a convergência da somatória de amplitude dos modos evanescentes em relação ao número de modos para o período de 2 segundos. Como critério, serão sempre considerados os primeiros trinta modos evanescentes, número considerado suficiente para garantir a convergência dos resultados.

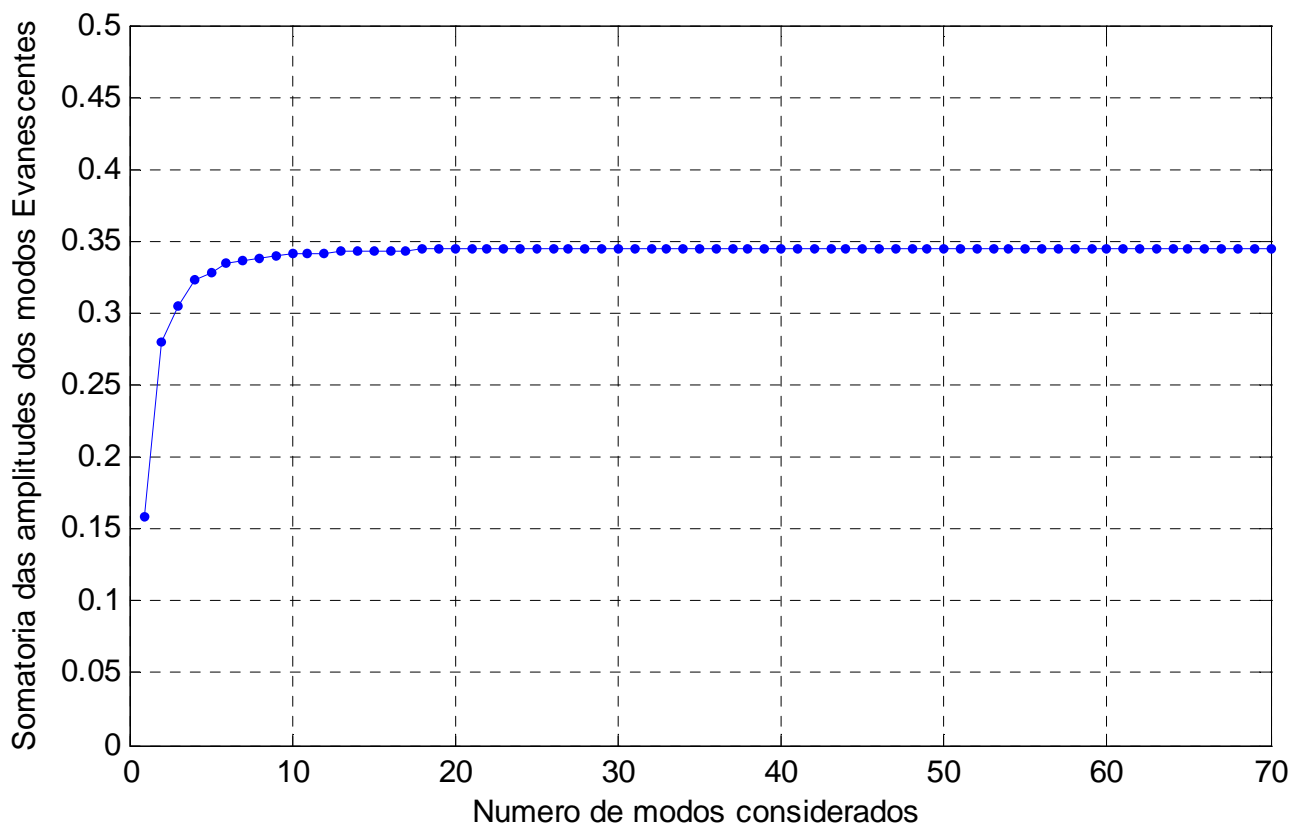

Figura 3.2: Convergência da somatória de amplitude das (ondas evanescentes, para o período de 2 segundos.

A defasagem da onda evanescente em relação à parcela progressiva tem grande influência ao compararmos os sinais do gerador de onda com os sinais do simulador e isto ficará claro no capítulo 4, quando discutirmos as validações do simulador. 


\subsubsection{Modelo de propagação de onda}

Como mostra a teoria linear de ondas, a propagação de uma onda de gravidade na superfície de um fluido envolve duas velocidades distintas. A primeira, denominada velocidade de fase ou de propagação, é a velocidade com que as cristas das ondas se deslocam, e a segunda, denominada velocidade de grupo, é a velocidade com que se propaga o trem de ondas e, portanto, a velocidade com que a energia média de ondas é transmitida.

Para ondas em região de profundidade constante $h$, a velocidade de fase pode ser obtida pela equação 3.7 .

$$
c_{p}=\sqrt{\frac{g \tanh \left(k_{p} h\right)}{k_{p}}}
$$

E a velocidade de grupo é dada por:

$$
c_{g}=c_{p}\left(1+\frac{2 k_{p} h}{\sinh \left(2 k_{p} h\right)}\right)
$$

As cristas das ondas geradas em um tanque se propagam com velocidade maior que a chamada frente de onda ${ }^{3}$. Portanto, para que esse efeito seja reproduzido pelo simulador, um modelo deve ser adotado. Esse modelo deve, fazer com que as ondas tenham um decréscimo em sua amplitude ao se aproximar da frente de onda, até desaparecer. Como mostra Newman ${ }^{[14]}$, a elevação da superfície livre ocasionada pelo movimento do batedor pode ser representada por uma integral de convolução no tempo na forma:

\footnotetext{
${ }^{3} \mathrm{O}$ frente de onda é uma linha imaginária que define o fim de uma onda. Na maioria dos casos, esta linha se move com uma velocidade menor que a crista das ondas que, ao atingi-la, desaparecem.
} 
$\eta(x, t)=\int_{0}^{t} x_{\text {flap }}(\tau) k(x, t-\tau) d \tau$

Onde a função impulso de resposta I é calculada por:

$$
I(x, t)=-\frac{1}{\pi} \int_{0}^{\infty} \cos (k x) \cos (\sqrt{g k}) t \int \varepsilon(z) e^{k z} d z d k
$$

No caso do flap, a integral com respeito a $z$ pode ser feita analiticamente, porém, a integral remanescente deve ser efetuada numericamente e enfrenta sérios problemas de convergência. Dado o custo computacional relativamente alto envolvido nesta integração e o pouco interesse prático em se analisar os transitórios de geração de ondas, ao menos no escopo do presente trabalho, esse modelo não foi adotado no simulador. Como alternativa, e de maneira simplificada, foi adicionada ao simulador uma envoltória que se desloca no tempo com velocidade de grupo e tem como objetivo fazer com que a onda decaia ao se aproximar da fronte. Esta envoltória pode ser conferida na figura a seguir.

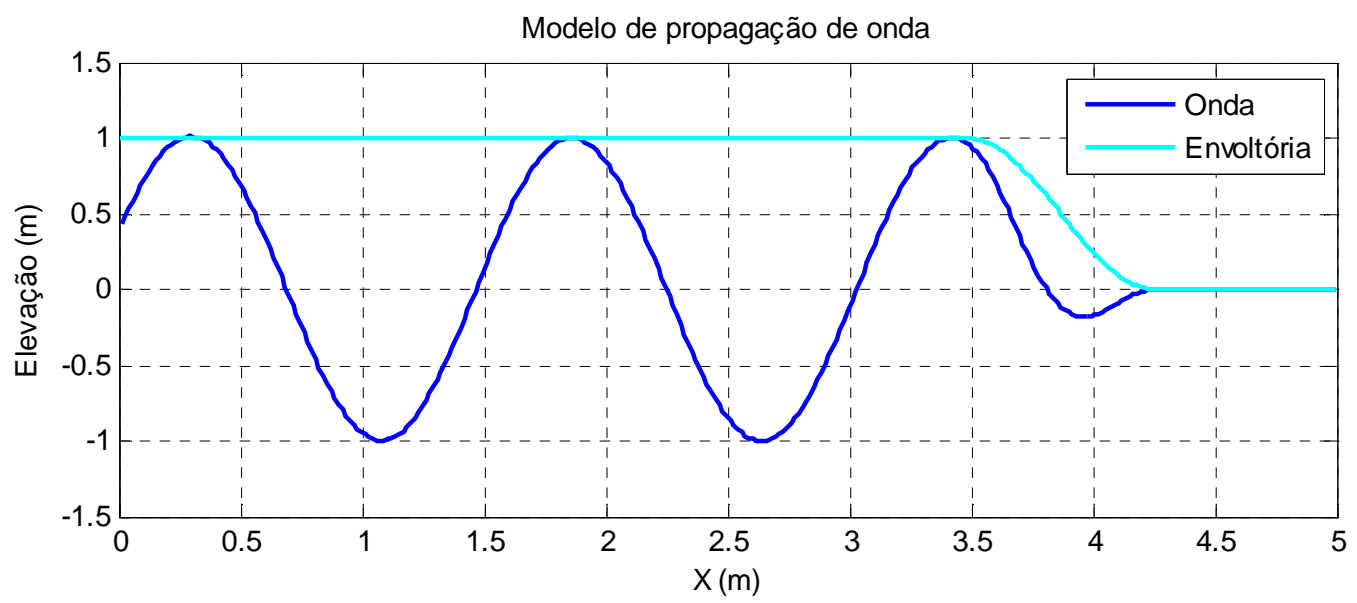

Figura 3.3: Modelo de propagação de onda. 


\subsection{Simulador Tridimensional}

O simulador tridimensional do tanque tem como principal objetivo fornecer a elevação da superfície em função do tempo para um tanque fechado gerando ondas regulares com uma direção de propagação escolhida, considerando a reflexão e/ou a absorção completa das ondas ocorridas nos flaps que compõe as paredes do tanque.

Cada gerador de onda do tanque é representado no simulador por uma fonte posicionada no centro do flap. Esta fonte gera uma onda com propagação radial, que será definida na seção 3.2.1, e é acompanhada por uma função envoltória que tem como finalidade criar o efeito de propagação da onda, de acordo com sua velocidade de grupo, a partir do momento em que o gerador de ondas começa a atuar, conforme foi mostrado na seção 3.1.1.

Caso seja necessário representar a reflexão da onda proveniente de um ou mais geradores em alguma das paredes do tanque, isso pode ser feito através da inclusão de uma ou mais imagens dos geradores através de espelhamentos das fontes com relação à(s) parede(s) refletora(s). A forma como isto é feito será apresentada em detalhes na seção 3.2.2, juntamente com o método escolhido para representar a absorção de ondas.

Finalmente, o simulador é unicamente composto por fontes, sejam elas as principais ou suas imagens. Para controlar as fontes de forma adequada é necessário reproduzir no simulador as mesmas hipóteses utilizadas para controlar os geradores do tanque, conforme será apresentado na seção 3.2.3. 


\subsubsection{Representação dos Geradores: Fontes}

As fontes que representam os geradores do tanque devem criar ondas similares à onda criada pelo movimento de um flap que compõe uma parede de geração de ondas. Uma aproximação para isto é apresentada por Hirayama ${ }^{[17]} \mathrm{em}$ um trabalho sobre geração e simulação de ondas transientes multi-direcionais, no qual as ondas geradas são representadas numericamente por uma onda circular com origem no centro do gerador de ondas e pode ser escrita como:

$\eta(r, t)=A(r) \cos (k \cdot r-\omega t)$

A amplitude da onda circular varia em função da distância com o gerador para respeitar a conservação de energia no sistema. A densidade de energia de uma onda bi-dimensional é proporcional ao quadrado de sua amplitude. Se considerarmos uma onda circular, a sua energia deverá ser proporcional a:

$\bar{E} \propto \pi r A^{2}$

Sendo assim, para conservar a energia do sistema, a variação da amplitude é dada por:

$A(r)=A_{p} \frac{1}{\sqrt{\pi \cdot r}}$, onde $A_{p}$ é a amplitude fornecida pela função de transferência do flap.

A equação 3.13 é valida para uma onda circular concêntrica em torno do gerador. Todavia, quando uma fonte de onda faz parte de uma parede, ele passa a gerar apenas um semicírculo. Sendo assim, o aumento do perímetro de uma crista da onda cai pela metade e, com isso, o decréscimo de amplitude para haver conservação de energia deve ser dado por: 


$$
A(r)=A_{p} \frac{1}{\sqrt{\frac{\pi \cdot r}{2}}}
$$

Esta ultima equação será utilizada para representar o decréscimo de amplitude da onda gerada pela onte no imulador. Substituindo a equação 3.14 em 3.11 obtém-se a seguinte equação para uma única fonte gerando ondas.

$$
\eta(r, t)=A p \frac{1}{\sqrt{\frac{\pi \cdot r}{2}}} \cos (k . r-\omega t)
$$

Uma maneira de conferir a adequação do modelo de geração proposto pela eq. 3.15 será tratada no capítulo 4, quando a mesma será comparada a resultados provenientes da solução potencial do problema através do programa Wamit.

\subsubsection{Representação da reflexão e da absorção}

Para tornar completo o simulador numérico de um tanque fechado é necessário representar de algum modo a reflexão ou a absorção de ondas que ocorre em suas paredes. Antes de apresentar detalhes sobre como isso é feito, duas hipóteses tem que ser destacadas:

1- Sempre que for possível realizar a absorção da onda incidente, esta será perfeita, não retornando qualquer tipo de onda residual para a região do tanque.

2- Caso não seja possível a absorção da onda incidente, a reflexão será completa, não havendo qualquer perda de energia na parede refletora.

O principal objetivo da absorção é fazer com que o tanque funcione como uma área infinita, ou seja, as ondas geradas se propagam para o infinito, não encontrando nenhum obstáculo e nunca retornando para a região de ensaio. Portanto, a maneira 
mais simples de fazer isso no simulador é considerar que a parede do tanque não existe sempre que absorção é possível, simulando um tanque aberto, ou semiaberto, dependendo das paredes que podem realizar a absorção da onda ou não.

O caso da reflexão de onda é um pouco mais complicado de ser representado. Ao encontrar uma parede rígida, a onda deve refletir-se da mesma forma que ocorre com um feixe de luz ao encontrar um espelho. O ângulo de incidência deve ser igual ao ângulo de propagação da onda refletida, como é apresentado na figura 3.4 e não há alteração de fase na reflexão.

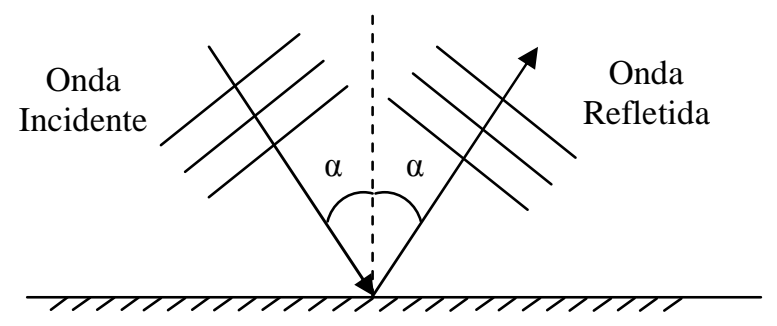

Figura 3.4: Reflexão de onda em uma parede.

Uma alternativa que pode ser implementada no simulador para representar as reflexões e re-reflexões é a adição de imagens dos geradores considerando o plano onde a parede está localizada como um espelho, como apresentado na figura 3.5. Esta figura mostra como as reflexões e re-reflexões são representadas na composição da superfície livre. O tanque principal, representado pela cor preta, contém o gerador. À sua direita e esquerda, em azul, estão as imagens do tanque responsáveis por criar os efeitos da primeira reflexão de onda nas paredes do tanque. Por fim, na parte superior da imagem, em vermelho, está representada a imagem do tanque à direita do principal com relação à parede esquerda do tanque. Esta é uma imagem de uma imagem e é responsável por criar a representação da segunda reflexão de ondas. Com o objetivo de identificar as ondas presentes nos tanques como gerada, refletida e re-refletida foram atribuídos tipos de traçados diferentes para representar cada uma: 
- Onda principal: linha continua.

- Onda refletida: linha tracejada.

- Onda re-refletida: linha traço e ponto.

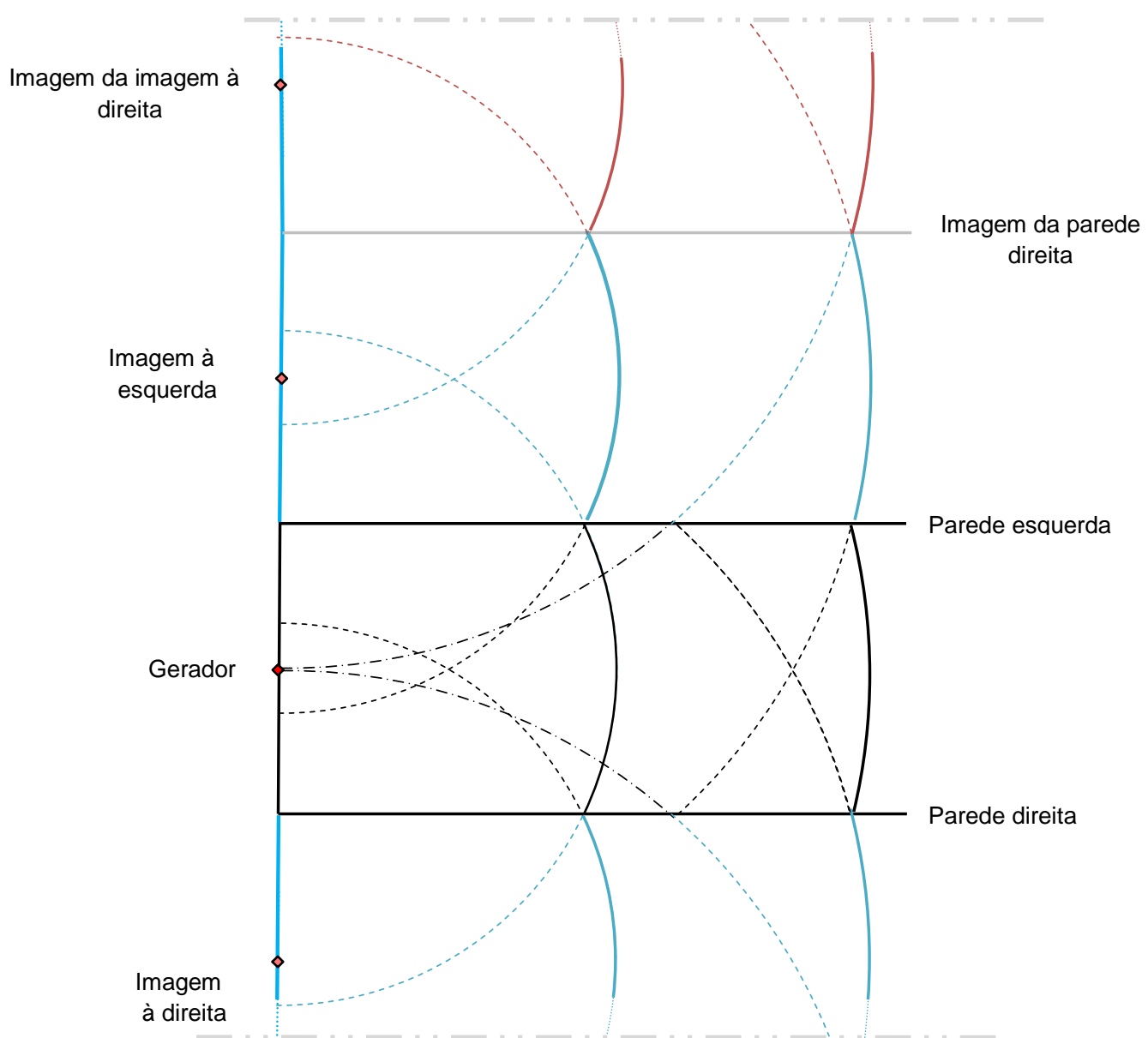

Figura 3.5: Método de representação de reflexão de ondas utilizando imagens dos geradores.

O princípio apresentado acima pode ser estendido para representar quantas reflexões forem necessárias. O número de imagens a ser empregado na simulação decorre de uma análise prévia de convergência do campo de ondas obtido. Após alguns testes realizados, verificou-se que para geração perpendicular a utilização de 20 reflexões nas paredes laterais do tanque se mostrou suficiente para todo o intervalo de períodos de interesse neste trabalho. No caso de ondas obliquas existem outros fatores a serem considerados. O número de reflexões está associado ao comprimento do tanque e ao ângulo de propagação e deve-se calcular o número 
de reflexões que a onda sofre nas paredes do tanque até que atinja a parede oposta à qual foi gerada, onde sempre será possível sua absorção.

\subsubsection{Funcionamento do simulador}

Dado o modo em que o tanque opera, o simulador deve ser capaz de reproduzir a superfície livre do tanque real. A idéia de operação inicial do tanque é a utilização de duas paredes adjacentes como geradoras, enquanto as outras duas operarão apenas como absorvedoras, conforme apresentado na figura 3.6. Esta figura também apresenta o sistema de coordenadas utilizado no simulador e como é considerada a direção de propagação da onda.

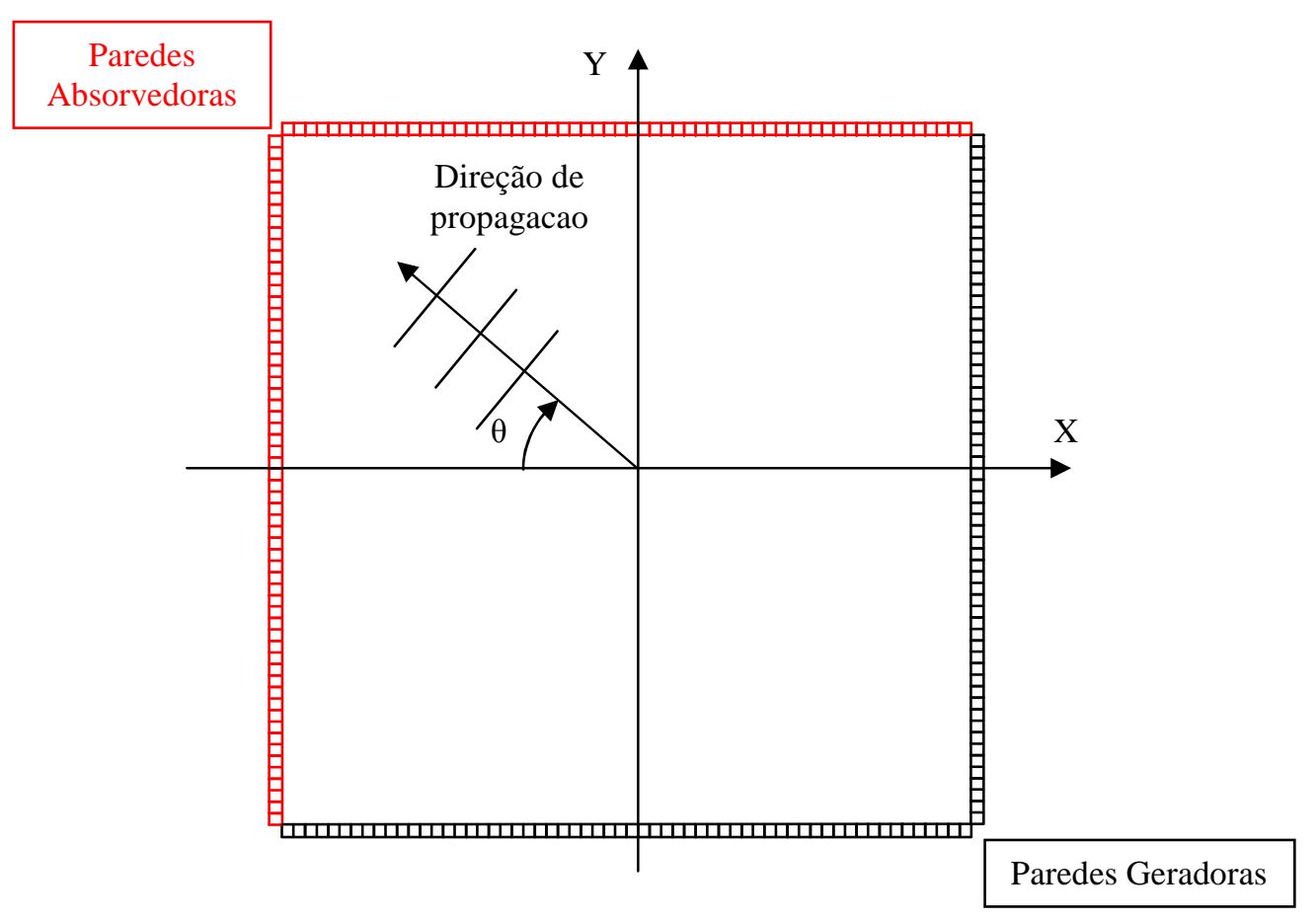

Figura 3.6: Sistema de coordenadas e definição de geradores e absorvedores utilizados no simulador

É necessário ressaltar que nem sempre é possível gerar ou absorver uma onda com um sistema de flaps, como foi discutido no capítulo 2.4.2, sendo necessário realizar a verificação do limite de Biesel. Este limite é definido apenas para a geração de ondas, mas pode ser aplicado também para se verificar a possibilidade de absorção de uma onda incidente, se considerarmos que a absorção nada mais é que a 
geração de uma onda com mesmo período e sentido de propagação da incidente, porém com fase invertida. Sempre que uma parede for incapaz de gerar ou absorver a onda, esta deve permanecer imóvel.

Assim como no tanque real, para iniciar o processo de geração de onda no simulador deve-se partir da definição da amplitude e direção da onda desejada. Feito isso, deve ser verificado o limite de Biesel em cada uma das paredes do tanque para definir se ela será capaz ou não de realizar a sua função ou se deverá permanecer imóvel. Uma vez definido o procedimento de operação de cada parede, o próximo passo consiste em calcular os parâmetros de cada fonte para gerar a onda desejada.

O primeiro parâmetro a ser calculado é o da amplitude da fonte. Consideremos uma parede infinita composta por $\mathrm{N}$ flaps de largura finita, como apresentado na figura 3.7. A onda mais simples a ser gerada por essa parede é uma onda com direção perpendicular a ela. Neste caso, todos os flaps devem operar em fase e poderíamos reduzir o problema ao caso $2 \mathrm{D}$, onde a amplitude da fonte é definida pela função de transferência do gerador.

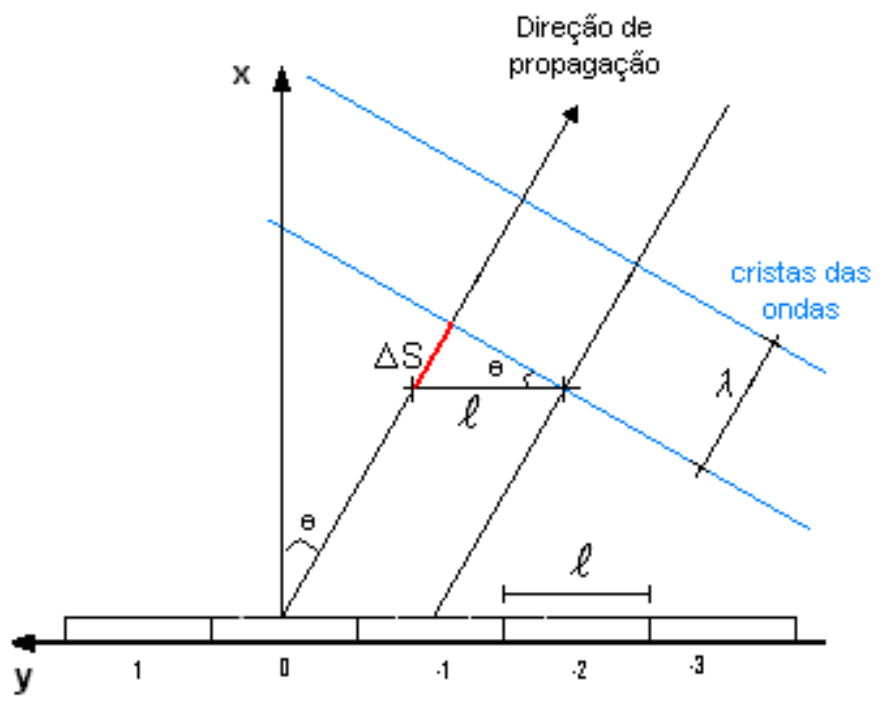

Figura 3.7 Parede geradora

Esta mesma parede, ao trabalhar gerando uma onda obliqua, deve ser interpretada pela teoria de geração apresentada no capitulo 2.4.1. Segundo a equação 2.65 , a 
amplitude da onda oblíqua gerada sofre um incremento de amplitude representado por 3.16:

$\frac{\sin \tau}{\tau \cos \theta}=\frac{\sin \left[\frac{1}{2}(k \cdot \ell \cdot \sin \theta)\right]}{\frac{1}{2}(k \cdot \ell \cdot \sin \theta) \cos \theta}$

Portanto, a amplitude da fonte deve ser corrigida em caso de geração obliqua, alterando a equação da fonte para:

$$
\eta(r, t)=A_{p} \frac{\frac{1}{2}(k \cdot \ell \cdot \sin \theta) \cos \theta}{\sin \left[\frac{1}{2}(k \cdot \ell \cdot \sin \theta)\right]} \frac{1}{\sqrt{\frac{\pi \cdot r}{2}}} \cos (k \cdot r-\omega t)
$$

Acertada a amplitude, devem ser calculadas as diferenças de fase entre as fontes de uma mesma parede para gerar a onda com o ângulo desejado e também a fase responsável pela sincronização entre as paredes geradoras.

O caso da defasagem entre os flaps de uma mesma parede foi apresentado no capítulo 2.4.1. A equação 2.47 representa a diferença percorrida pelas cristas das ondas geradas por dois flaps adjacentes. Generalizando para uma parede com vários flaps e multiplicando a diferença de distância percorrida pelo número de onda chegamos à diferença de fase de cada flap, dada por:

k.n.l. $\sin \theta, \quad$ onde $n$ representa o índice do gerador de onda. $\mathrm{O}$ gerador $n=0$ é o mais próximo à quina entre as paredes geradores e é considerado como referência.

A última defasagem a ser incorporada é a de sincronização entre as duas paredes do tanque. De forma análoga ao caso de flaps adjacentes, deve-se encontrar a diferença de percurso entre as ondas dos flaps de cada parede. Esta diferença é apresentada na figura 3.8 e seu valor é dado por: 
$\Delta S=\frac{\ell}{2}(\cos \theta-\sin \theta)$

A equação 3.19 pode ter valores positivos ou negativos em função do ângulo de propagação, definindo assim um adiantamento ou atraso de fase em relação ao flap $n=0$, tomado como referência da geração. Resta agora multiplicá-la pelo número de onda para obter a defasagem:

$k \frac{\ell}{2}(\cos \theta-\sin \theta)$

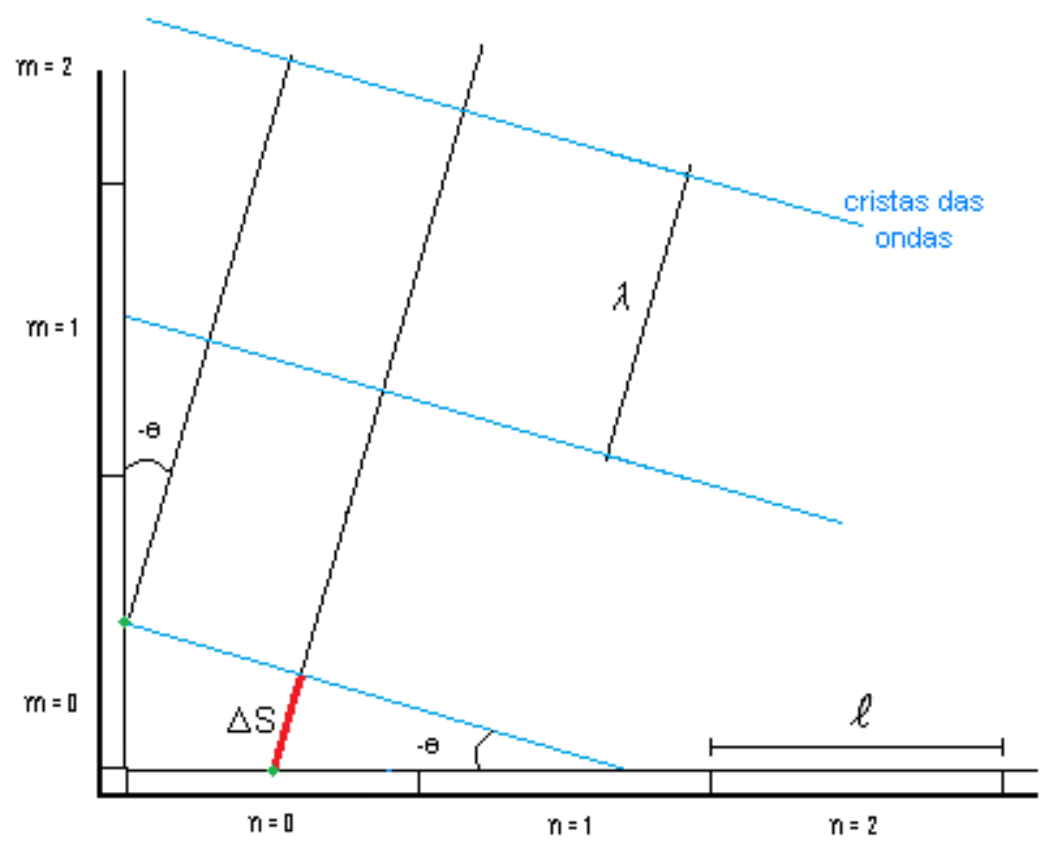

Figura 3.8: Sincronização entre as duas paredes geradoras

Esta defasagem deve ser aplicada somente a uma das paredes do tanque, resultando em equações distintas para cada uma. Para a parede de referência, representada pelos índices $n$, adiciona-se à equação 3.17 apenas a defasagem de flaps adjacentes, resultando em: 
$\eta(r, t)=A_{p} \frac{\frac{1}{2}(k \cdot \ell \cdot \sin \theta) \cos \theta}{\sin \left[\frac{1}{2}(k \cdot \ell \cdot \sin \theta)\right]} \frac{1}{\sqrt{\frac{\pi \cdot r}{2}}} \cos (k \cdot r+k \cdot n \cdot \ell \cdot \sin \theta-\omega t)$

Por fim, para a parede representada pelos índices $\mathrm{m}$, adicionam-se as duas defasagens à equação 3.17, resultando em:

$$
\begin{aligned}
\eta(r, t)=A_{p} & \frac{\frac{1}{2}(k \cdot \ell \cdot \sin \theta) \cos \theta}{\sin \left[\frac{1}{2}(k \cdot \ell \cdot \sin \theta)\right]} \frac{1}{\sqrt{\frac{\pi \cdot r}{2}}} \cos (k \cdot r+k \cdot m \cdot \ell \cdot \sin \theta+ \\
& \left.+k \cdot \frac{\ell}{2}(\cos \theta-\sin \theta)-\omega t\right)
\end{aligned}
$$




\section{Validação do Simulador}

O simulador numérico foi criado com base em uma teoria bastante estudada e já bem conhecida. O processo de validação tem como objetivo a verificação se a teoria foi implementada corretamente no simulador e este consegue reproduzir de forma satisfatória resultados considerados válidos.

A validação do simulador foi feita em etapas, iniciando com casos mais simples e adicionando complexidade a cada etapa. O primeiro caso avaliado foi o simulador bidimensional, que teve sua teoria apresentada na seção 3.1. Como base de comparação foram utilizados testes realizados com um protótipo do gerador de ondas montado em um canal, apresentado na figura 4.1 .

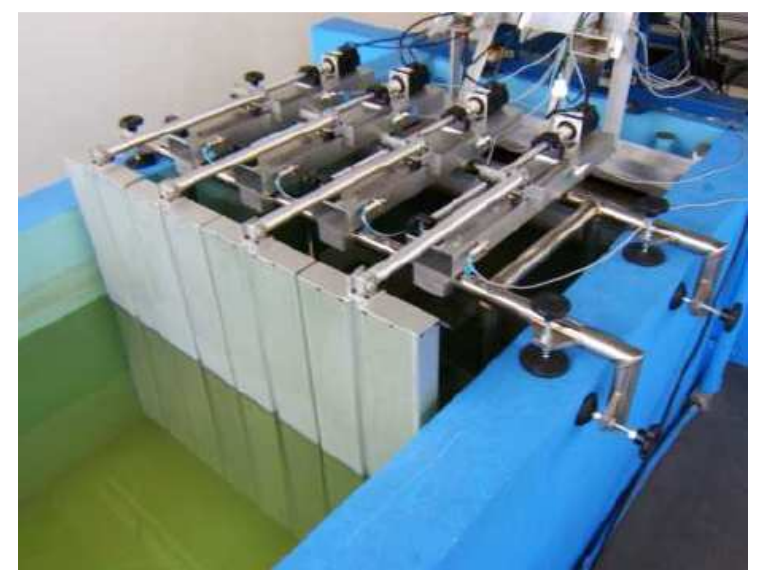

Figura 4.1: Protótipo de gerador com quatro flaps montado em um canal.

Uma vez validado o simulador bidimensional, foram realizadas comparações do simulador tridimensional com resultados fornecidos pelo Wamit. Seguindo a idéia de começar pelo simples e adicionar complexidade aos poucos, as comparações foram divididas em quatro etapas e serão apresentadas em detalhes na seção 4.2. 


\subsection{Validação do simulador bidimensional}

As comparações do simulador bidimensional foram feitas para casos de geração de ondas com períodos variando entre 0.5 e 2.0 segundos. O objetivo é avaliar se o simulador é capaz de reproduzir bem a onda obtida durante os ensaios.

Os ensaios foram executados com uma profundidade de 0.67 metros. Foram geradas ondas regulares, varrendo toda a faixa de freqüências de operação do gerador e algumas declividades de ondas, com o objetivo de levantar a função de transferência real do gerador e compará-la com a teórica. Detalhes sobre estes ensaios podem ser verificados na dissertação de Carneiro $^{[3]}$, de onde foram extraídos os gráficos da função de transferência do protótipo.
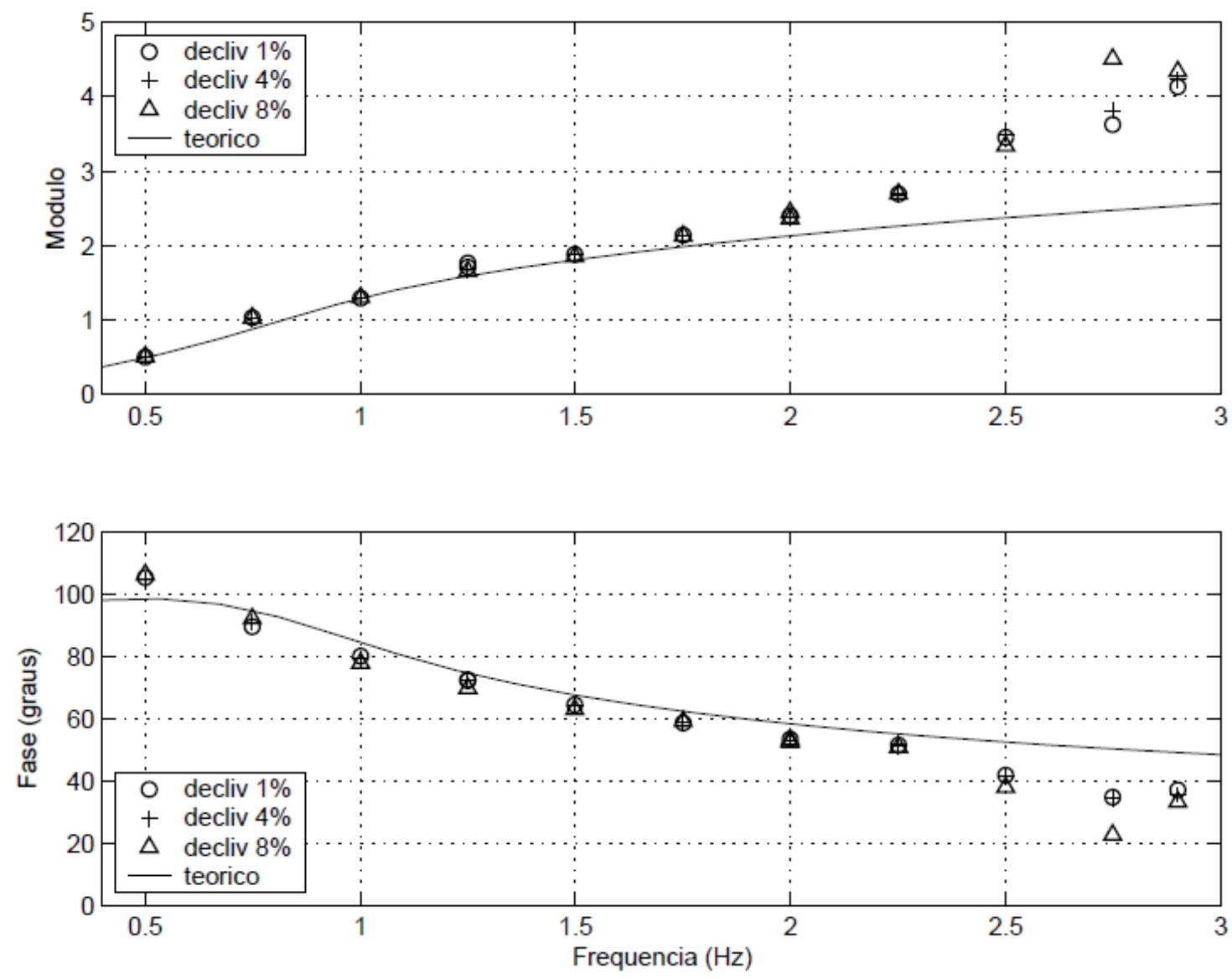

Figura 4.2: Função de transferência do protótipo. (Carneiro, 2008) 
A tabela 4.1 apresenta um resumo dos ensaios que serão comparados ao simulador.

Tabela 4.1: Características dos ensaios comparados.

\begin{tabular}{|c|c|c|c|}
\hline $\begin{array}{c}\text { Número do } \\
\text { Ensaio }\end{array}$ & $\begin{array}{c}\mathrm{f} \\
(\mathrm{hz})\end{array}$ & $\begin{array}{c}\text { Declividade } \\
(\%)\end{array}$ & $\begin{array}{c}\mathrm{S} \\
(\mathrm{mm})\end{array}$ \\
\hline 1 & 0.50 & 1.00 & 88.30 \\
\hline 2 & 0.50 & 1.40 & 126.30 \\
\hline 3 & 0.50 & 2.90 & 252.70 \\
\hline 4 & 1.00 & 1.00 & 11.10 \\
\hline 5 & 1.00 & 4.00 & 44.60 \\
\hline 6 & 1.00 & 8.00 & 89.10 \\
\hline 7 & 1.50 & 1.00 & 4.20 \\
\hline 8 & 1.50 & 4.00 & 16.10 \\
\hline 9 & 1.50 & 8.00 & 39.20 \\
\hline 10 & 2.00 & 1.00 & 2.50 \\
\hline 11 & 2.00 & 4.00 & 10.00 \\
\hline 12 & 2.00 & 8.00 & 20.10 \\
\hline
\end{tabular}

Foram feitas comparações da leitura da onda na parede do flap e da posição em que ele se encontra. Como dito anteriormente, a leitura do simulador pode ser feita sobre o ponto $x=0$.

Para análise e discussão foram escolhidos os dois extremos dos ensaios comparados, sendo então um com período de 2 segundos e outro com período de 0.5 segundos, ambos considerando a declividade intermediária ensaiada, ou seja, os ensaios de número 2 e número 11, da Tabela 4.1.

O primeiro período analisado foi o de 2 segundos, cujas comparações podem ser vistas na figura 4.3. Descontado o transitório inicial do movimento dos flaps, não há diferença entre o sinal do encoder de posição do protótipo e da posição calculada pelo simulador. No entanto, os sinais da onda tiveram uma pequena defasagem, que pode ser observada melhor na figura 4.4 . 

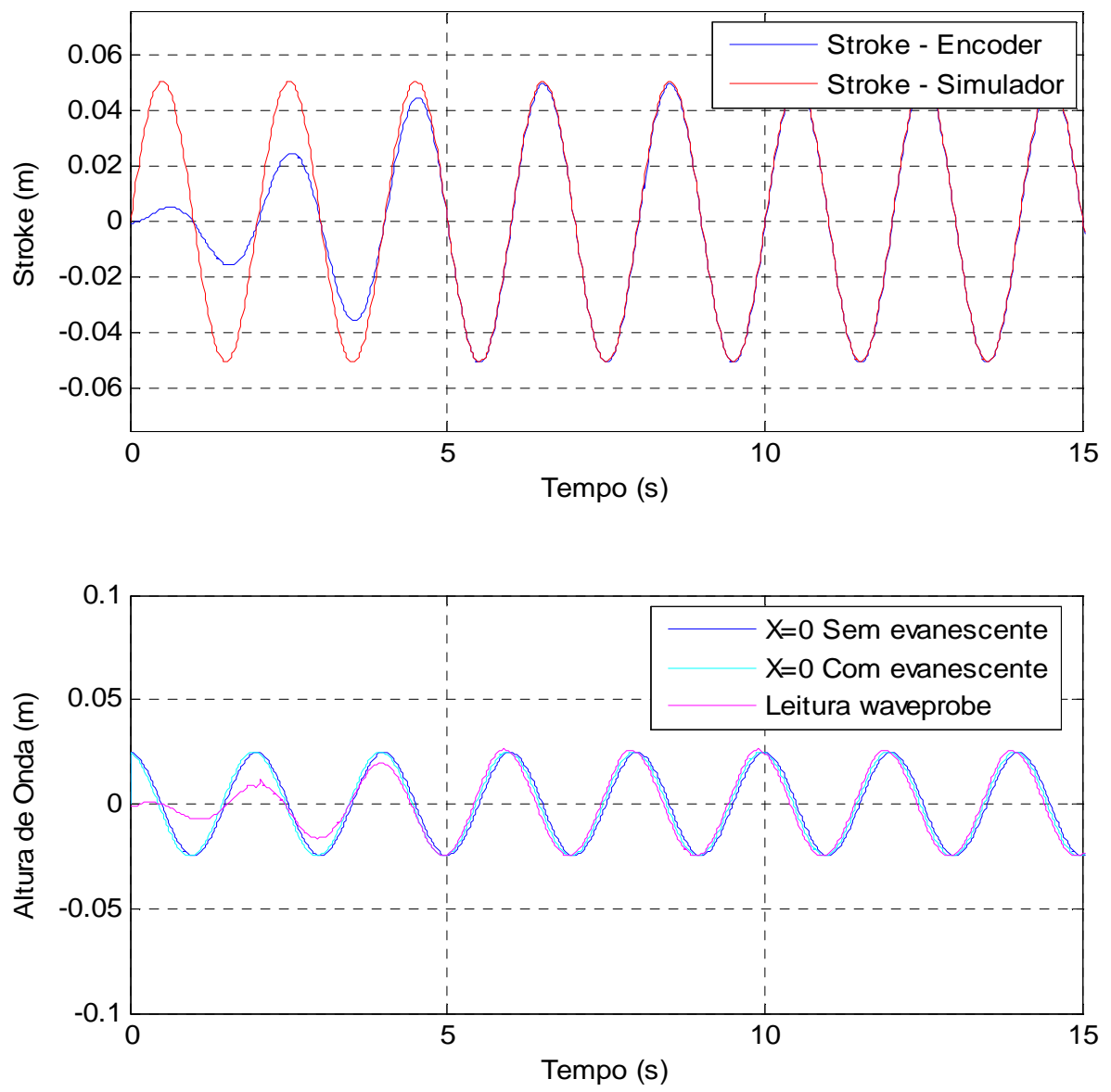

Figura 4.3: Comparação Protótipo e Simulador para onda 2 segundos.

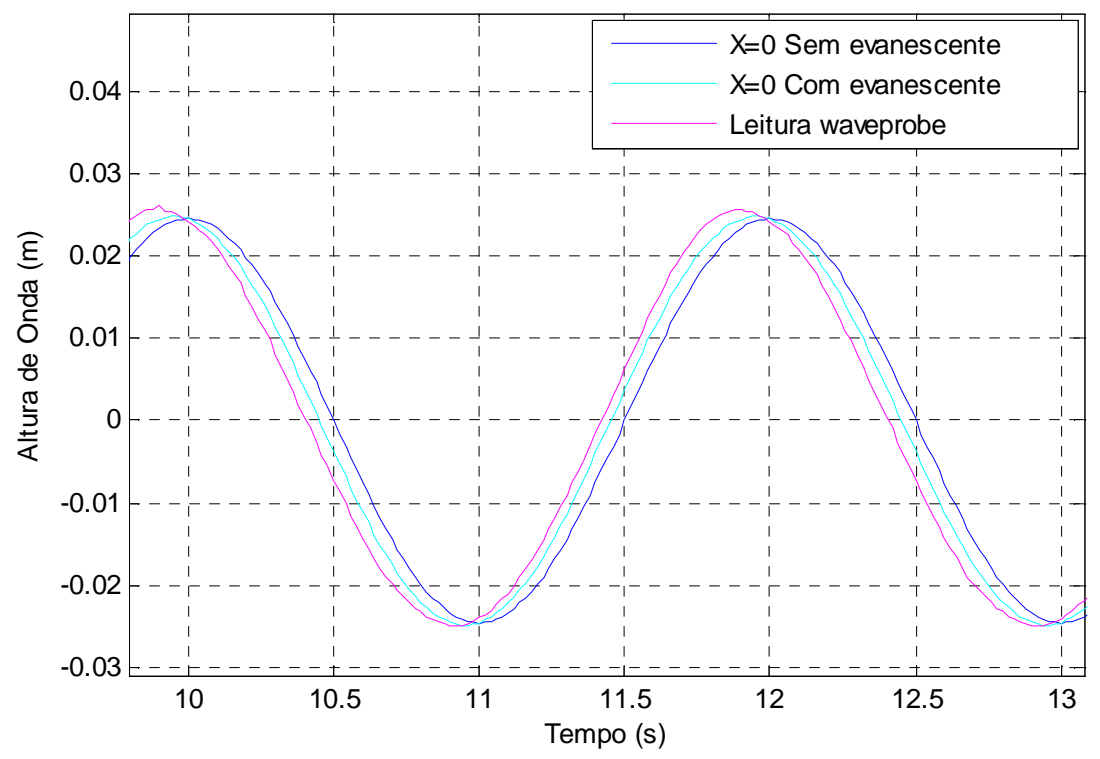

Figura 4.4: Aproximação do sinal de leitura de onda $\mathrm{T}=2$ segundos. 
A soma da onda evanescente à onda progressiva gera defasagem e alteração na amplitude da progressiva. Teoricamente, aplicada essa soma, a onda resultante deveria estar em fase com a leitura do ondógrafo, porém, ao medirmos a defasagem entre a onda calculada pelo simulador e a medida no ondógrafo, constatamos uma defasagem de aproximadamente 7 graus, a mesma defasagem que foi obtida na função de transferência real do gerador de ondas, apresentada na figura 4.2.

Sendo assim, o simulador reproduziu satisfatoriamente a geração da onda de período 2 segundos, fora a pequena defasagem existente, que é justificada pela diferença entre a função de transferência real do batedor obtida experimentalmente e da função de transferência teórica.

A próxima análise é do ensaio número 11, com período de 0.5 segundos. Seu gráfico é apresentado na figura 4.5.
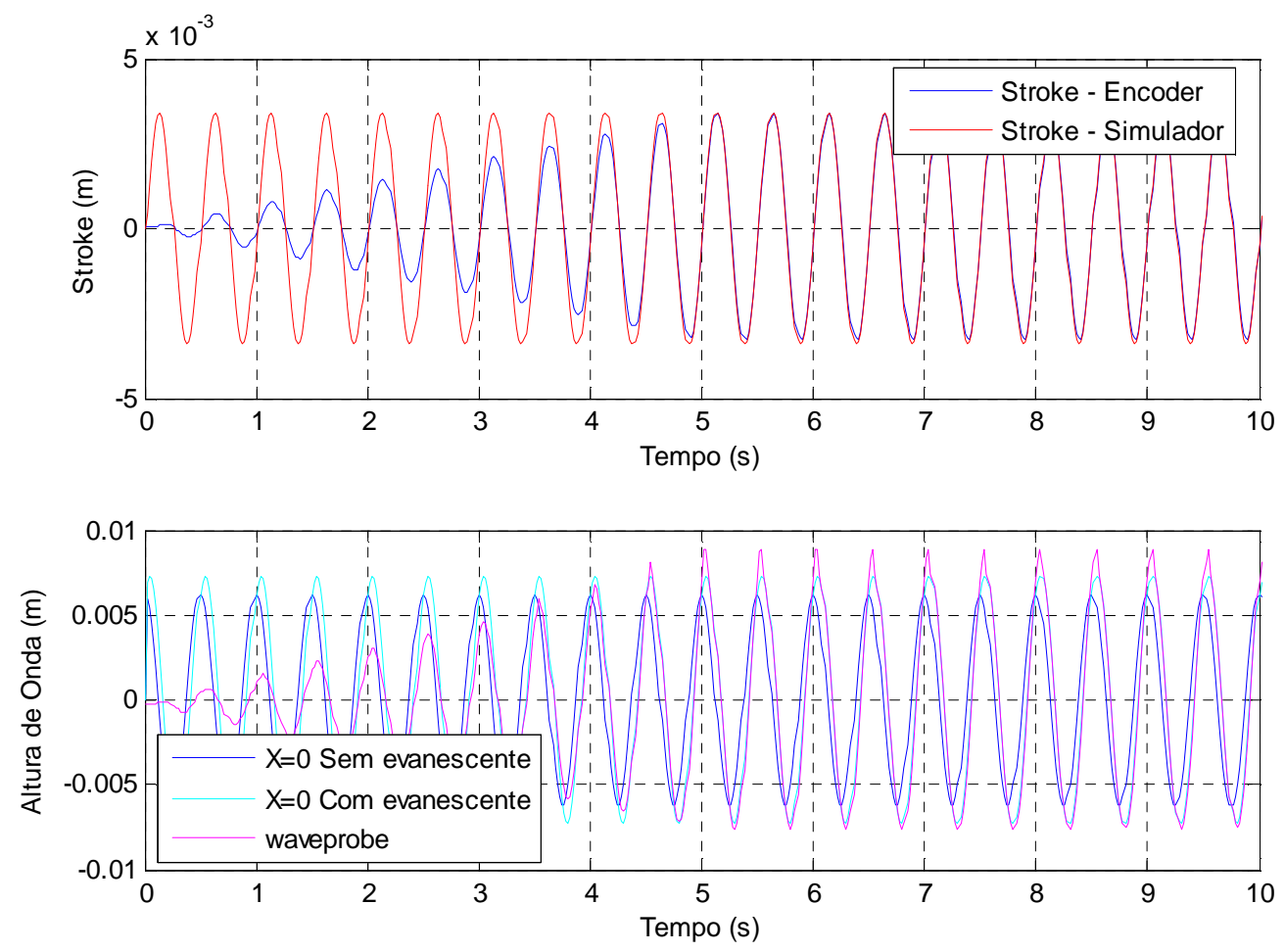

Figura 4.5: Comparação Protótipo X Simulador para onda de 0.5 segundos

Neste caso, o período da onda é menor e a relação entre as amplitudes da onda progressiva e da evanescente é maior, ficando nítida a influência da evanescente na 
leitura de onda. Para observar melhor esta influência, a figura 4.6 apresenta um trecho da leitura do ondógrafo.

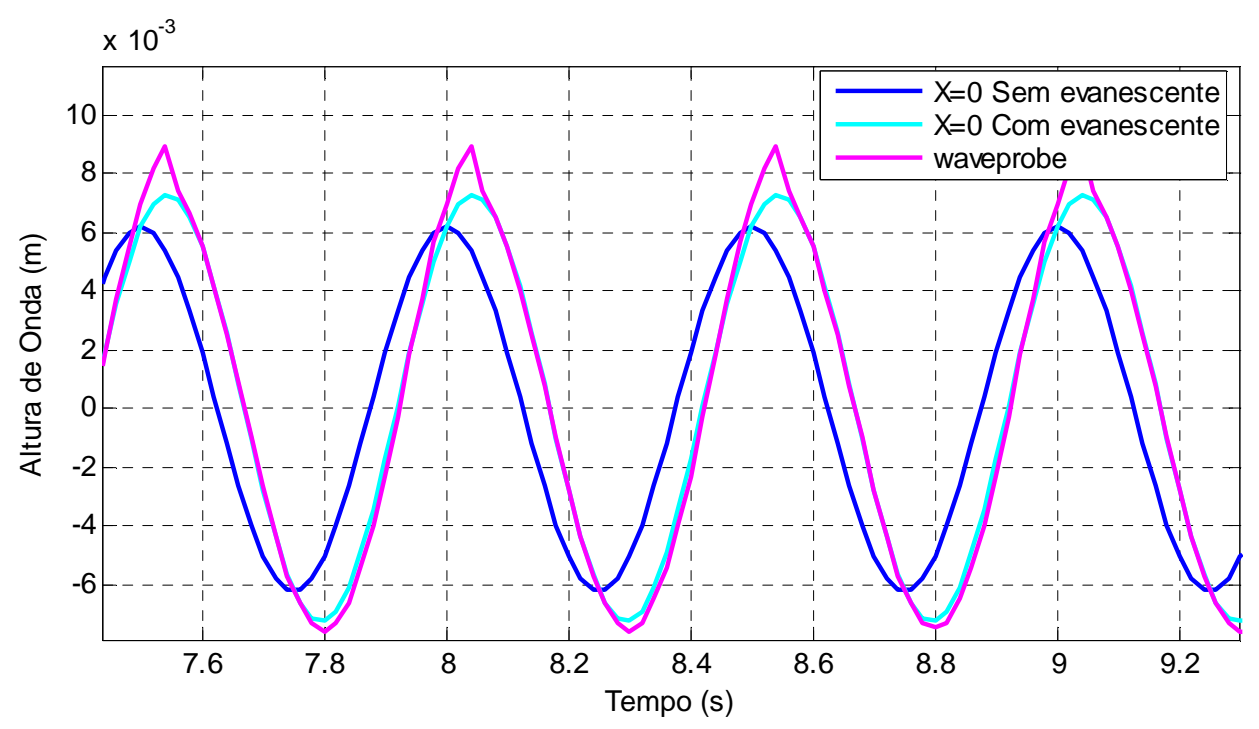

Figura 4.6: Sinal de leitura de onda $\mathrm{T}=0.5$ segundos

Neste caso não é quase notada defasagem entre a leitura do ondógrafo e a medição feita pelo simulador. Novamente podemos voltar na função de transferência real do gerador e verificar que a diferença de fase para a freqüência de $2 \mathrm{~Hz}$ é relativamente pequena, se aproximando da teórica. Nesta figura também pode-se notar uma distorção no sinal quando ocorrem os picos das ondas. Esta distorção na leitura é atribuída a problemas no sensor de ultra-som, cuja discussão fica além do propósito deste trabalho.

As outras comparações feitas levaram a resultados semelhantes, mostrando que o simulador pode avaliar de forma bastante próxima e rápida a geração de ondas quando efetuamos comparações sobre o comportamento em regime, principal intenção na geração de ondas. A tabela 4.2 apresenta um resumo com o restante das comparações. 
Tabela 4.2: Resumo das comparações para o simulador bidimensional.

\begin{tabular}{|c|c|c|c|c|}
\hline $\begin{array}{c}\text { Número do } \\
\text { Ensaio }\end{array}$ & $\begin{array}{c}\mathrm{T} \\
(\mathrm{s})\end{array}$ & $\begin{array}{c}\text { Declividade } \\
(\%)\end{array}$ & $\begin{array}{c}\text { Diferença de } \\
\text { amplitue (\%) }\end{array}$ & $\begin{array}{c}\text { Diferença de } \\
\text { fase (graus) }\end{array}$ \\
\hline 1 & 2.00 & $1.00 \%$ & $0.80 \%$ & 6.70 \\
\hline 2 & 2.00 & $1.40 \%$ & $0.27 \%$ & 7.00 \\
\hline 3 & 2.00 & $1.90 \%$ & $0.10 \%$ & 6.90 \\
\hline 4 & 1.00 & $1.00 \%$ & $3.49 \%$ & -5.20 \\
\hline 5 & 1.00 & $4.00 \%$ & $2.73 \%$ & -4.30 \\
\hline 6 & 1.00 & $8.00 \%$ & $4.12 \%$ & -4.30 \\
\hline 7 & 1.50 & $1.00 \%$ & $1.75 \%$ & -3.20 \\
\hline 8 & 1.50 & $4.00 \%$ & $2.13 \%$ & -3.10 \\
\hline 9 & 1.50 & $8.00 \%$ & $1.36 \%$ & -3.30 \\
\hline 10 & 0.50 & $1.00 \%$ & $2.31 \%$ & -3.70 \\
\hline 11 & 0.50 & $4.00 \%$ & $0.80 \%$ & -1.00 \\
\hline 12 & 0.50 & $8.00 \%$ & $1.81 \%$ & -2.50 \\
\hline
\end{tabular}

Com estes resultados garante-se que o simulador representa bem casos de geração bidimensional. Seguindo a hipótese de que o simulador tridimensional nada mais é do que uma sucessão de geradores bidimensionais lado a lado, o simulador tridimensional também é valido. Para confirmar isso, a próxima seção apresenta os resultados das comparações feitas entre o simulador tridimensional e o Wamit.

\subsection{Validação simulador $3 D$}

Este capítulo tem como objetivo apresentar comparações de resultados obtidos utilizando o simulador desenvolvido com resultados fornecidos pelo programa Wamit ${ }^{[15]}$. O foco das comparações foram casos de tanque semi aberto com flaps dispostos em duas paredes adjacentes gerando ondas que se propagam para o infinito. A escolha destes casos foi feita porque são os que mais se aproximam do simulador criado e serão apresentadas na seção 4.1 .

As comparações de tanque aberto foram divididas em quatro casos, iniciando pelo caso mais simples possível e adicionando complexidade aos poucos. Isto foi feito para facilitar as comparações e também por esta ser a primeira vez que se trabalhava com a função de análise de geradores de onda implementada no Wamit. 
De modo a garantir que a utilização do Wamit estava sendo feita corretamente foi decidido seguir um trabalho apresentado por O'Dea e Newman ${ }^{[15]}$, no qual ele separa os testes de sua rotina em quatro casos, relacionados abaixo e apresentados nas figuras 4.7 a 4.10 .

- Caso 1: Gerador único, com um metro de largura, posicionado em Y=50m de uma parede infinita criada sobre o eixo Y.

- Caso 2: Igual ao caso 1, porém agora com uma parede criada sobre o eixo X, fazendo assim com que exista reflexão.

- Caso 3: 100 geradores de onda, cada um com um metro de largura, posicionados em $0<\mathrm{Y}<100$ e uma parede sobre o eixo $\mathrm{X}$.

- Caso 4: 100 geradores de onda, cada um com um metro de largura, posicionados em $0<Y<100$ e 60 geradores sobre o eixo $X(0<X<60)$.

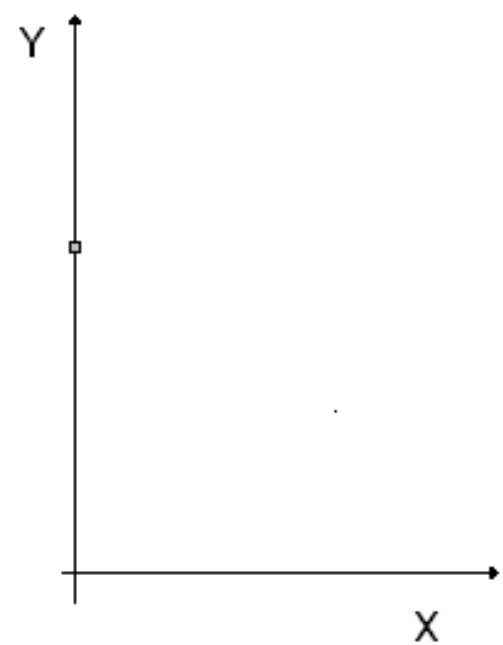

Figura 4.7: Caso 1

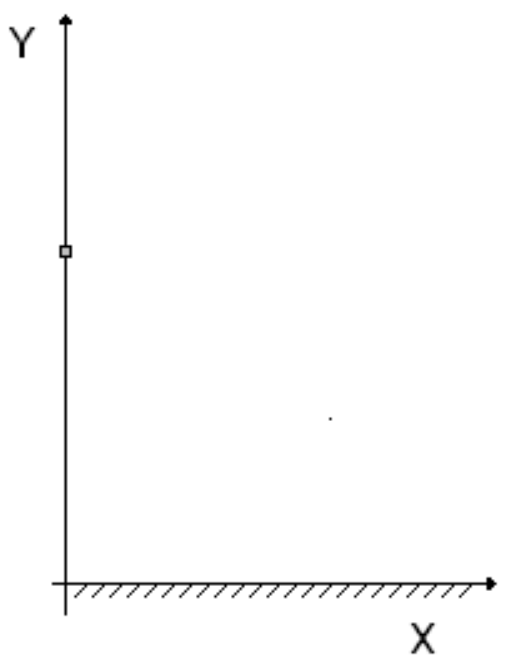

Figura 4.8: Caso 2 


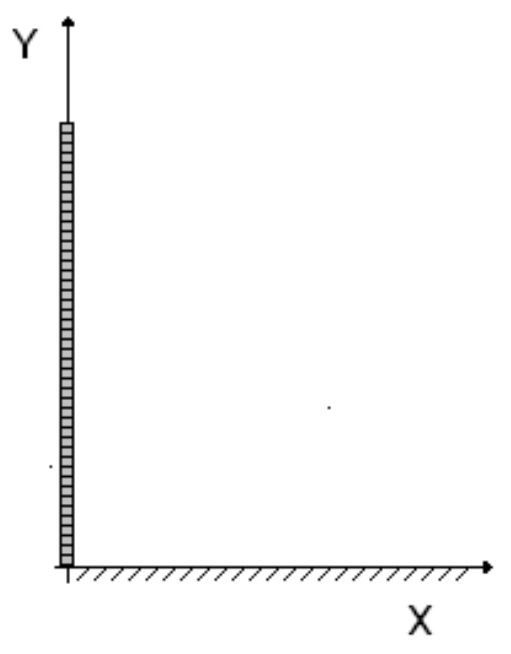

Figura 4.9: Caso 3

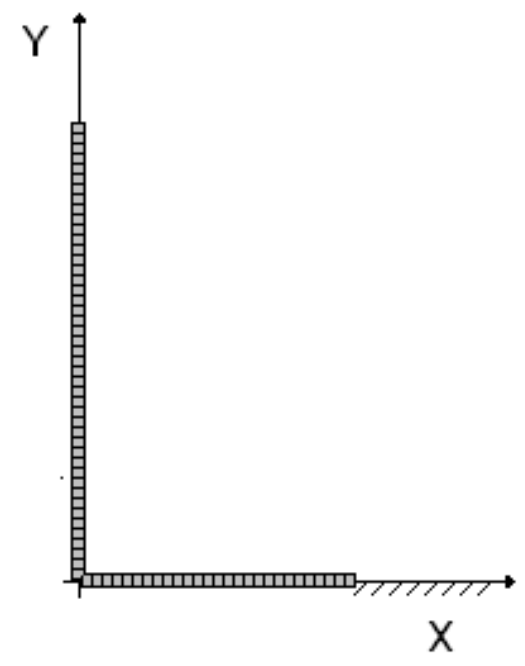

Figura 4.10: Caso 4

Em todos os casos foram feitas comparações do mapa de superfície livre e alguns cortes para valores de $X$ ou $Y$ constantes. Estes casos serão detalhados nas seções a seguir:

\subsubsection{Caso 1}

O primeiro caso tratado por Newman em seu trabalho foi de um gerador único sobre uma parede posicionada sobre o eixo $Y$, na posição $Y=50$, gerando uma onda que se propaga no semi-plano infinito definido por $\mathrm{X}$ positivo.

A primeira comparação envolve apenas os mapas de superfície livre do Wamit e do simulador e está apresentada nas figuras 4.11 e 4.12. Observando estas duas figuras é possível notar uma grande semelhança entre os mapas de superfície livre gerados para um mesmo instante de tempo. Para obter uma melhor visualização da onda foram feitos alguns cortes para valores de $Y$ constantes, apresentados nas figuras 4.13 a 4.15 , onde se nota que o simulador apresenta resultados muito semelhantes aos do Wamit. 


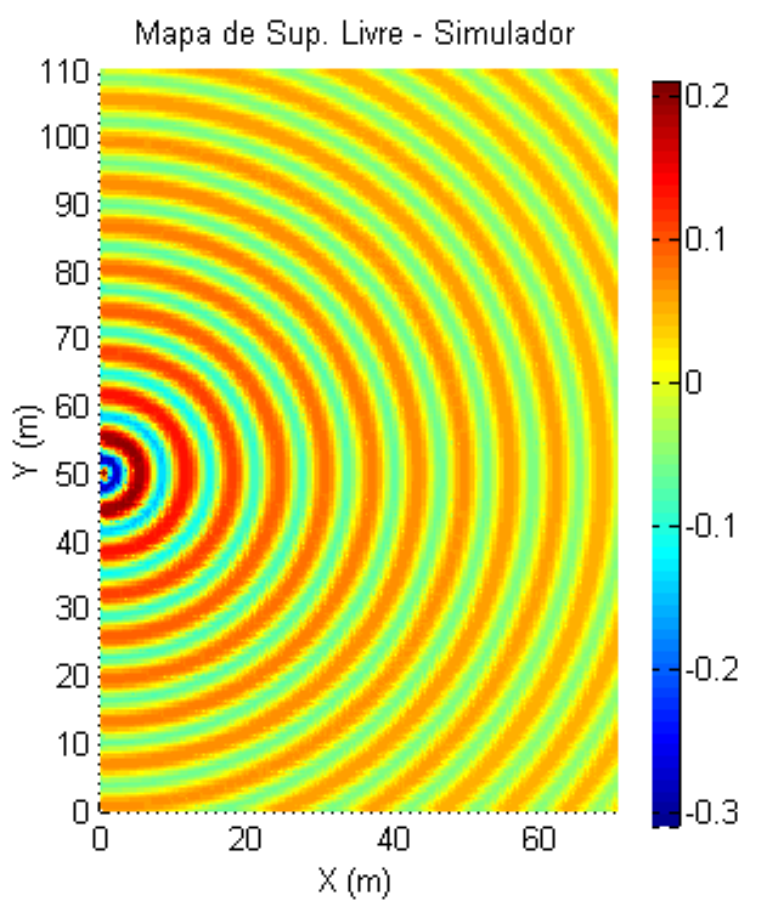

Figura 4.11: Caso 1 - Mapa da superfície livre para apenas um gerador, obtido com o Simulador

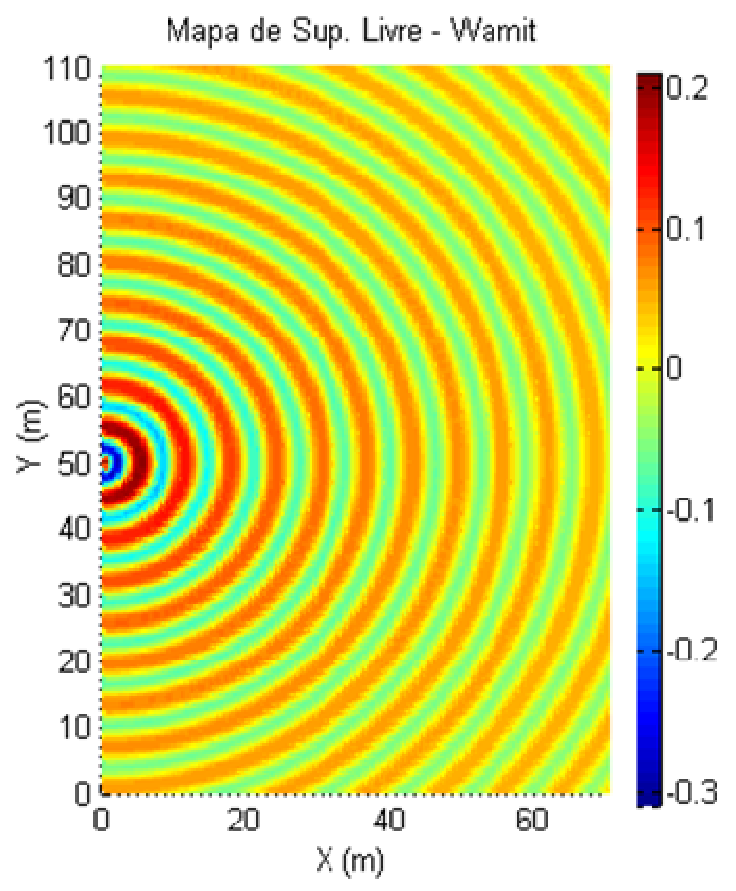

Figura 4.12: Caso 1 - Mapa de superfície livre fornecido pelo Wamit

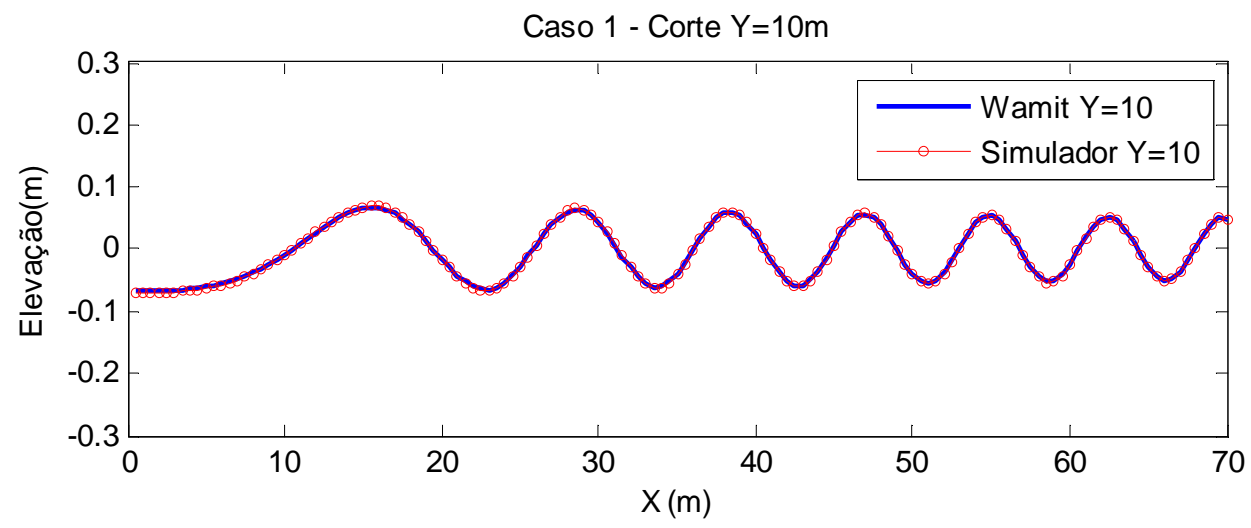

Figura 4.13: Caso 1 - Corte para $Y=10 \mathrm{~m}$

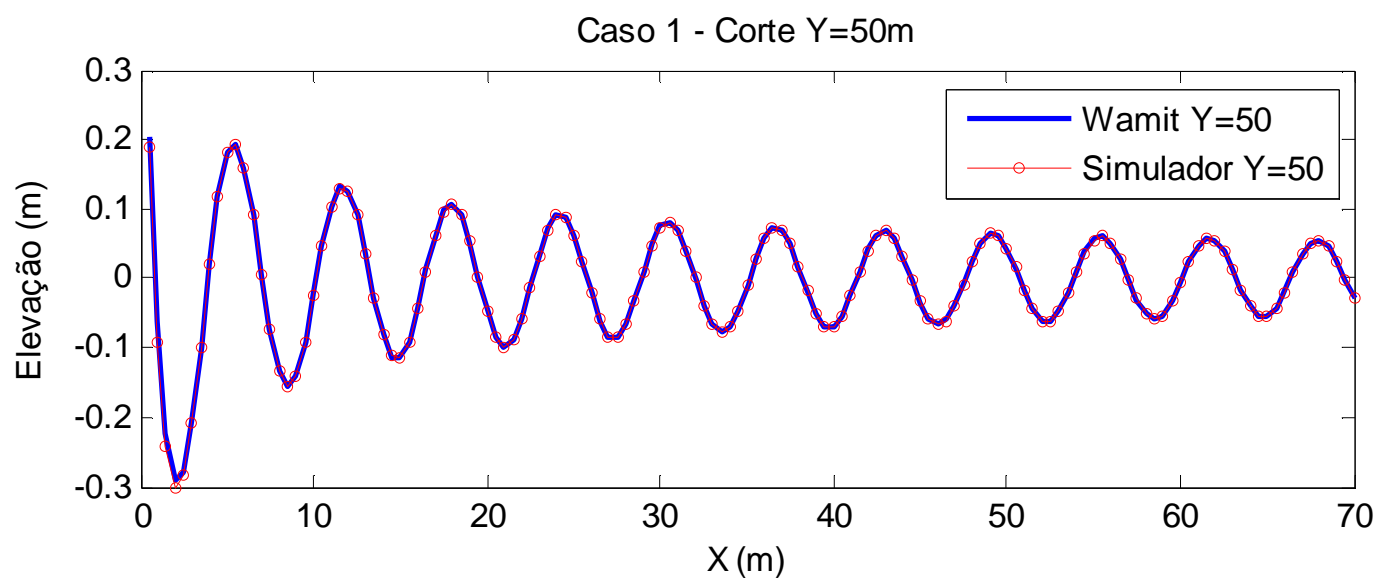

Figura 4.14: Caso 1 - Corte para $Y=50 \mathrm{~m}$ 


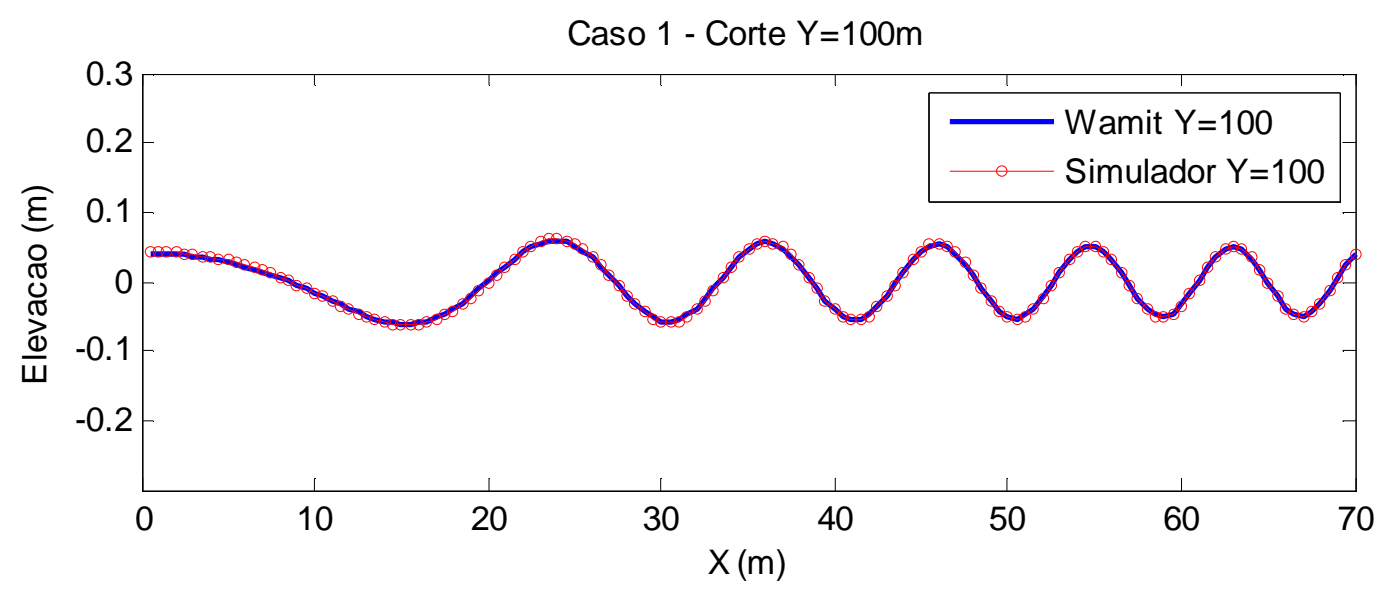

Figura 4.15: Caso 1 - Corte para $Y=100 \mathrm{~m}$

\subsubsection{Caso 2}

Este caso é igual ao caso 1, com exceção da inclusão de uma parede posicionada sobre o eixo $X$ assim refletindo a onda. Para representar a reflexão no simulador foi adicionada uma imagem do gerador em $\mathrm{Y}=-50 \mathrm{~m}$. $\mathrm{O}$ resultado pode ser conferido nas figuras 4.16 e 4.17 .

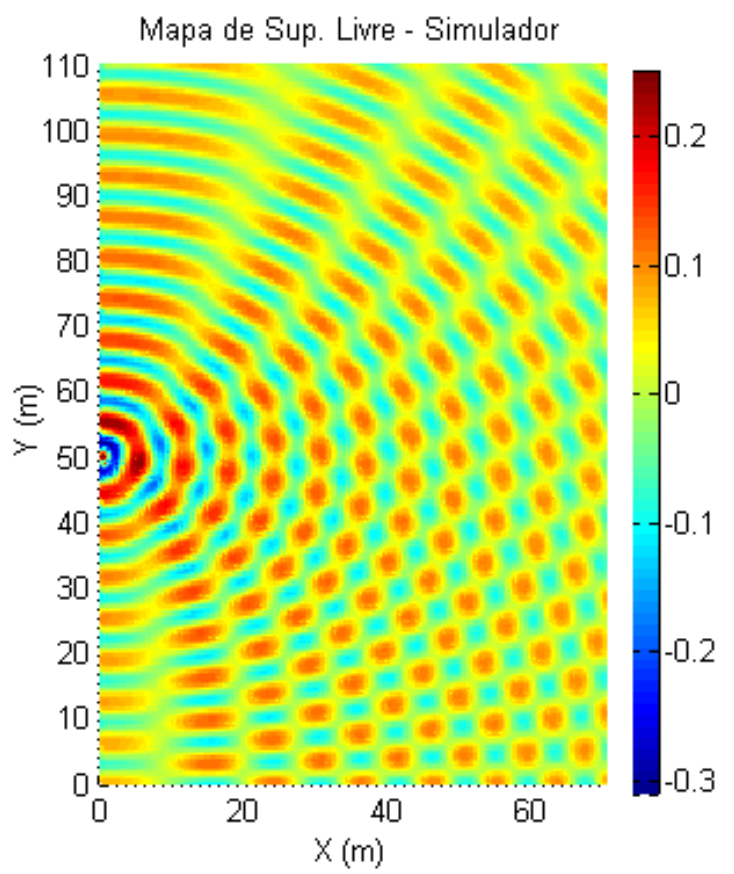

Figura 4.16: Caso 2 - Mapa da superfície livre para apenas um gerador, obtido com o Simulador, com reflexão.

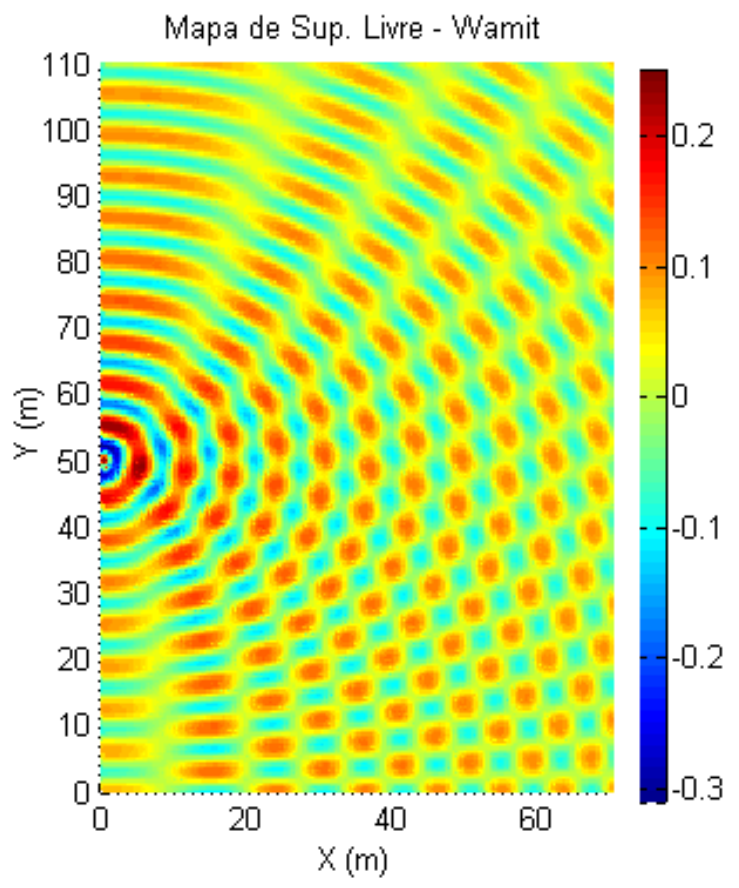

Figura 4.17: Caso 2 - Mapa de superfície livre fornecido pelo Wamit 
Da mesma forma feita no caso 1, cortes para valores de $Y$ constante foram feitos para comparação dos resultados e podem ser conferidos nas figuras 4.18 a 4.20. É necessário destacar que a utilização de um gerador espelho para representar a reflexão de ondas apresentou resultados muito bons, demonstrando assim que esta técnica pode ser utilizada.

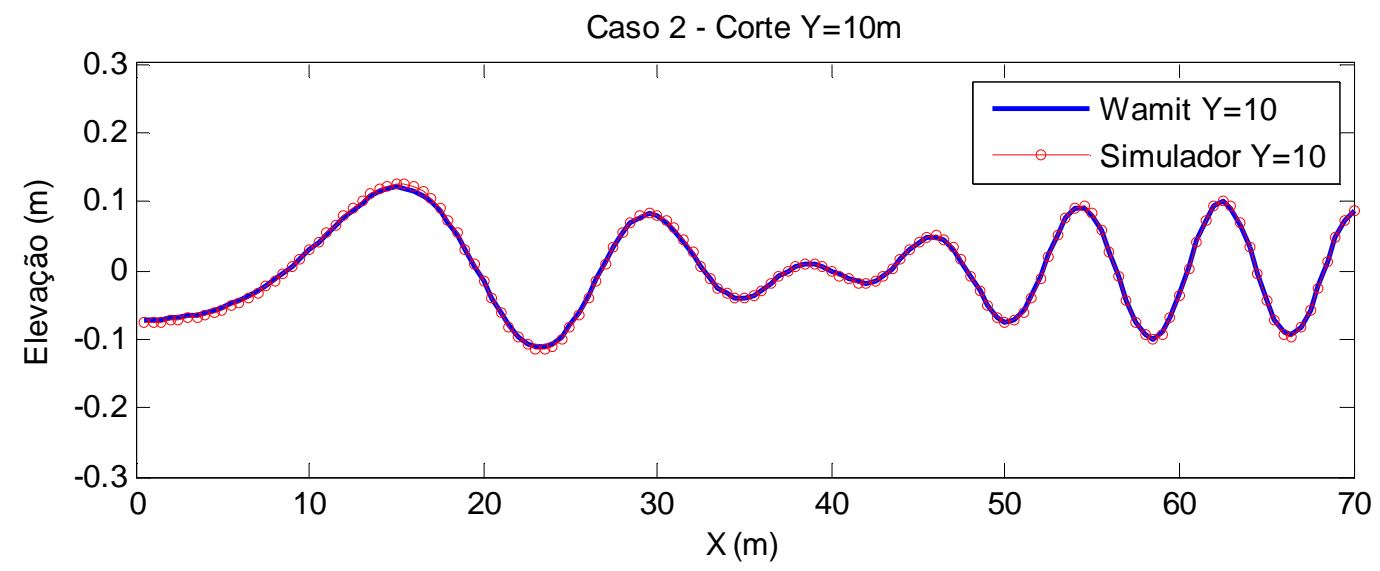

Figura 4.18: Caso 2 - Corte para $Y=10 \mathrm{~m}$

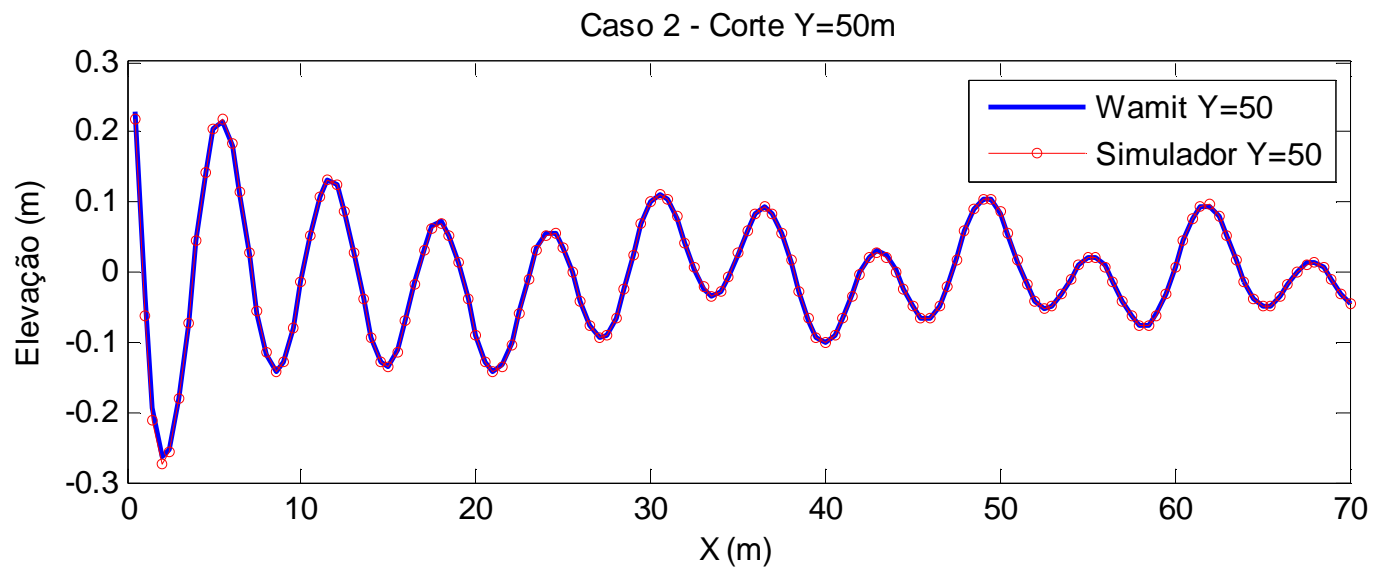

Figura 4.19: Caso 2 - Corte para $Y=50 \mathrm{~m}$ 


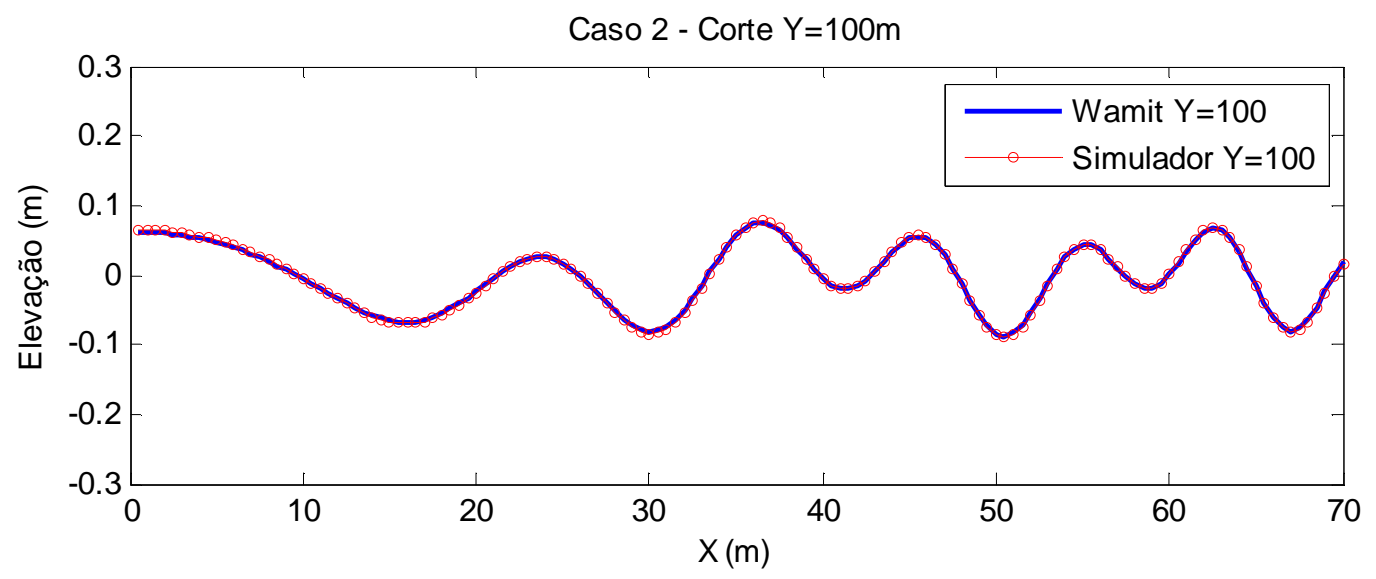

Figura 4.20: Caso 2 - Corte para $Y=100 \mathrm{~m}$

\subsubsection{Caso 3}

O terceiro caso é constituído por uma parede geradora com 100 flaps, posicionados sobre o semi-eixo positivo $Y$ entre $Y=0 m$ e $Y=100 m$, e uma parede refletora sobre todo semi-eixo positivo. Com esta configuração é possível realizar comparações para geração de ondas obliquas adicionando defasagens aos geradores de onda. Duas direções de propagação serão avaliadas neste caso.

A primeira direção de propagação é perpendicular à parede de geração e torna possível, além das comparações entre o Wamit e o Simulador, a verificação se a amplitude da onda gerada se aproxima da função de transferência 2D uma vez que um grande número de geradores dispostos lado a lado e atuando em fase se aproximam do caso 2D.

Observando os mapas de superfície livre apresentados nas figuras 4.21 e 4.22 notase que os resultados são muito semelhantes. Cortes para valores de $X$ e $Y$ constantes foram feitos para este caso para uma melhor comparação e apresentaram uma boa aproximação feita pelo simulador, conforme pode ser notado nas figuras 4.23 e 4.24. A partir de agora, apenas um corte para $X=35 \mathrm{~m}$ e um para $\mathrm{Y}=50 \mathrm{~m}$ serão apresentados no corpo deste trabalho. 


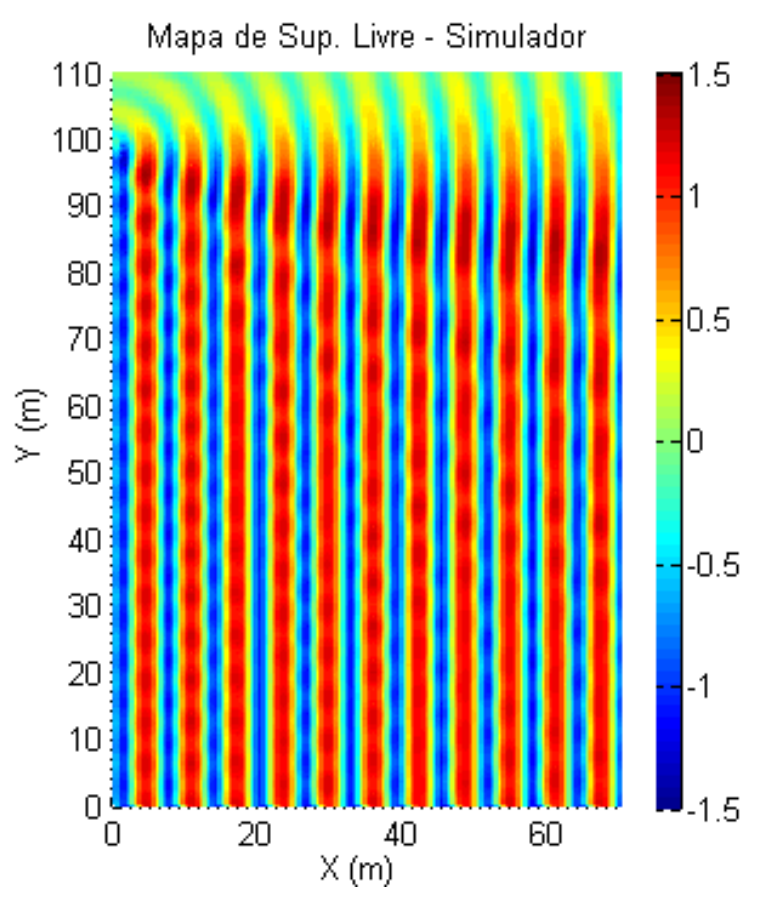

Figura 4.21: Caso 3 - Mapa da superfície livre obtido com o Simulador para direção de propagação igual a 0 graus, com reflexão.

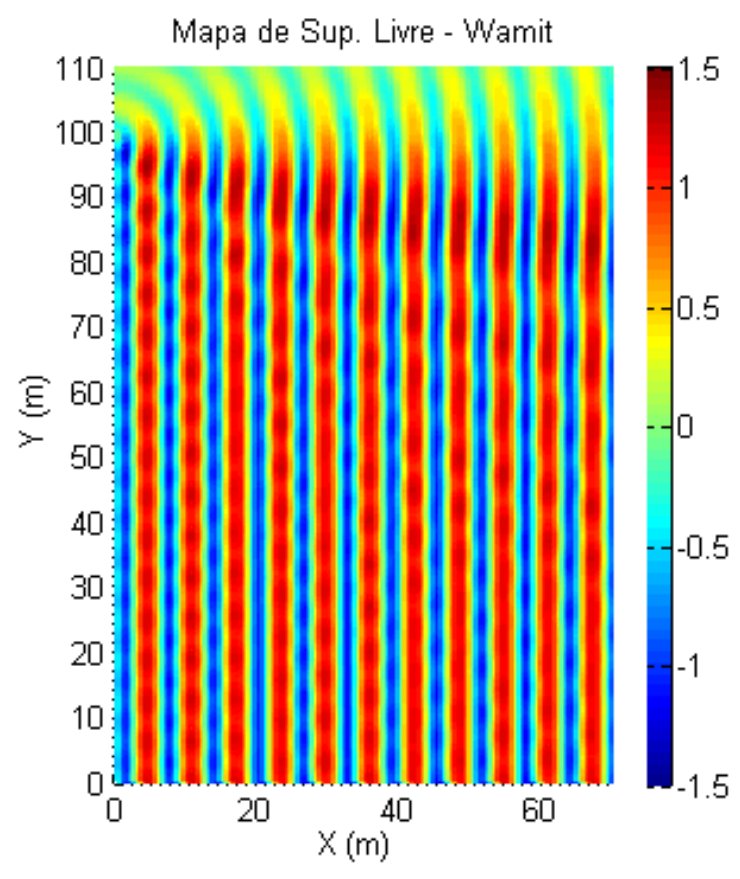

Figura 4.22: Caso 3 - Mapa de superfície livre fornecido pelo Wamit para direção de propagação igual a 0 graus.

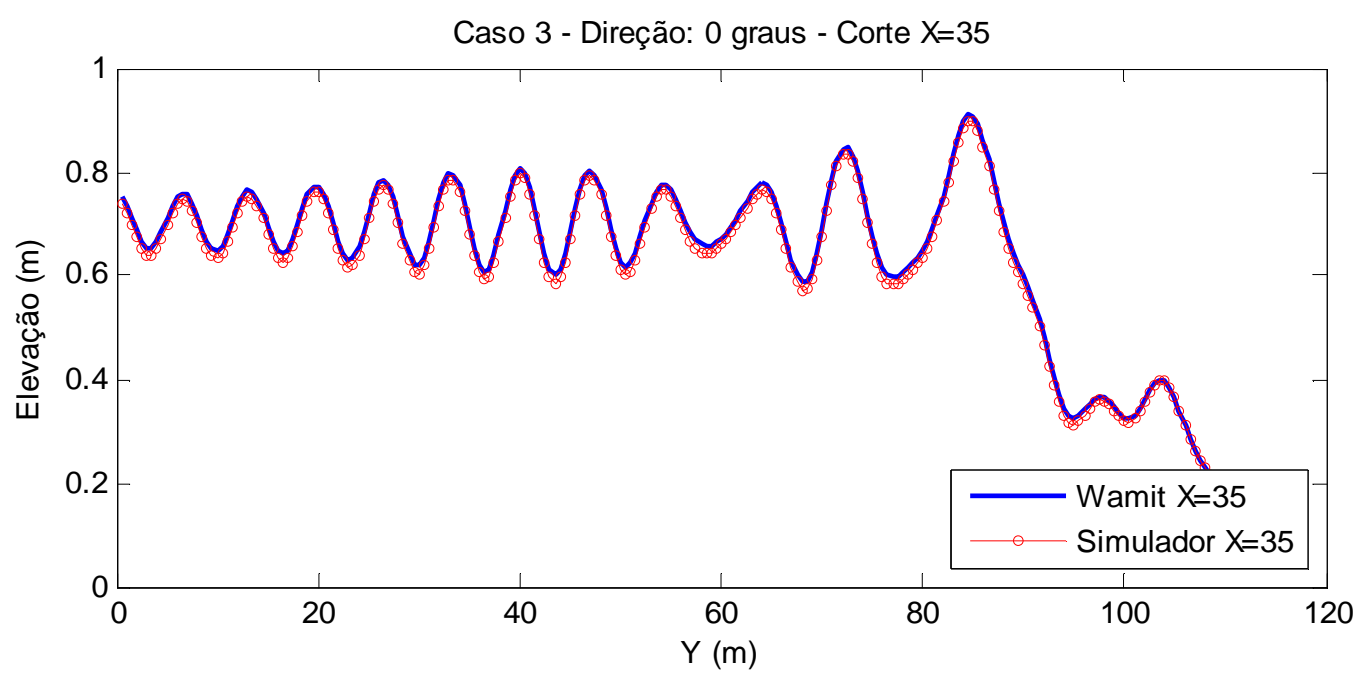

Figura 4.23: Caso 3 - Direção de propagação de 0 graus - Cortes para $X=35 m$ 


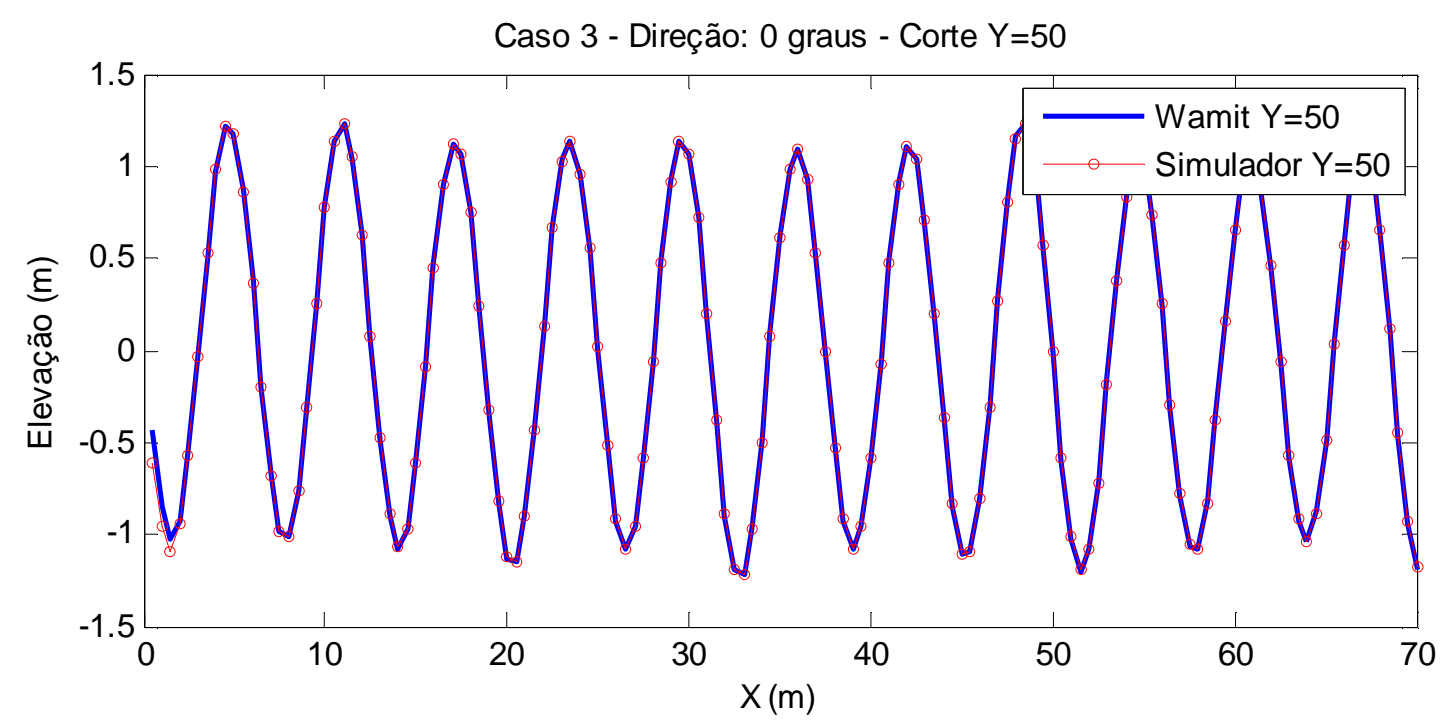

Figura 4.24: Caso 3 - Direção de propagação de 0 graus - Cortes para $Y=50 \mathrm{~m}$

Realizando uma análise de picos para o resultado apresentado na Figura 4.24 obtém-se uma amplitude média de onda igual à 1.152 metros quando utilizando um stroke unitário, muito próximo dos $1.139 \mathrm{~m}$ obtido com a função de transferência. Este resultado pode ser visto na figura a seguir.

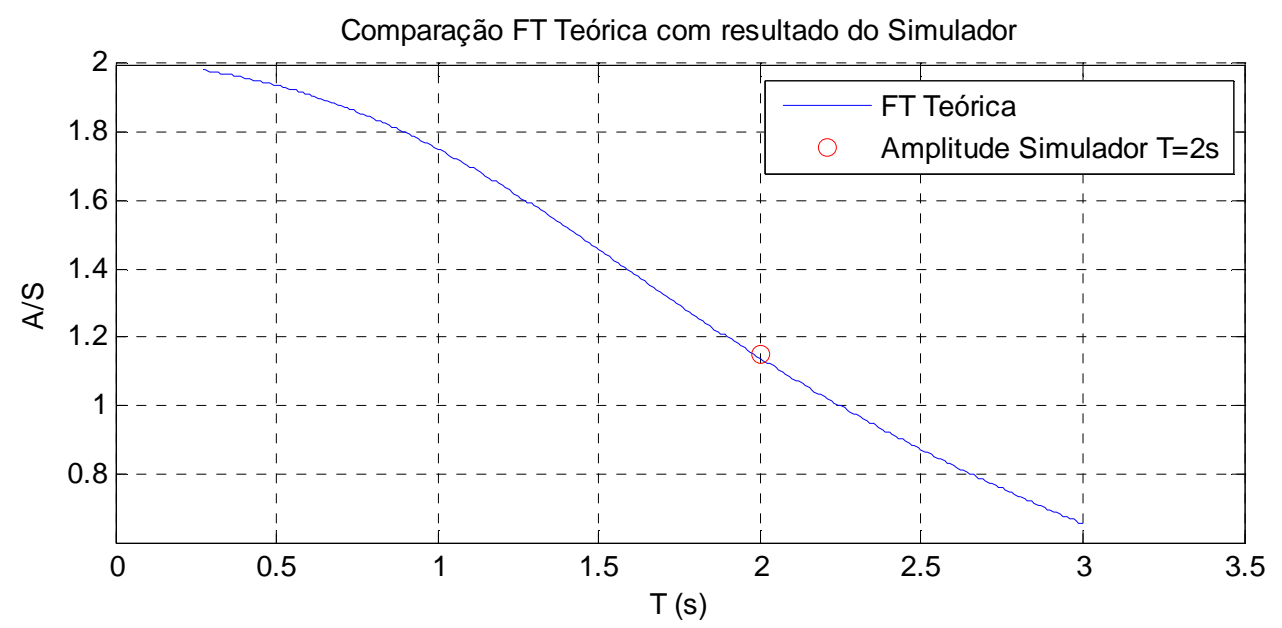

4.25: Comparação da amplitude de onda obtida no simulado com a função de transferência teórica.

A segunda direção de propagação é de 22.5 graus. Este primeiro teste com ondas oblíquas demonstrou bons resultados, que podem ser conferidos nas figuras 4.26 a 4.27, demonstrando que o simulador também representa com precisão as ondas obliquas. 


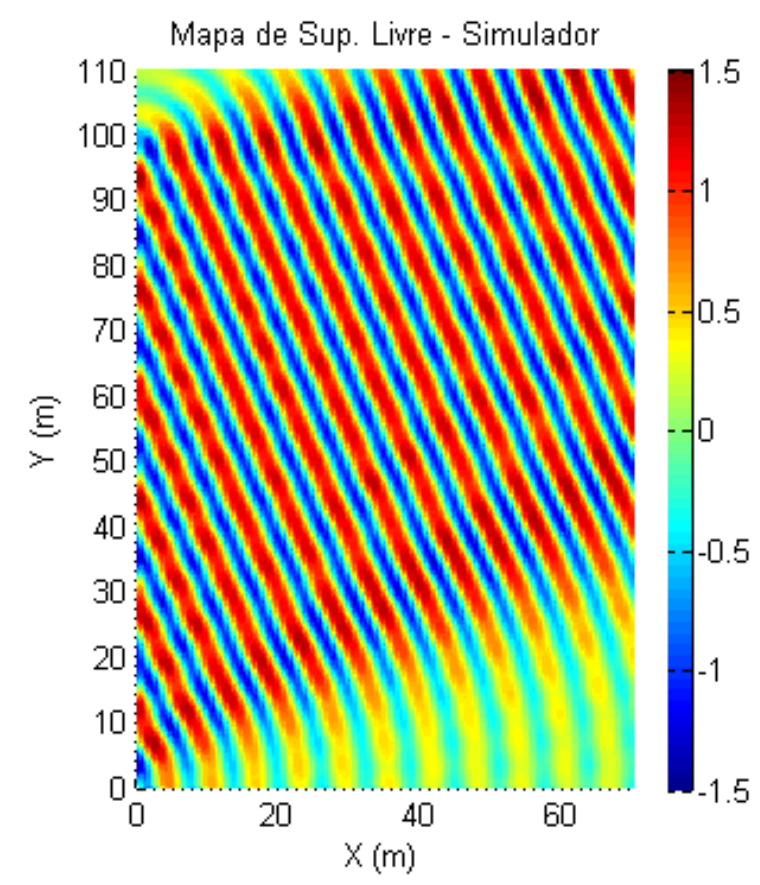

Figura 4.26: Caso 3 - Mapa da superfície livre obtido com o Simulador para direção de propagação igual a 22.5 graus, com reflexão.

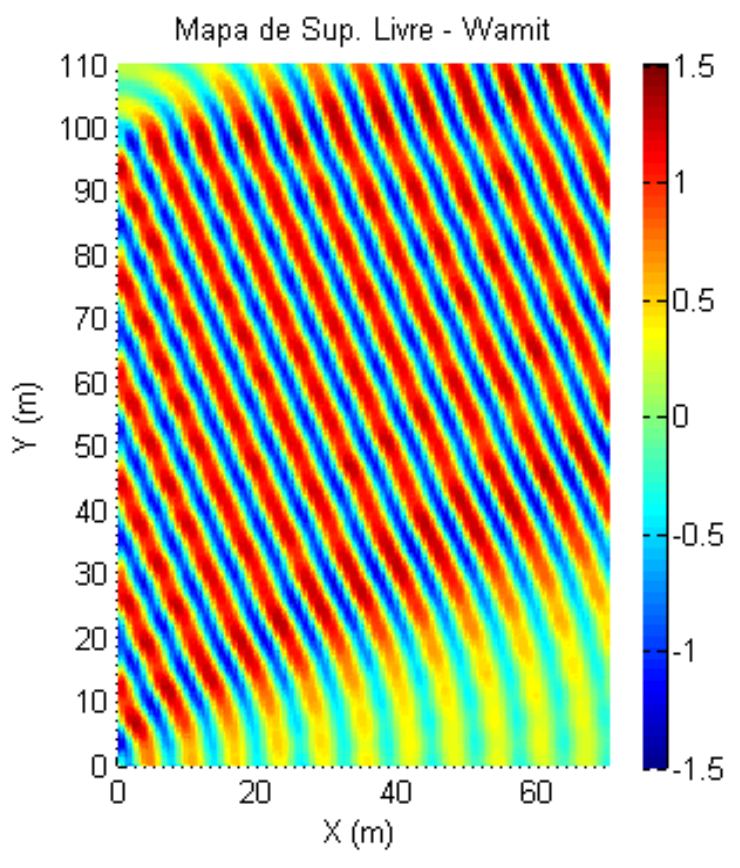

Figura 4.27: Caso 3 - Mapa de superfície livre fornecido pelo Wamit para direção de propagação igual a 22.5 graus.

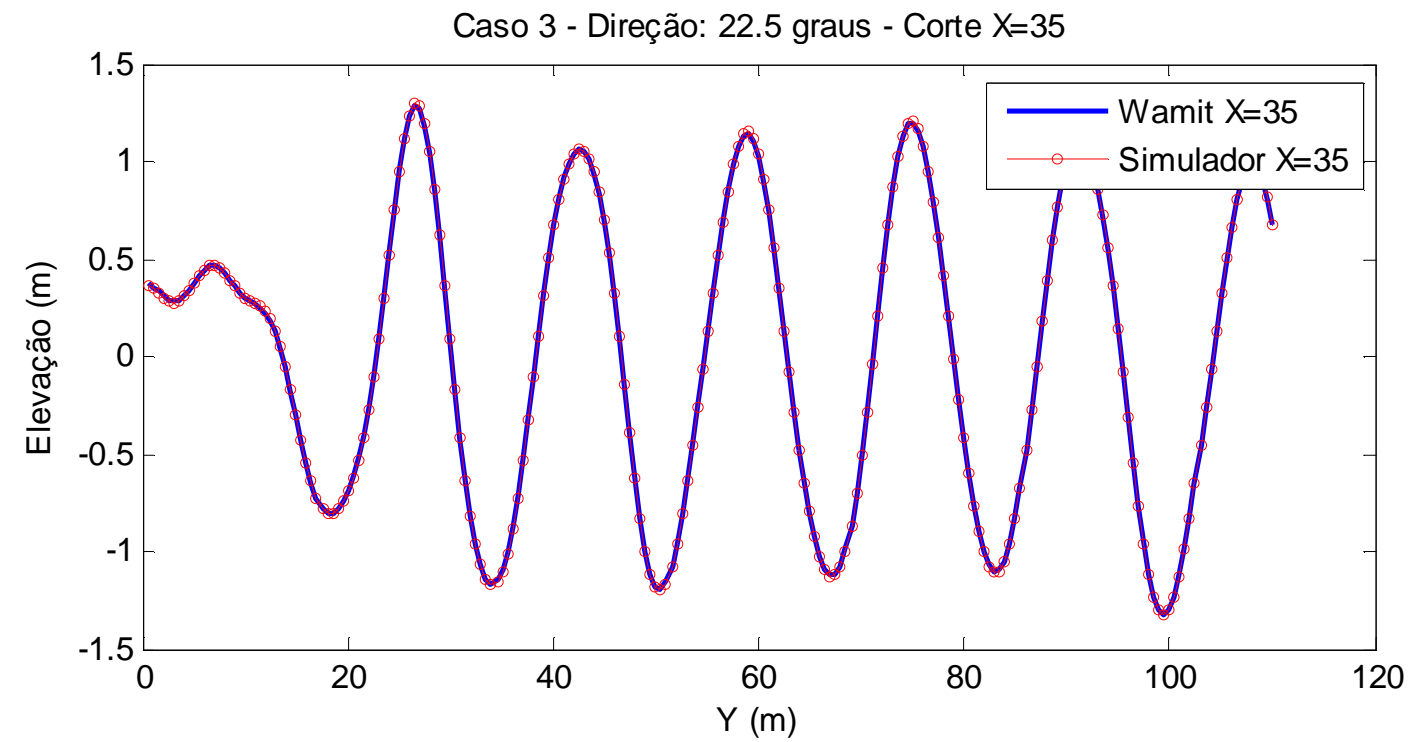

Figura 4.28: Caso 3 - Direção de propagação de 22.5 graus - Cortes para $X=35 m$ 


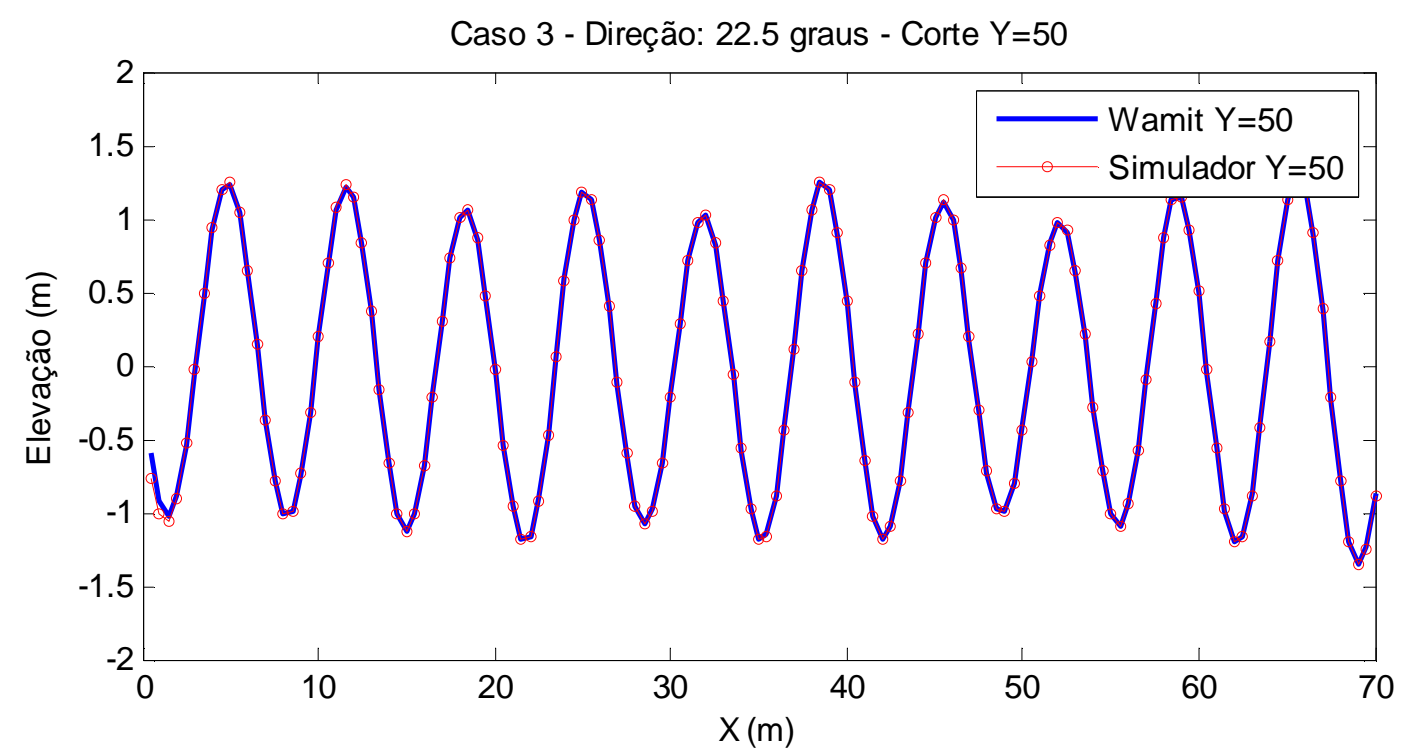

Figura 4.29: Caso 3 - Direção de propagação de 22.5 graus - Cortes para $Y=50 m$

\subsubsection{Caso 4}

O último caso, e mais completo, envolve a geração de onda com a utilização de duas paredes simultaneamente. Além dos 100 geradores localizados sobre o semieixo $\mathrm{Y}$ positivo foram adicionados 60 geradores com um metro de largura cada um sobre o semi-eixo positivo $X$, se estendendo de $X=0$ a $X=60$. $O$ restante desse semieixo, com $X>60$, continua sendo uma parede.

A adição dos geradores em $X$ não causa nenhum tipo de alteração em como é considerada a geração feita pela parede $\mathrm{Y}$, havendo reflexão nos flaps em $\mathrm{X}$ como se eles fossem uma parede. O mesmo é válido para os geradores posicionados em $\mathrm{X}$, portanto a os geradores em $\mathrm{Y}$ são considerados como uma parede refletora.

Seguindo o trabalho de Newman, o ângulo de geração escolhido para testar este caso com duas paredes gerando é 67.5 graus. A sincronização da paredes é feita conforme foi apresentado no capítulo 3.2.3. Os resultados entre o simulador e o Wamit foram novamente muito próximos e podem ser conferidos nas figuras 4.30 a 4.33 . 


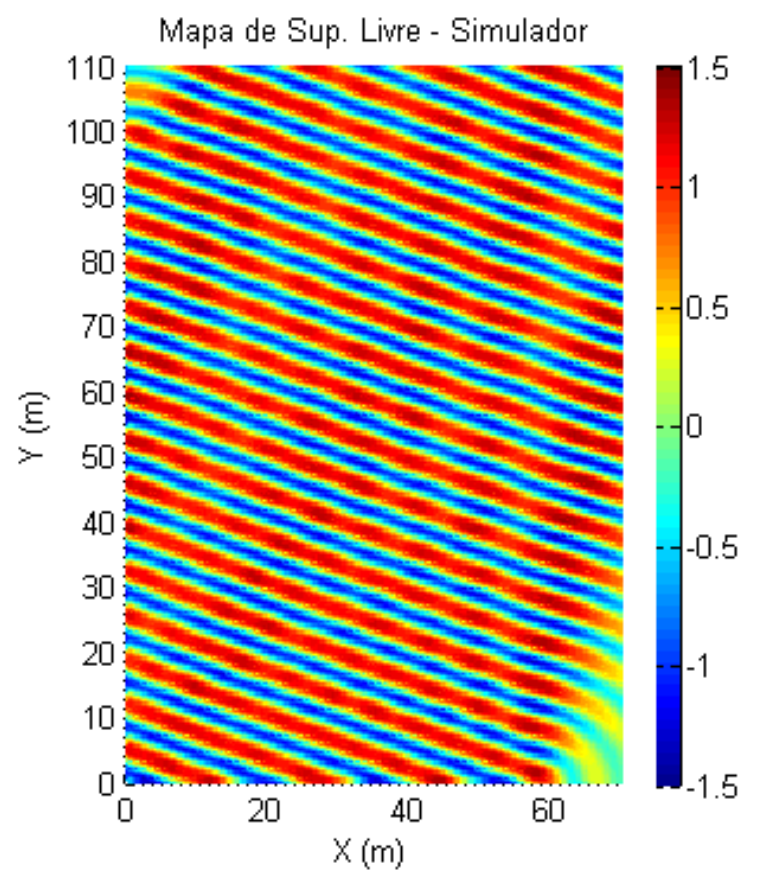

Figura 4.30: Caso 4 - Mapa da superfície livre obtido pelo simulador, gerando onda em 67.5 graus

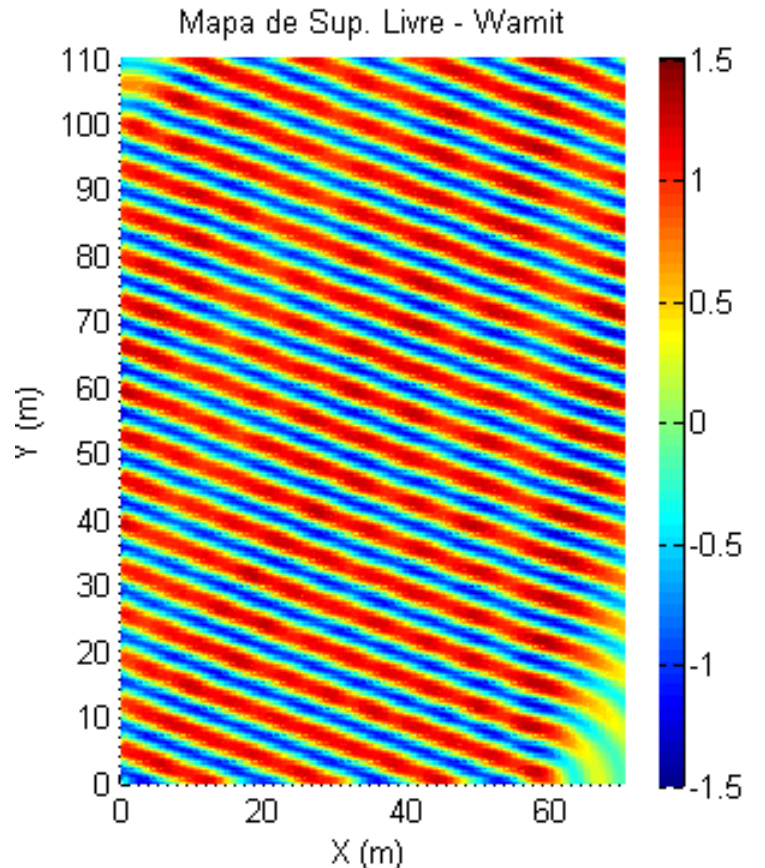

Figura 4.31: Mapa de superfície livre fornecido pelo Wamit, , gerando onda em 67.5 graus

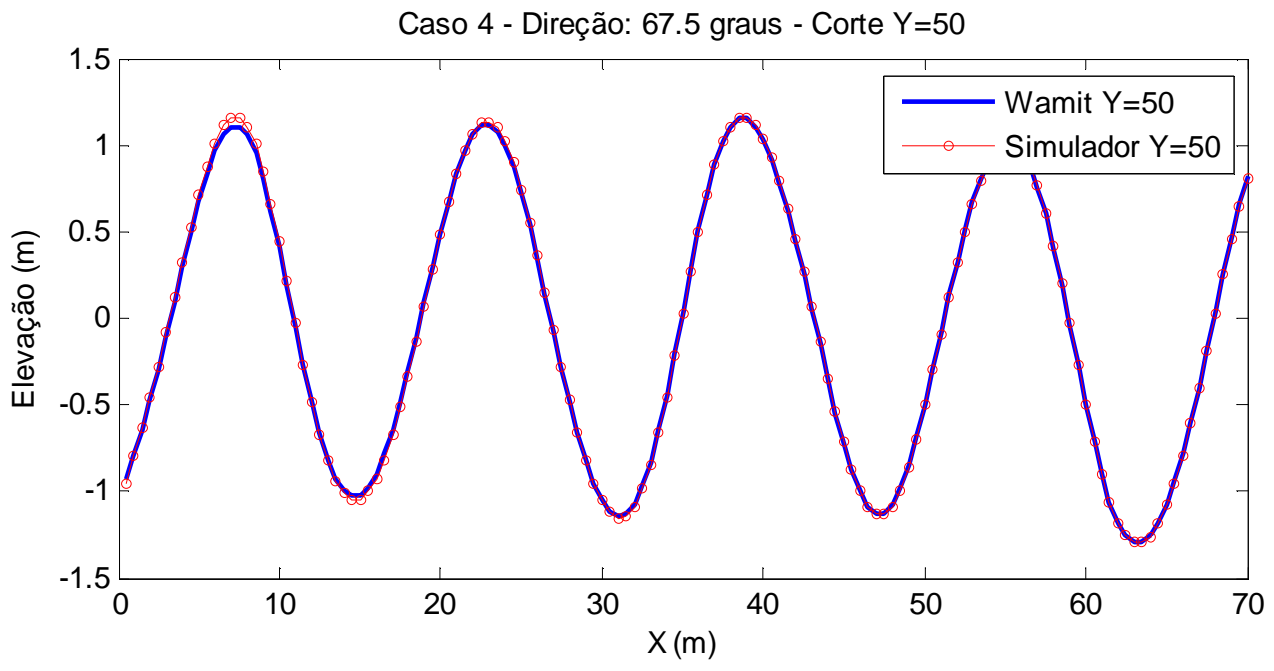

Figura 4.32: Caso 4 - Direção de propagação de 67.5 graus - Cortes para $Y=50 m$. 


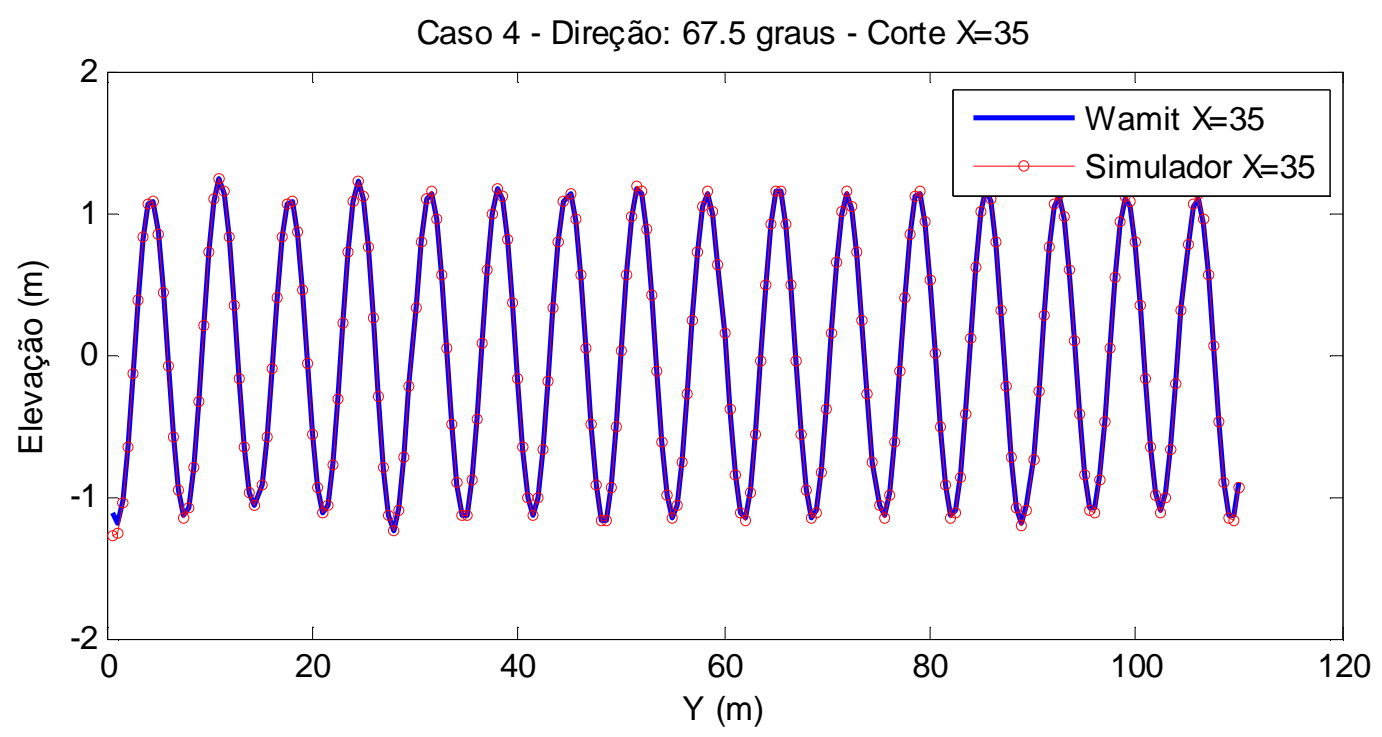

Figura 4.33: Caso 4 - Cortes para $X=35 m$

Finalizada a fase de validação dos simulador, o foco passa a ser o estudo das geometrias do tanque, utilizando-o, assunto tratado em detalhes no próximo capítulo. 


\section{Análises do Calibrador Hidrodinâmico}

As análises do Calibrador Hidrodinâmico através do simulador numérico desenvolvido foram feitas com foco na utilização do tanque para a realização de ensaios com modelos em escala reduzida.

Usualmente, durante os ensaios em ondas, deseja-se obter dados sobre a hidrodinâmica do modelo para diversas direções de incidência e é nesse ponto que - Calibrador Hidrodinâmico se destaca pelo fato de ter geradores/absorvedores de onda em toda a sua volta, o que possibilita alterar a direção da onda gerada apenas escolhendo de forma conveniente os flaps que irão executar as tarefas.

É intuitivo que, dada a intenção de se gerar ondas para todas as direções de incidência, o modelo deve ser localizado, preferencialmente, no centro do tanque. No entanto, o tanque não é simétrico do ponto de vista operacional porque algumas atitudes foram tomadas para evitar riscos de colisão entre os flaps posicionados nas quinas do tanque.

$\mathrm{Na}$ configuração atual do tanque, para evitar as colisões, foi decido que duas paredes do tanque operariam com seus 39 flaps, sem restrição alguma de movimento, enquanto as outras duas paredes operariam apenas com 35 flaps cada uma, sendo os dois flaps mais próximos de cada quina travados.

Tal configuração foi escolhida pela praticidade de ser aplicada, sem a avaliação do impacto que isso poderia causar na onda gerada por não haver ferramental para tal durante a fase de projeto. Com consciência de que esta configuração pode não ser a ideal a construção do tanque foi feita de modo a permitir uma futura alteração da configuração sem grandes dificuldades.

Existe a possibilidade de alteração da configuração atual para outras duas configurações. Uma delas, mais simples de ser realizada, consiste em bloquear apenas os dois flaps que compõe a quina, fazendo com que todas as paredes 
operem com 37 flaps cada uma. A outra possibilidade é a de tanque quadrado com cantos arredondados. Nesta configuração, cada parede é composta por 25 flaps e os quatro cantos do tanque são compostos por 9 flaps cada um. Ambas as configurações serão apresentadas com maiores detalhes na próxima seção.

Portanto, para tirar dúvidas sobre a melhor configuração a ser adotada, o simulador numérico será utilizado com o objetivo de avaliar a configuração atual e, também, as outras duas possibilidades de configuração que foram descartadas e compará-las.

\subsection{Configurações da simulação}

O primeiro passo é definir como o tanque será considerado em cada condição analisada. Para isso, as condições foram divididas em 2 categorias:

- Tanque quadrado

- Tanque com cantos arredondados

Para trabalhar com o tanque quadrado, as paredes e seus flaps foram identificados por números conforme pode ser conferido na figura 5.1. Com a utilização do tanque quadrado, foram avaliados 3 casos diferentes que estão descritos na tabela 5.1. $O$ caso nomeado completo é uma condição ideal de geração, na qual todos os flaps podem funcionar sem restrições. Os outros dois casos, 2Flaps e 1Flap, são duas possibilidades que foram pensadas para a operação no tanque.

Tabela 5.1: Modos de utilização do tanque quadrado no simulador

\begin{tabular}{|c|c|c|}
\hline Nomenclatura & Quantidade de flaps travados & Flaps travados \\
\hline Completo & 0 & Nenhum \\
\hline 2 Flaps & 8 & $40,41,77,78,118,119,155$ e 156 \\
\hline 1 Flap & 8 & $1,39,40,78,79,117,118$ e 156 \\
\hline
\end{tabular}




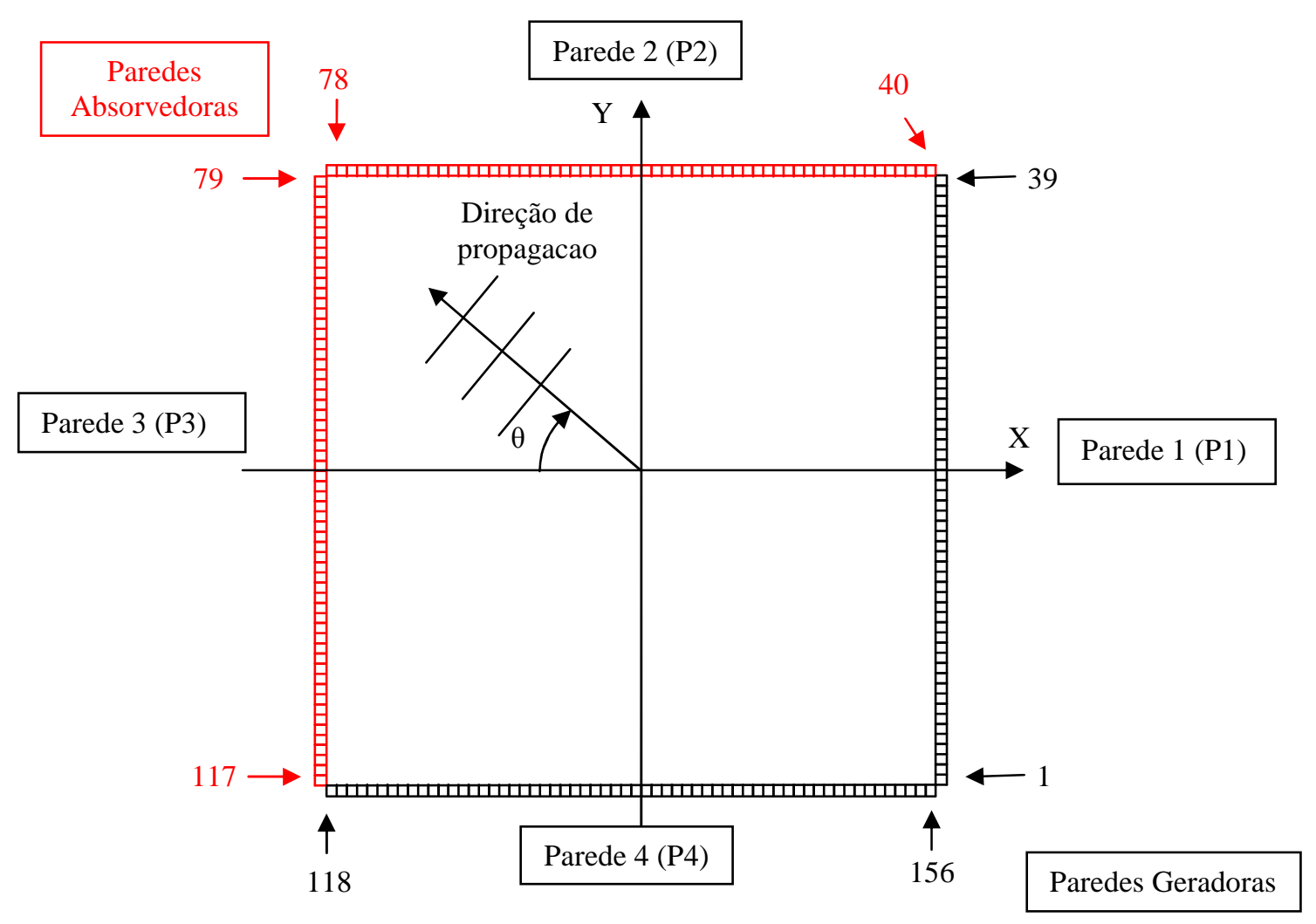

Figura 5.1: Nomenclatura das paredes e numeração dos flaps para o tanque quadrado

O tanque com cantos arredondados conta com menos flaps que o tanque quadrado. Segundo a configuração pensada durante a fase de projetos, este tanque contém 136 flaps, dos quais 100 estão dispostos sobre as quatro paredes e os outros 36 compões os cantos arredondados, como é possível visualizar na figura 5.2.

Nesta condição, todos os flaps são capazes de gerar ondas sem restrição alguma de movimentos, mas, dependendo da direção de propagação da onda a ser gerada, a escolha dos flaps que irão operar precisa ser alterada.

O caso onde essa escolha dos flaps chama mais atenção acontece na geração de uma onda perpendicular à alguma das paredes. Como exemplo, é possível citar a geração de uma onda na direção zero graus, perpendicular à parede 1. Neste caso, além dos flaps dispostos na parede 1 ( flaps 6 a 30), deve-se escolher quais flaps das partes curvas efetivamente participarão da geração de onda, visando a obtenção da melhor qualidade possível na onda gerada. 


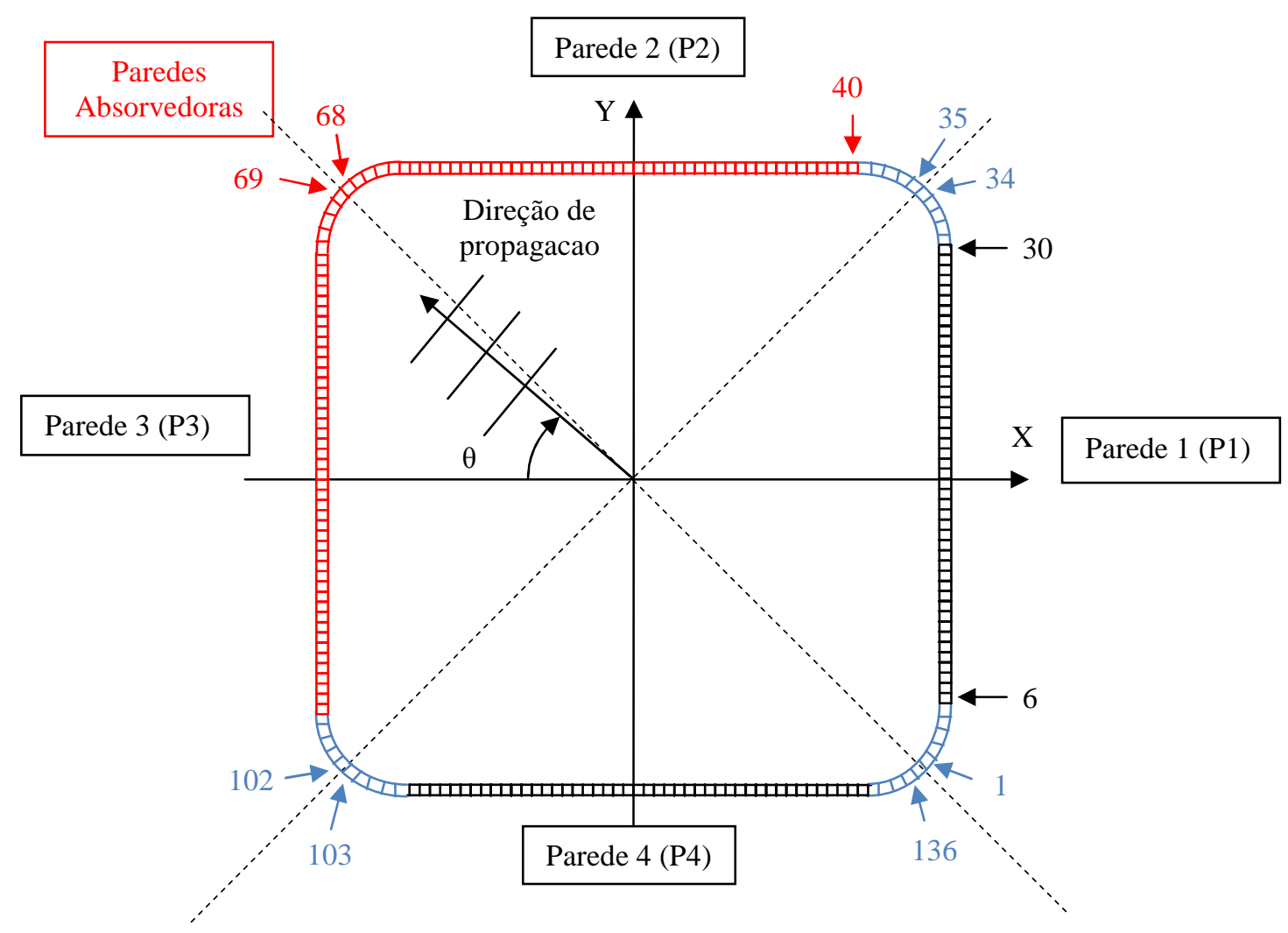

Figura 5.2: Nomenclatura das paredes e numeração dos flaps para o tanque com cantos arredondados

Com objetivo de fazer a escolha da melhor configuração para o caso da geração de ondas perpendiculares às paredes, uma análise sobre a utilização dos flaps da parte curva foi realizada e está apresentada na seção 5.3. Para as demais direções de propagação, foi escolhido utilizar os flaps 108 a 136 da parede 4 em conjunto com os flaps 1 a 30 da parede 2 .

Os resultados comparativos entre as diferentes configurações serão apresentados e discutidos na seção 5.4. Antes, porém, é necessário apresentar a metodologia de análise utilizada para avaliar a qualidade da onda gerada, assunto da próxima seção deste texto. 


\subsection{Metodologia de análise e comparações}

O primeiro passo para realizar as análises da qualidade da onda gerada foi a definição de uma área de interesse no tanque. Como citado, é interessante poder varrer todas as incidências de onda sem a necessidade de mover o modelo. Com base nisso, foi definida a área de interesse como sendo uma região quadrada de $5 \times 5$ metros posicionada no centro do tanque.

As análises no interior dessa área são realizadas após as ondas terem atingido o regime. Ao considerar um caso ideal, com uma geração perfeita, é esperada a obtenção de uma onda com a mesma amplitude máxima para qualquer ponto da superfície. Porém, ao gerar uma onda, isso não ocorre por causa das descontinuidades na parede geradora e também pelas interferências provenientes de reflexões

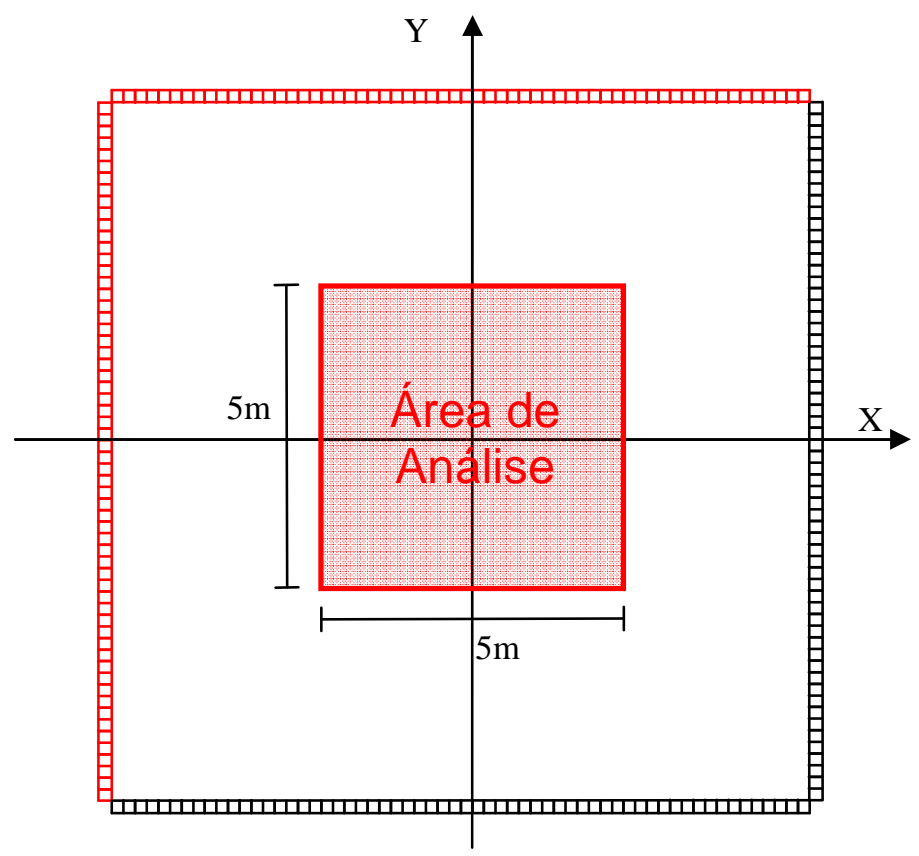

Figura 5.3: Área do tanque na qual serão realizadas as análises

Reflexões e outras imperfeições inerentes à geração podem ser consideradas como flutuações na amplitude. Para mensurar estas flutuações é calculado o desvio padrão das amplitudes em diferentes pontos da área de interesse, normalizado pela 
amplitude média dentro da área. Quanto mais próximo o desvio padrão de zero, melhor é a qualidade da onda gerada.

Para obter as amplitudes máximas de todos os pontos dentro da área de análise foi considerado o valor máximo, em módulo, atingido em cada ponto que compõe a superfície durante quatro períodos consecutivos de onda. Como exemplo, a figura 5.4 apresenta uma superfície contendo-as. Segundo a função de transferência dos geradores, a amplitude esperada é de 1.18 metros.

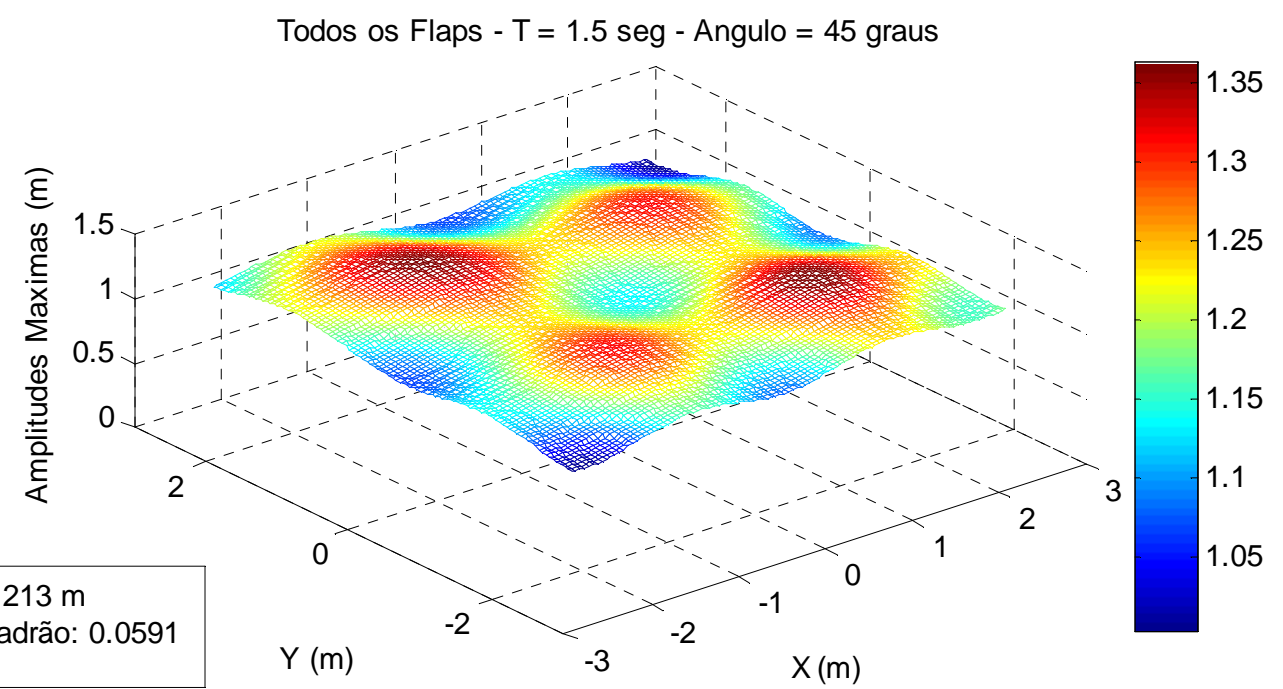

Figura 5.4: Máximas amplitudes dentro de um período de onda obtidas para a análise.

O Calibrador Hidrodinâmico foi projetado para gerar ondas com períodos entre $0.5 \mathrm{e}$ 2.0 segundos. Para varrer a região de operação do tanque foram escolhidos quatro períodos e 5 direções de propagação para análise. Seus valores encontram-se na tabela 5.2 .

Tabela 5.2: Períodos e ângulos de propagação para análise

\begin{tabular}{|c|c|}
\hline Período (s) & $\begin{array}{c}\text { Ãngulo de Propagação } \\
\text { (graus) }\end{array}$ \\
\hline 2.0 & 0.0 \\
\hline 1.5 & 22.5 \\
\hline 1.0 & 45.0 \\
\hline 0.7 & 67.5 \\
\hline & 90.0 \\
\hline
\end{tabular}


O período de 0.7 foi escolhido como sendo o menor período de análise com base no limite de Biesel. Para este período, o máximo ângulo de geração é pouco maior que 45 graus, portanto, existem casos em que as duas paredes não conseguem gerar a onda juntas. Um resumo de como as paredes do tanque operam para cada período e ângulo é apresentado na tabela 5.3.

Tabela 5.3: Modo de operação das paredes do tanque para cada período e ângulo.

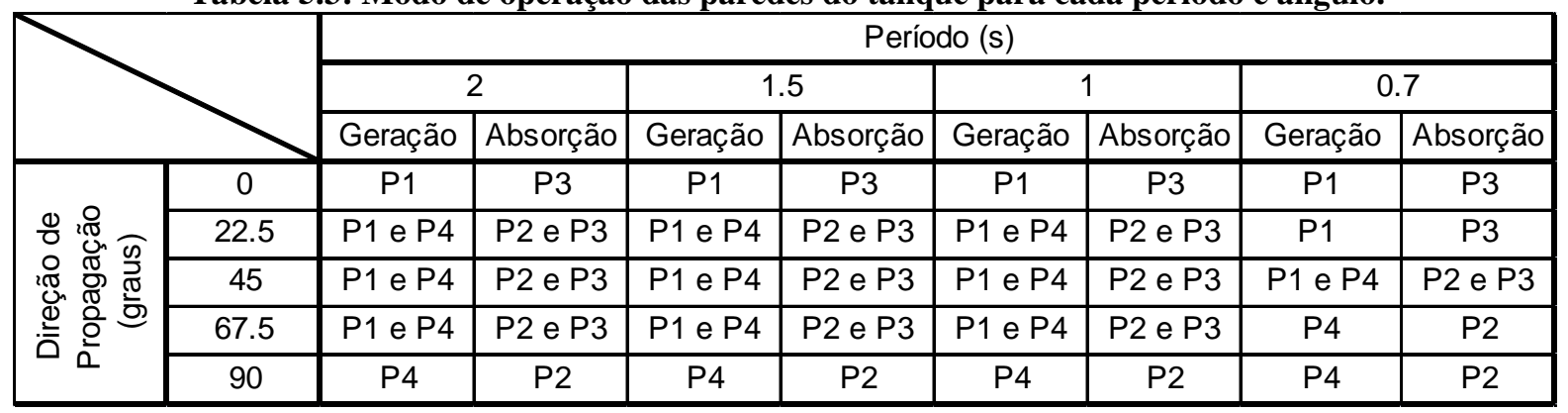

Deve-se lembrar que sempre que uma parede não está atuando na geração ou na absorção de ondas, ela está imóvel e, portanto, reflete qualquer onda incidente.

\subsection{Análise dos cantos arredondados na geração de ondas perpendiculares à parede}

A dúvida sobre quais flaps da parte curva do tanque deveriam ser usados na geração de ondas perpendiculares a uma das paredes do tanque criou a necessidade de um estudo mais aprofundado sobre o tema.

Para realizar este estudo foram escolhidas cinco configurações diferentes de utilização dos flaps da região arredondada em conjunto com uma parede. A tabela 5.4 apresenta um resumo das configurações, partindo da utilização de todos os flaps da região curva e diminuindo-os gradativamente. 
Tabela 5.4: Configurações escolhidas para análise

\begin{tabular}{|c|c|c|}
\hline Configuração & Flaps Região curva & Flaps Região Plana \\
\hline c1 & 133 a $136 ; 1$ a $5 ; 31$ a 39 & 6 a 30 \\
\hline$c 2$ & 135 a $136 ; 1$ a $5 ; 31$ a 37 & 6 a 30 \\
\hline$c 3$ & 1 a $5 ; 31$ a 35 & 6 a 30 \\
\hline$c 4$ & 3 a $5 ; 31$ a 33 & 6 a 30 \\
\hline$c 5$ & 5 e 31 & 6 a 30 \\
\hline
\end{tabular}

Utilizando o simulador, foram rodados os quatro períodos de onda apresentados na tabela 5.2 e o desvio padrão da amplitude na área de interesse foi calculado. Os resultados obtidos foram condensados no gráfico apresentado na figura 5.5.

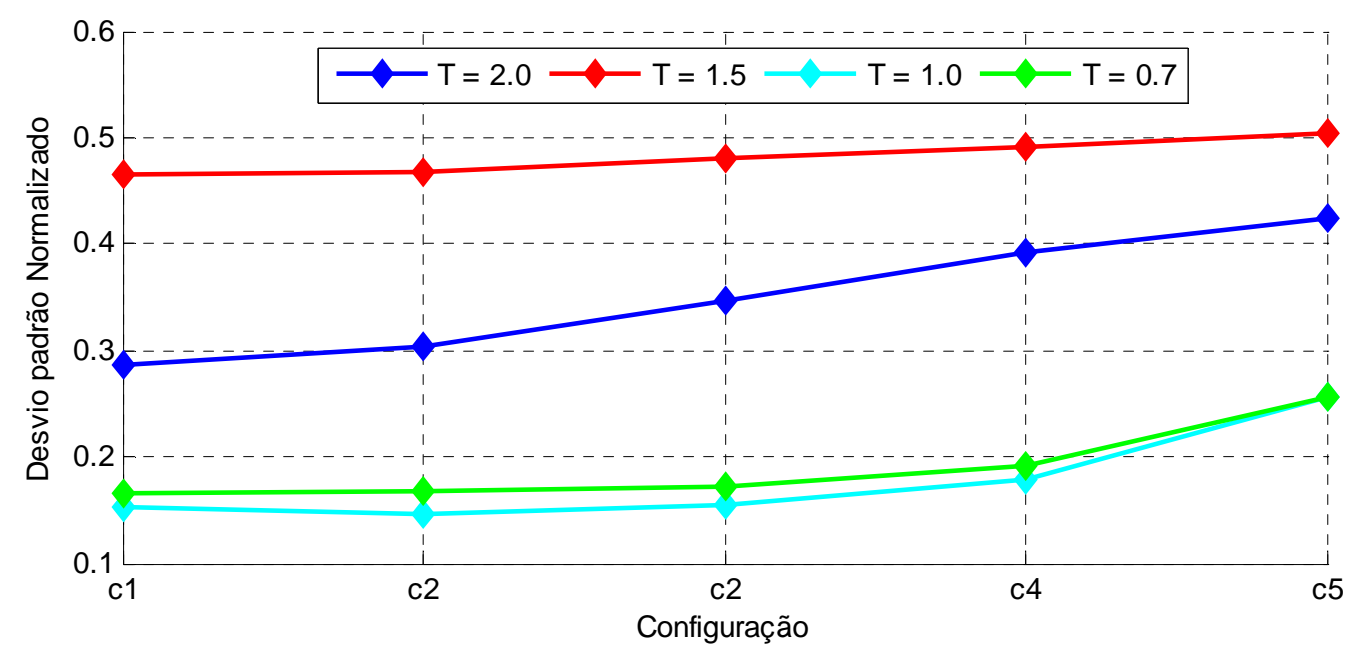

Figura 5.5: Desvio padrão normalizado em função do período de onda para as cinco configurações

Analisando esta figura fica claro que, para todos os períodos, o menor desvio padrão ocorre para a configuração $c 1$, na qual todos os flaps de ambos os lados são utilizados. Portanto, a configuração $c 1$ será utilizada para todos os casos apresentados na próxima seção que envolvam a geração de ondas perpendiculares a alguma das paredes do tanque. 


\subsection{Resultados e comparações}

As análises foram realizadas utilizando o simulador numérico e, para cada caso, foram calculados a amplitude média e o desvio padrão da região de interesse. A apresentação dos resultados será dividida em duas etapas. Primeiro, serão apresentados e discutidos os resultados para os casos individualmente, iniciando pela configuração, ideal, onde todos os flaps poderiam operar, passando em seguida para o caso que está em operação no tanque atualmente. Por fim, serão analisados o caso com os flaps mais próximos das quinas de cada parede travados e o caso de cantos arredondado, os quais foram deixados como opções futuras para o tanque.

\subsubsection{Configuração ideal - Todos os flaps operando}

Este caso, apesar de hipotético, pode servir como uma boa base de comparações com os casos futuros, por ser o mais próximo do ideal que é possível chegar quando um tanque com quinas em 90 graus é considerado.

Com base nos dados da tabela tabela 5.5 foram construídas curvas que relacionam a variação do desvio padrão com a variação do período, para cada direção de propagação, apresentadas na figura 5.6. 
Tabela 5.5: Resultados obtidos para o caso ideal, com todos os flaps operando.

\begin{tabular}{|c|c|c|c|c|c|}
\hline $\begin{array}{c}\text { Direção } \\
\text { (graus) }\end{array}$ & $\begin{array}{c}\text { Período } \\
(\mathrm{s})\end{array}$ & $\begin{array}{c}\text { Amplitude } \\
\text { Esperada }(\mathrm{m})\end{array}$ & $\begin{array}{c}\text { Amplitude Média } \\
\text { Obtida }(\mathrm{m})\end{array}$ & $\begin{array}{c}\text { Diferença nas } \\
\text { Amplitudes (\%) }\end{array}$ & $\begin{array}{c}\text { Desvio } \\
\text { Padrão }\end{array}$ \\
\hline 0.0 & 2.0 & 0.836 & 0.871 & $4.2 \%$ & 0.004 \\
\hline 0.0 & 1.5 & 1.177 & 1.220 & $3.6 \%$ & 0.004 \\
\hline 0.0 & 1.0 & 1.589 & 1.634 & $2.8 \%$ & 0.003 \\
\hline 0.0 & 0.7 & 1.797 & 1.839 & $2.3 \%$ & 0.003 \\
\hline 22.5 & 2.0 & 0.836 & 0.802 & $4.1 \%$ & 0.084 \\
\hline 22.5 & 1.5 & 1.177 & 1.202 & $2.1 \%$ & 0.064 \\
\hline 22.5 & 1.0 & 1.589 & 1.588 & $0.1 \%$ & 0.052 \\
\hline 22.5 & 0.7 & 1.797 & 1.832 & $2.0 \%$ & 0.096 \\
\hline 45.0 & 2.0 & 0.836 & 0.864 & $3.4 \%$ & 0.066 \\
\hline 45.0 & 1.5 & 1.177 & 1.205 & $2.4 \%$ & 0.059 \\
\hline 45.0 & 1.0 & 1.589 & 1.612 & $1.4 \%$ & 0.044 \\
\hline 45.0 & 0.7 & 1.797 & 1.889 & $5.1 \%$ & 0.087 \\
\hline 67.5 & 2.0 & 0.836 & 0.802 & $4.1 \%$ & 0.084 \\
\hline 67.5 & 1.5 & 1.177 & 1.202 & $2.1 \%$ & 0.064 \\
\hline 67.5 & 1.0 & 1.589 & 1.588 & $0.1 \%$ & 0.052 \\
\hline 67.5 & 0.7 & 1.797 & 1.832 & $2.0 \%$ & 0.096 \\
\hline 90.0 & 2.0 & 0.836 & 0.871 & $4.2 \%$ & 0.004 \\
\hline 90.0 & 1.5 & 1.177 & 1.220 & $3.6 \%$ & 0.004 \\
\hline 90.0 & 1.0 & 1.589 & 1.634 & $2.8 \%$ & 0.003 \\
\hline 90.0 & 0.7 & 1.797 & 1.839 & $2.3 \%$ & 0.003 \\
\hline
\end{tabular}

Todos os flaps operando

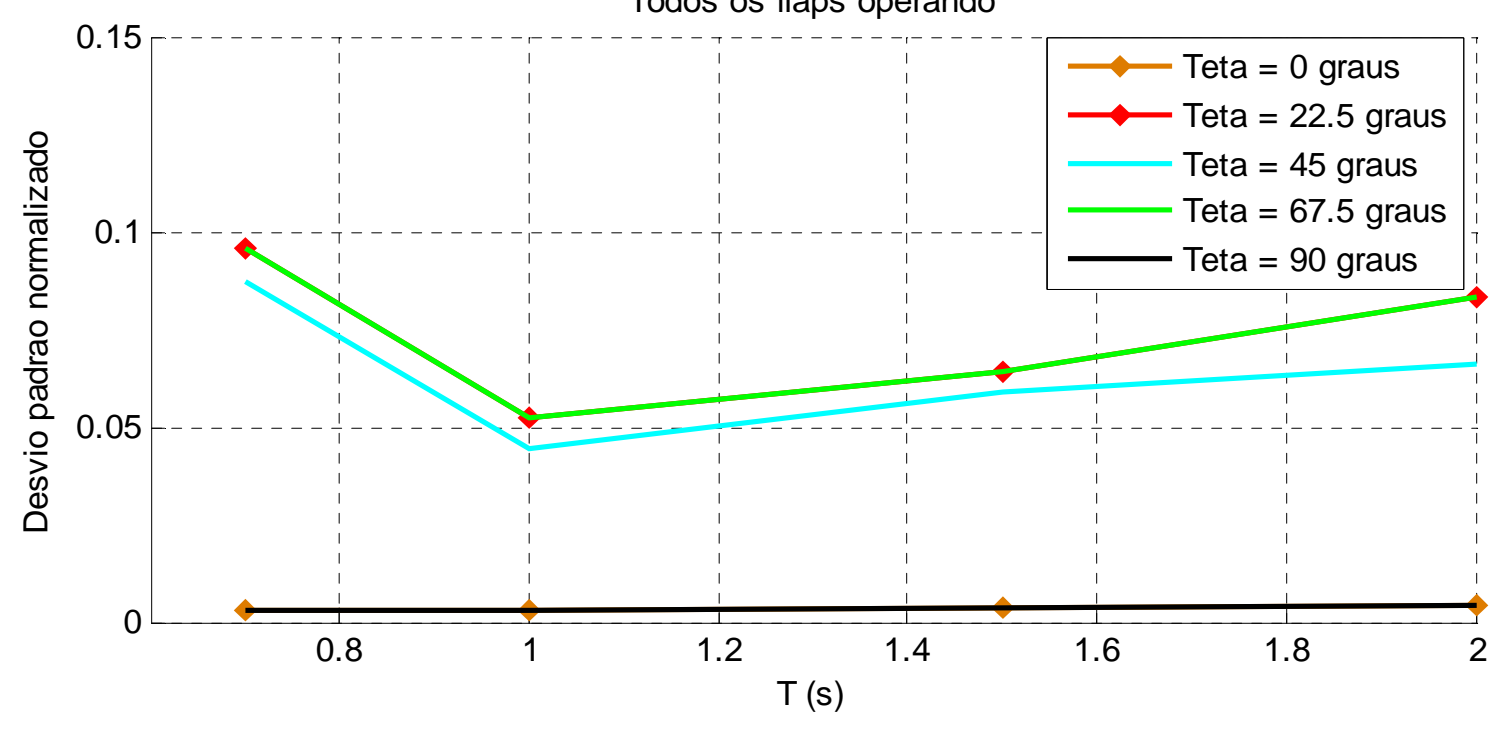

Figura 5.6: Desvio padrão em função do período para todos os flaps operando.

O primeiro fato a ser destacado neste gráfico é que a simetria do tanque se torna aparente ao olhar os ângulos de 0 e 90 graus e também os de 22.5 e 67.5 graus. Outro ponto importante são os baixos desvio padrão que apresentaram os ângulos 
de 0 e 90 graus, fato esperado, pois esta configuração é a que mais se aproxima do caso de geração bidimensional.

Para os outros ângulos, o desvio padrão mostra um decréscimo com a diminuição do período de onda até chegar nos períodos de 1.0 segundos, onde aumenta. Este aumento ocorre porque, para este período, apenas uma das paredes gera a onda pois a outra excedeu o limite de Biesel e, pelo mesmo motivo, a parede oposta também não pode absorver a onda, existindo reflexão no tanque.

\subsubsection{Flaps}

Este caso representa a configuração atual do tanque. O interesse deste caso está em verificar a influência dos flaps travados na qualidade da onda gerada. Os resultados obtidos pelo simulador são apresentados na tabela 5.6 e resumidos na figura 5.7 .

Tabela 5.6: Resultados obtidos para o caso 2 flaps.

\begin{tabular}{|c|c|c|c|c|c|}
\hline $\begin{array}{c}\text { Direção } \\
\text { (graus) }\end{array}$ & $\begin{array}{c}\text { Período } \\
(\mathrm{s})\end{array}$ & $\begin{array}{c}\text { Amplitude } \\
\text { Esperada }(\mathrm{m})\end{array}$ & $\begin{array}{c}\text { Amplitude Média } \\
\text { Obtida }(\mathrm{m})\end{array}$ & $\begin{array}{c}\text { Diferença nas } \\
\text { Amplitudes (\%) }\end{array}$ & $\begin{array}{c}\text { Desvio } \\
\text { Padrão }\end{array}$ \\
\hline 0.0 & 2.0 & 0.836 & 0.871 & $4.2 \%$ & 0.004 \\
\hline 0.0 & 1.5 & 1.177 & 1.220 & $3.6 \%$ & 0.004 \\
\hline 0.0 & 1.0 & 1.589 & 1.634 & $2.8 \%$ & 0.003 \\
\hline 0.0 & 0.7 & 1.797 & 1.839 & $2.3 \%$ & 0.003 \\
\hline 22.5 & 2.0 & 0.836 & 0.748 & $10.5 \%$ & 0.097 \\
\hline 22.5 & 1.5 & 1.177 & 1.159 & $1.5 \%$ & 0.092 \\
\hline 22.5 & 1.0 & 1.589 & 1.575 & $0.9 \%$ & 0.066 \\
\hline 22.5 & 0.7 & 1.797 & 1.832 & $2.0 \%$ & 0.096 \\
\hline 45.0 & 2.0 & 0.836 & 0.781 & $6.6 \%$ & 0.082 \\
\hline 45.0 & 1.5 & 1.177 & 1.010 & $14.2 \%$ & 0.058 \\
\hline 45.0 & 1.0 & 1.589 & 1.444 & $9.1 \%$ & 0.060 \\
\hline 45.0 & 0.7 & 1.797 & 1.610 & $10.4 \%$ & 0.143 \\
\hline 67.5 & 2.0 & 0.836 & 0.695 & $16.9 \%$ & 0.124 \\
\hline 67.5 & 1.5 & 1.177 & 1.090 & $7.4 \%$ & 0.162 \\
\hline 67.5 & 1.0 & 1.589 & 1.566 & $1.5 \%$ & 0.132 \\
\hline 67.5 & 0.7 & 1.797 & 1.819 & $1.2 \%$ & 0.166 \\
\hline 90.0 & 2.0 & 0.836 & 1.000 & $19.6 \%$ & 0.186 \\
\hline 90.0 & 1.5 & 1.177 & 1.375 & $16.8 \%$ & 0.368 \\
\hline 90.0 & 1.0 & 1.589 & 1.624 & $2.2 \%$ & 0.182 \\
\hline 90.0 & 0.7 & 1.797 & 1.859 & $3.4 \%$ & 0.110 \\
\hline & & & & & \\
\hline
\end{tabular}




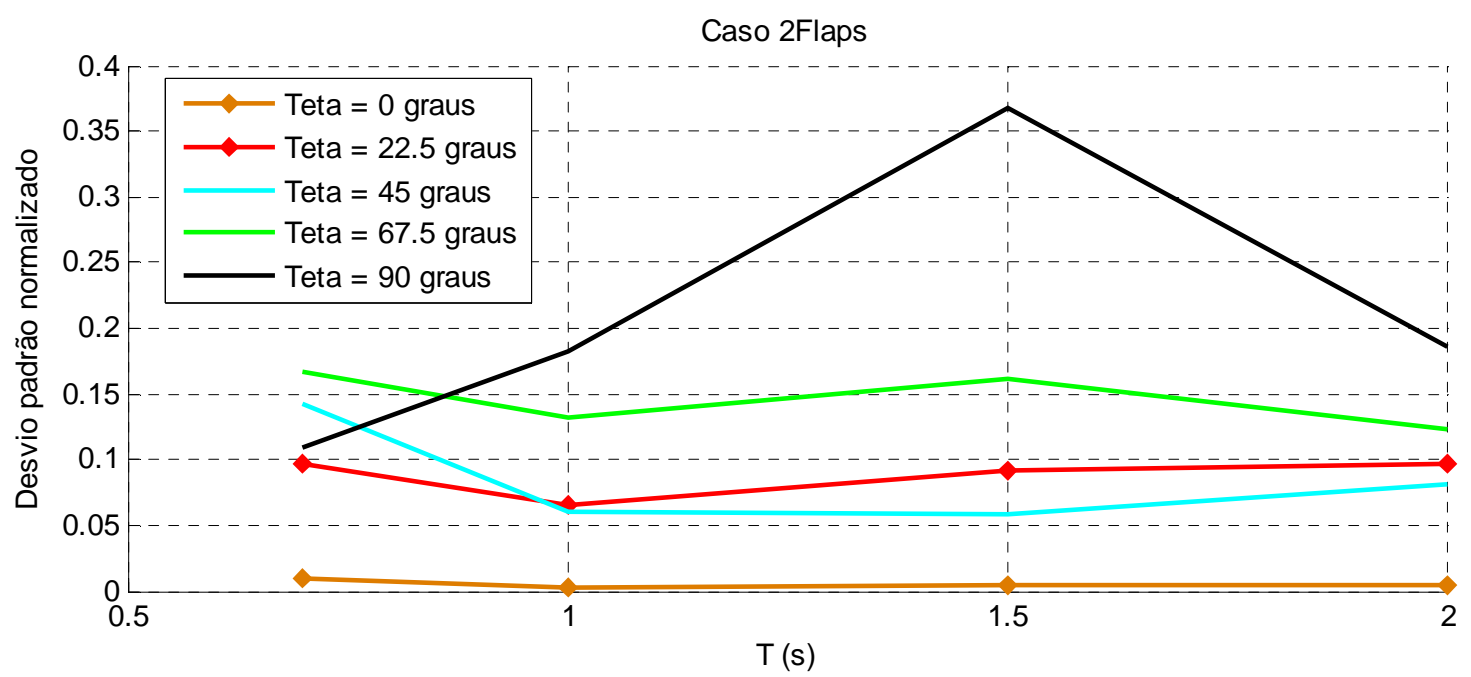

Figura 5.7: Desvio padrão em função do período para o caso 2Flaps.

Este caso apresentou resultados bem diferentes do anterior, a não ser pela direção de propagação de 0 graus, que é igual ao anterior. Houve um aumento no desvio padrão para todos os outros ângulos, resultado dos flaps inoperantes, tendo de ser destacado o grande aumento ocorrido para o período de 1.5 segundos.

Após uma análise sobre as possíveis causas deste grande aumento, a hipótese mais provável é que ele esteja ligado à relação entre o comprimento de onda e a largura dos flaps. O comprimento de onda é da ordem de 3.51 metros e a largura dos flaps é de 0.359 metros, aproximadamente dez vezes menor.

\subsubsection{Flap}

O terceiro caso analisado é o mais fácil de ser aplicado no tanque, apenas sendo necessário trocar os flaps que estão travados. Os seus resultados providos pelo simulador podem ser encontrados na tabela 5.7 e figura 5.8. 
Tabela 5.7: Resultados obtidos para o caso 1Flap.

\begin{tabular}{|c|c|c|c|c|c|}
\hline $\begin{array}{c}\text { Direção } \\
\text { (graus) }\end{array}$ & $\begin{array}{c}\text { Período } \\
(\mathrm{s})\end{array}$ & $\begin{array}{c}\text { Amplitude } \\
\text { Esperada }(\mathrm{m})\end{array}$ & $\begin{array}{c}\text { Amplitude Média } \\
\text { Obtida }(\mathrm{m})\end{array}$ & $\begin{array}{c}\text { Diferença nas } \\
\text { Amplitudes (\%) }\end{array}$ & $\begin{array}{c}\text { Desvio } \\
\text { Padrão }\end{array}$ \\
\hline 0.0 & 2.0 & 0.836 & 0.932 & $11.5 \%$ & 0.105 \\
\hline 0.0 & 1.5 & 1.177 & 1.282 & $8.9 \%$ & 0.251 \\
\hline 0.0 & 1.0 & 1.589 & 1.657 & $4.3 \%$ & 0.216 \\
\hline 0.0 & 0.7 & 1.797 & 1.858 & $3.4 \%$ & 0.122 \\
\hline 22.5 & 2.0 & 0.836 & 0.712 & $14.8 \%$ & 0.112 \\
\hline 22.5 & 1.5 & 1.177 & 1.116 & $5.2 \%$ & 0.135 \\
\hline 22.5 & 1.0 & 1.589 & 1.620 & $1.9 \%$ & 0.150 \\
\hline 22.5 & 0.7 & 1.797 & 1.860 & $3.5 \%$ & 0.174 \\
\hline 45.0 & 2.0 & 0.836 & 0.793 & $5.2 \%$ & 0.086 \\
\hline 45.0 & 1.5 & 1.177 & 1.004 & $14.8 \%$ & 0.062 \\
\hline 45.0 & 1.0 & 1.589 & 1.350 & $15.1 \%$ & 0.087 \\
\hline 45.0 & 0.7 & 1.797 & 1.782 & $0.8 \%$ & 0.097 \\
\hline 67.5 & 2.0 & 0.836 & 0.712 & $14.8 \%$ & 0.112 \\
\hline 67.5 & 1.5 & 1.177 & 1.116 & $5.2 \%$ & 0.135 \\
\hline 67.5 & 1.0 & 1.589 & 1.620 & $1.9 \%$ & 0.150 \\
\hline 67.5 & 0.7 & 1.797 & 1.860 & $3.5 \%$ & 0.174 \\
\hline 90.0 & 2.0 & 0.836 & 0.932 & $11.5 \%$ & 0.105 \\
\hline 90.0 & 1.5 & 1.177 & 1.282 & $8.9 \%$ & 0.251 \\
\hline 90.0 & 1.0 & 1.589 & 1.657 & $4.3 \%$ & 0.216 \\
\hline 90.0 & 0.7 & 1.797 & 1.858 & $3.4 \%$ & 0.122 \\
\hline & & & & & \\
\hline
\end{tabular}

Caso 1Flap

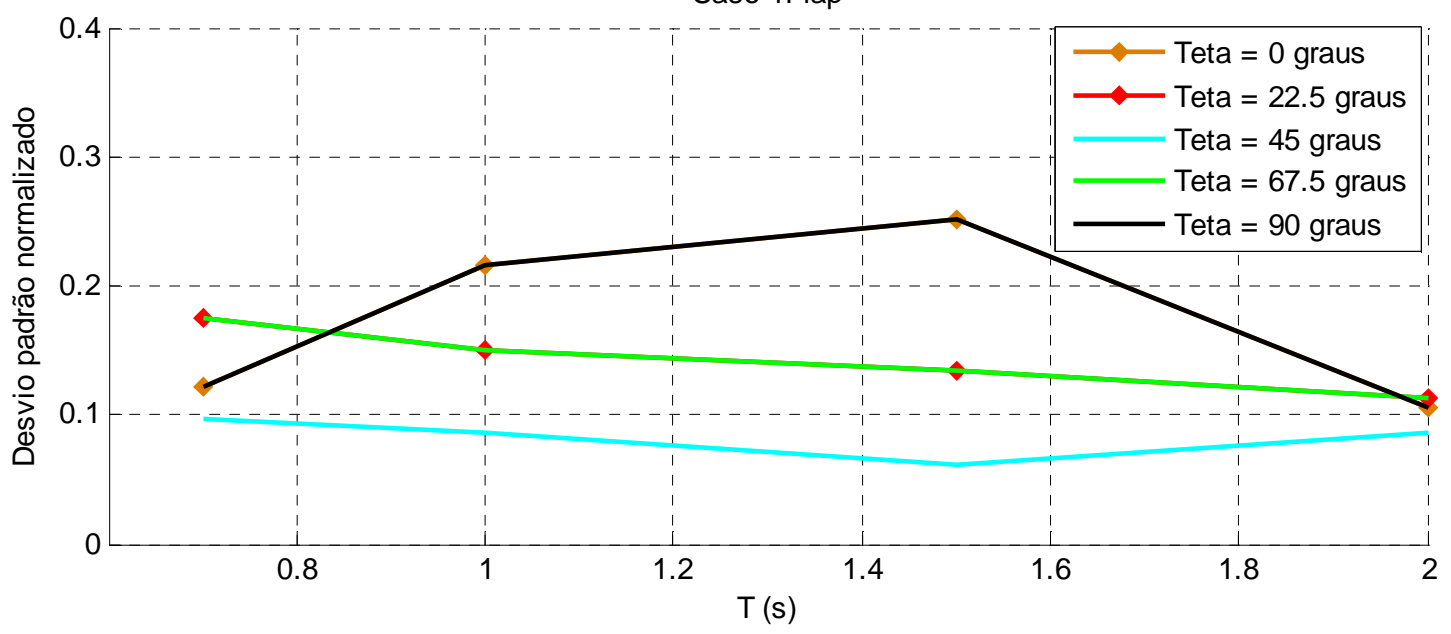

Figura 5.8: Desvio padrão em função do período para o caso 1Flap.

Este terceiro apresentou resultados semelhantes ao anterior, com um ganho de performance na direção 90 graus enquanto teve uma grande perda em relação a direção de zero graus. 


\subsubsection{Cantos arredondados}

O quarto e último caso representa uma opção em que todos os flaps podem trabalhar sem restrição. Durante a construção do tanque foram deixadas prontas as furações para que esta configuração seja aplicada caso seja decidido por ela. Os resultados obtidos estão apresentados na tabela 5.8 e na figura 5.9.

Tabela 5.8: Resultados obtidos para o caso com cantos arredondados

\begin{tabular}{|c|c|c|c|c|c|}
\hline $\begin{array}{c}\text { Direção } \\
\text { (graus) }\end{array}$ & $\begin{array}{c}\text { Período } \\
(\mathrm{s})\end{array}$ & $\begin{array}{c}\text { Amplitude } \\
\text { Esperada }(\mathrm{m})\end{array}$ & $\begin{array}{c}\text { Amplitude Média } \\
\text { Obtida }(\mathrm{m})\end{array}$ & $\begin{array}{c}\text { Diferença nas } \\
\text { Amplitudes }(\%)\end{array}$ & $\begin{array}{c}\text { Desvio } \\
\text { Padrão }\end{array}$ \\
\hline 0.0 & 2.0 & 0.836 & 0.850 & $1.7 \%$ & 0.286 \\
\hline 0.0 & 1.5 & 1.177 & 1.503 & $27.7 \%$ & 0.466 \\
\hline 0.0 & 1.0 & 1.589 & 1.642 & $3.3 \%$ & 0.152 \\
\hline 0.0 & 0.7 & 1.797 & 1.631 & $9.2 \%$ & 0.164 \\
\hline 22.5 & 2.0 & 0.836 & 0.849 & $1.6 \%$ & 0.201 \\
\hline 22.5 & 1.5 & 1.177 & 1.191 & $1.2 \%$ & 0.115 \\
\hline 22.5 & 1.0 & 1.589 & 1.604 & $0.9 \%$ & 0.091 \\
\hline 22.5 & 0.7 & 1.797 & 1.784 & $0.7 \%$ & 0.126 \\
\hline 45.0 & 2.0 & 0.836 & 0.804 & $3.9 \%$ & 0.152 \\
\hline 45.0 & 1.5 & 1.177 & 1.168 & $0.8 \%$ & 0.077 \\
\hline 45.0 & 1.0 & 1.589 & 1.575 & $0.9 \%$ & 0.079 \\
\hline 45.0 & 0.7 & 1.797 & 1.755 & $2.4 \%$ & 0.104 \\
\hline 67.5 & 2.0 & 0.836 & 0.849 & $1.6 \%$ & 0.201 \\
\hline 67.5 & 1.5 & 1.177 & 1.191 & $1.2 \%$ & 0.115 \\
\hline 67.5 & 1.0 & 1.589 & 1.604 & $0.9 \%$ & 0.091 \\
\hline 67.5 & 0.7 & 1.797 & 1.811 & $0.8 \%$ & 0.126 \\
\hline 90.0 & 2.0 & 0.836 & 0.850 & $1.7 \%$ & 0.286 \\
\hline 90.0 & 1.5 & 1.177 & 1.503 & $27.7 \%$ & 0.466 \\
\hline 90.0 & 1.0 & 1.589 & 1.642 & $3.3 \%$ & 0.152 \\
\hline 90.0 & 0.7 & 1.797 & 1.631 & $9.2 \%$ & 0.164 \\
\hline
\end{tabular}




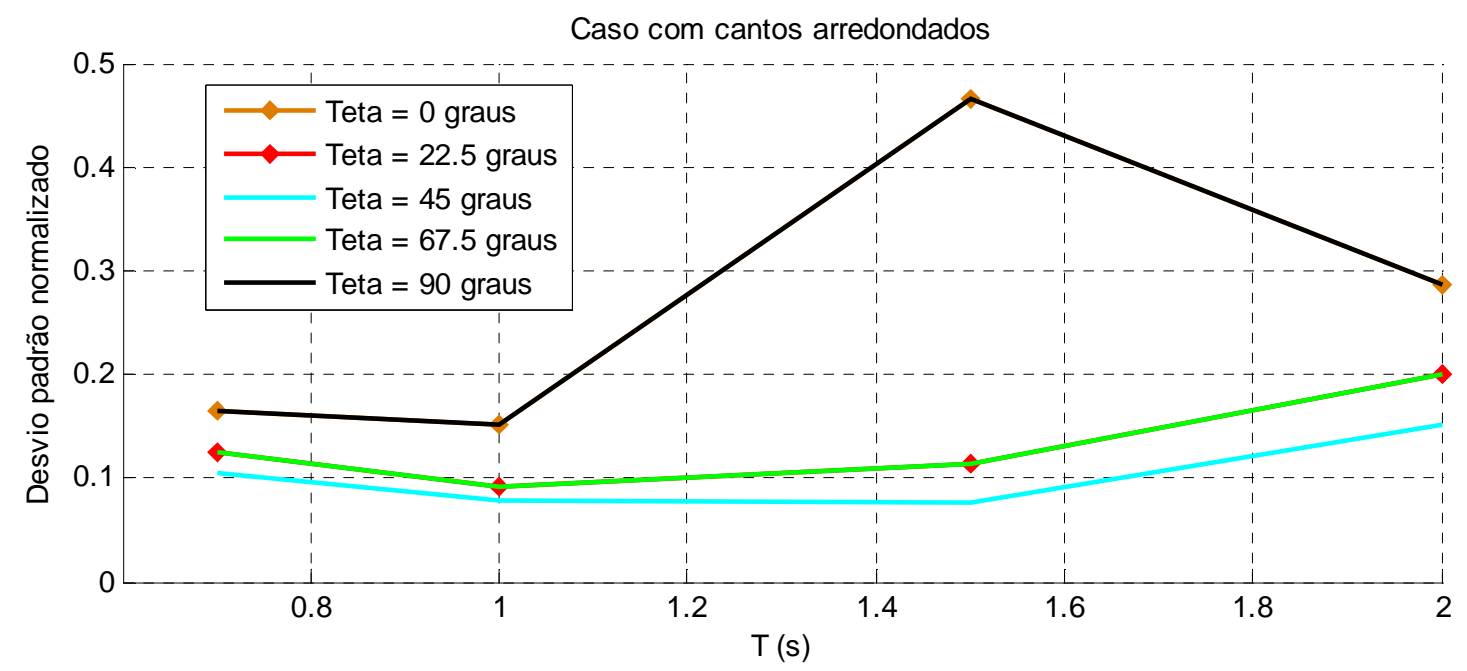

Figura 5.9: Desvio padrão em função do período para o caso com cantos arredondados.

Este ultimo caso apresentou uma melhora significativa em relação aos dois anteriores para os períodos acima de 1.5 e direções de propagação de 22.5 e 67.5 . No entanto, para o período de 2 segundos houve uma grande piora em relação aos casos anteriores.

Comparações mais precisas serão feitas na próxima seção, na qual os quatro casos são comparados diretamente, para cada direção de propagação.

\subsubsection{Comparações entre configurações}

Com o objetivo de uma comparação direta entre todos casos, foram criados gráficos do desvio padrão em função do período de onda para cada uma das direções de propagação. Estas comparações estão apresentadas nas figuras 5.10 a 5.14. 


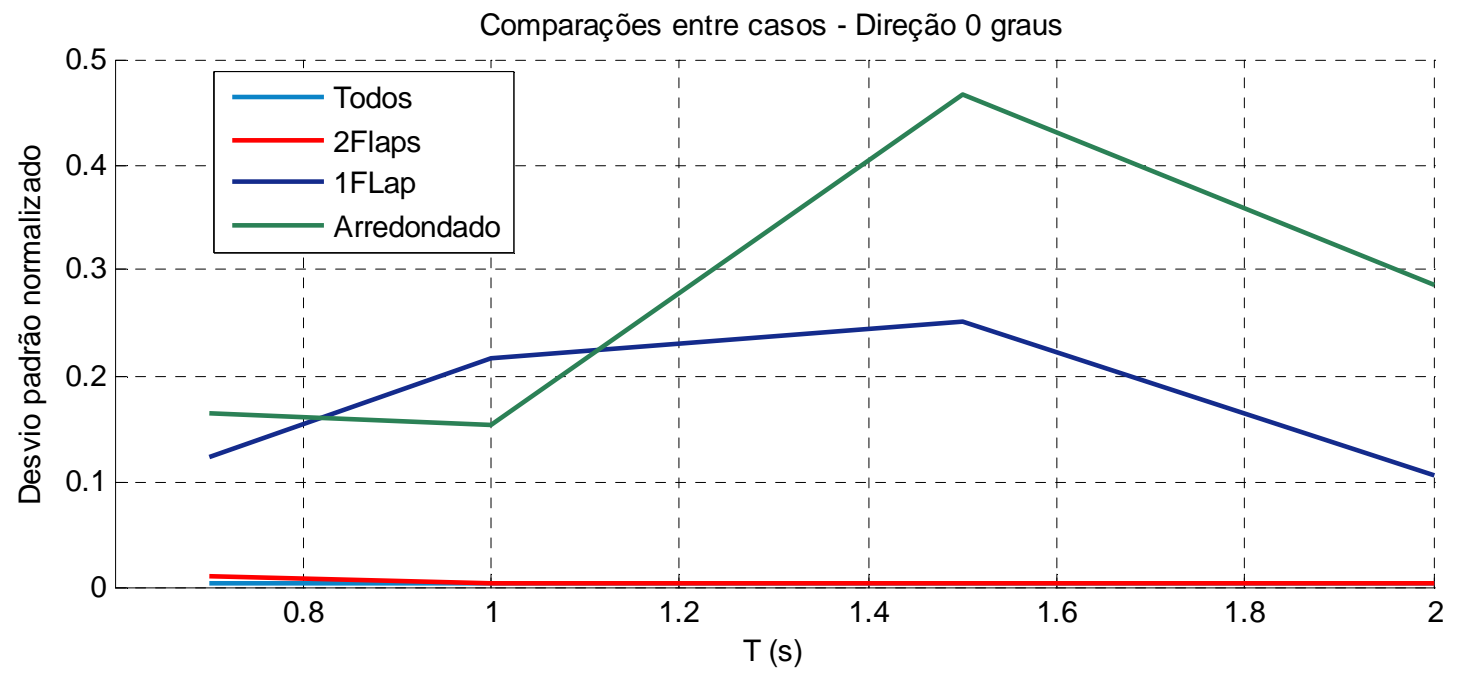

Figura 5.10: Comparação entre os quatro casos - Direção 0 graus.

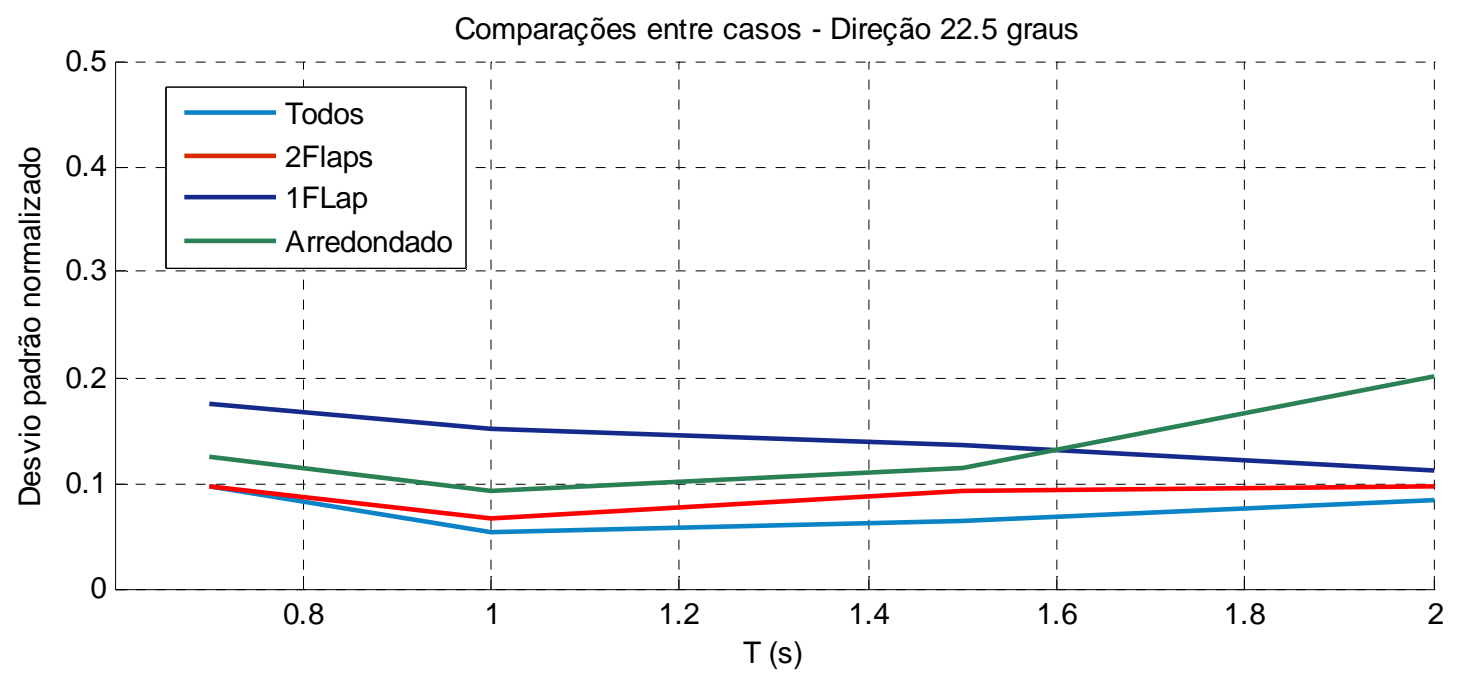

Figura 5.11: Desvio padrão Comparação entre os quatro casos - Direção 22.5 graus. 


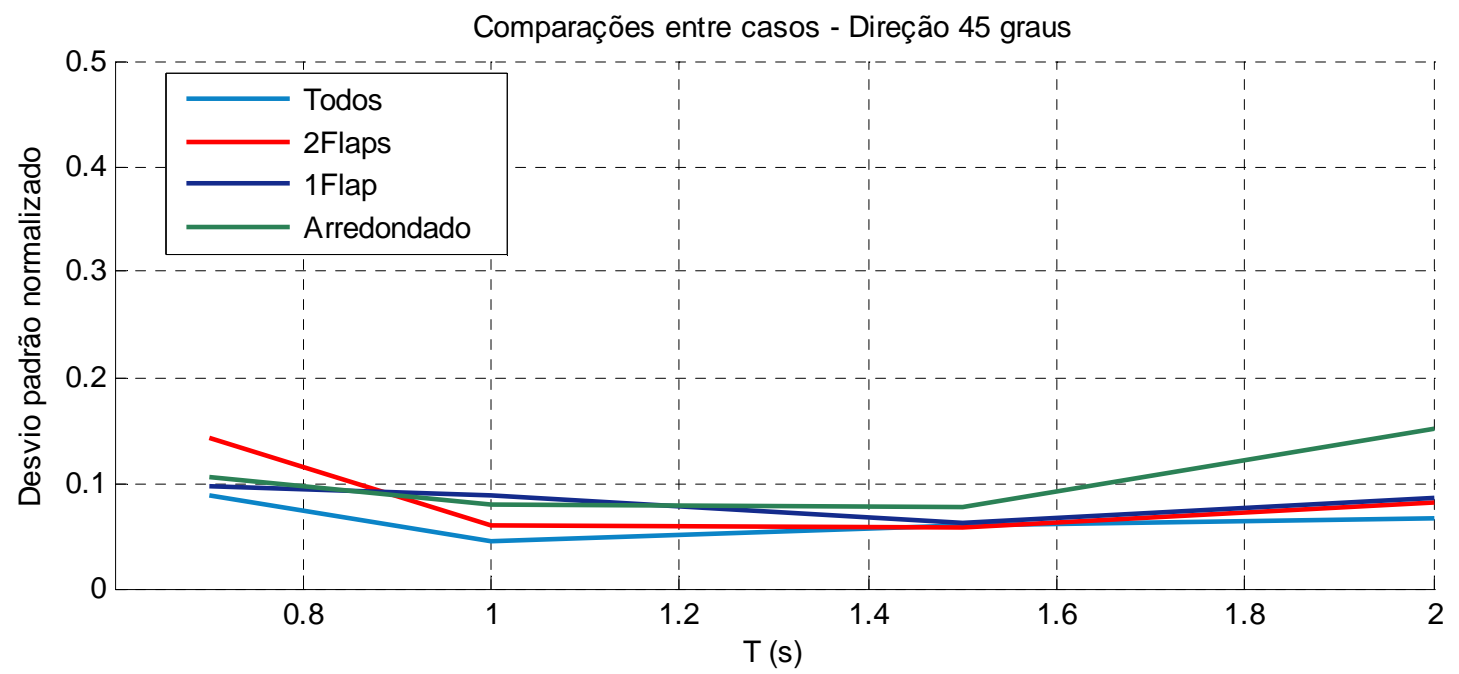

Figura 5.12: Comparação entre os quatro casos - Direção 45 graus.

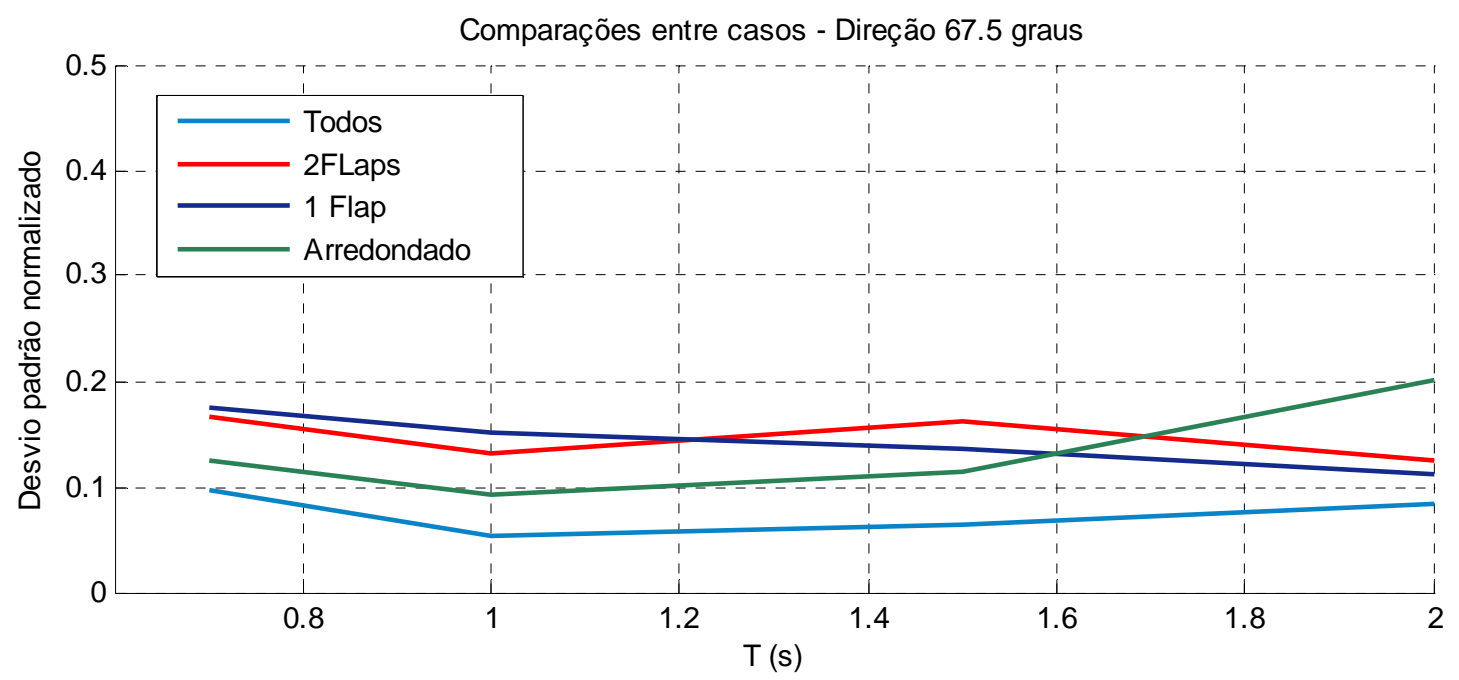

Figura 5.13: Comparação entre os quatro casos - Direção 67.5 graus. 


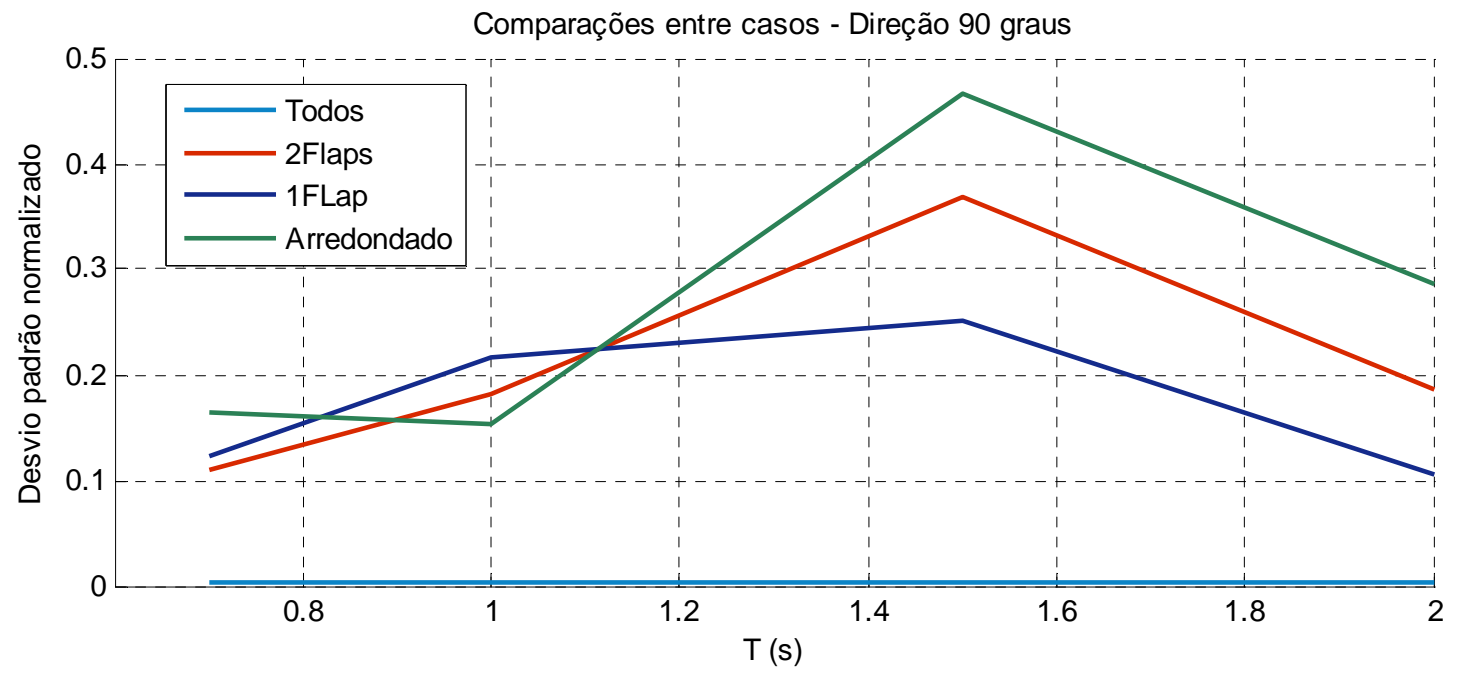

Figura 5.14: Desvio Comparação entre os quatro casos - Direção 90 graus.

O caso que apresentou melhor resultado para todas as direções de propagação foi o tanque quadrado, com todos os flaps em funcionamento. Este caso é ideal e não pode ser aplicado no tanque, mas trás uma boa fonte de comparação pois mostra o desvio padrão mínimo que é possível atingir.

Com a direção de propagação de zero graus, os caso 2Flaps é igual ao tanque com todos os flaps, sendo esta a melhor configuração possível para a geração de ondas nesta direção. As outras duas configurações apresentaram desvios maiores, destacando-se a de cantos arredondados que apresentou flutuações consideráveis para os períodos mais altos. Estes dois casos serão discutidos novamente para a direção de propagação de 90 graus, quando se repetem, e então comparados com a parede do caso 2Flaps que tem flaps travados.

Analisando a direção de 22.5 graus, constata-se que todos os casos têm desvio padrão entre 0.05 e 0.2 e que o caso 2Flaps se encontra bastante próximo ao caso ideal, não havendo muita influência dos flaps travados. Destaca-se também o desvio padrão do tanque com cantos arredondados para o período de 2 segundos, com valor próximo ao dobro dos outros casos.

A direção de 45 graus foi a que apresentou valores de desvio padrão mais próximos do ideal, principalmente para os casos 1Flap e 2Flaps, havendo um aumento mais significativo apenas para o período de 0.7 segundos, quando os 2 flaps travados em 
uma mesma parede do caso 2Flaps demonstraram causar uma influência negativa maior do que apenas 1 flap travado por parede. Repetindo as direções anteriores, os cantos arredondados apresentaram desvios maiores para os períodos maiores.

Com resultados praticamente iguais à direção de 22.5 graus, a direção de 67.5 graus fica marcada por um aumento significativo nos desvios para o caso 2Flaps, causado pela predominância de ondas geradas pela parede com flaps travados na área de ensaios. Outro ponto de destaque é o que ocorre entre os casos 2 FLaps e 1 Flap para períodos inferiores a 1.2 segundos, quando o desvio padrão do caso 2Flaps passa a ser menor do que o desvio padrão do caso 1Flap, quando era esperado o contrário, uma vez que o caso 2Flaps conta com menos geradores funcionando nestas condições.

Para detectar a origem deste fato, foram analisados os mapas da superfície livre. Iniciando pelo período de 0.7 segundos, foram criadas as figuras 5.15 e 5.16 . A onda apresentada é gerada apenas pela parede inferior da figura e ocorre a reflexão na parede da esquerda, lembrando que neste caso ela não pode absorver a onda. Observando estas figuras é possível verificar que existe influência das reflexões no interior da área de ensaio, principalmente na figura 5.16, que representa o caso 1Flap. Esta influência das reflexões deve ser responsável pelo desvio padrão ser maior no caso 1 Flap do que no caso 2 Flaps.

Da mesma forma, foram criadas as figuras 5.17 e 5.18 para o período de 1 segundo. Neste caso, não há reflexão alguma e ambas as paredes estão gerando onda. Comparando as duas figuras, é possível observar que, dentro da área de ensaio, o caso com 1Flap apresenta mais variações de cores ao longo das cristas e vales da onda do que no caso 2 Flaps. 


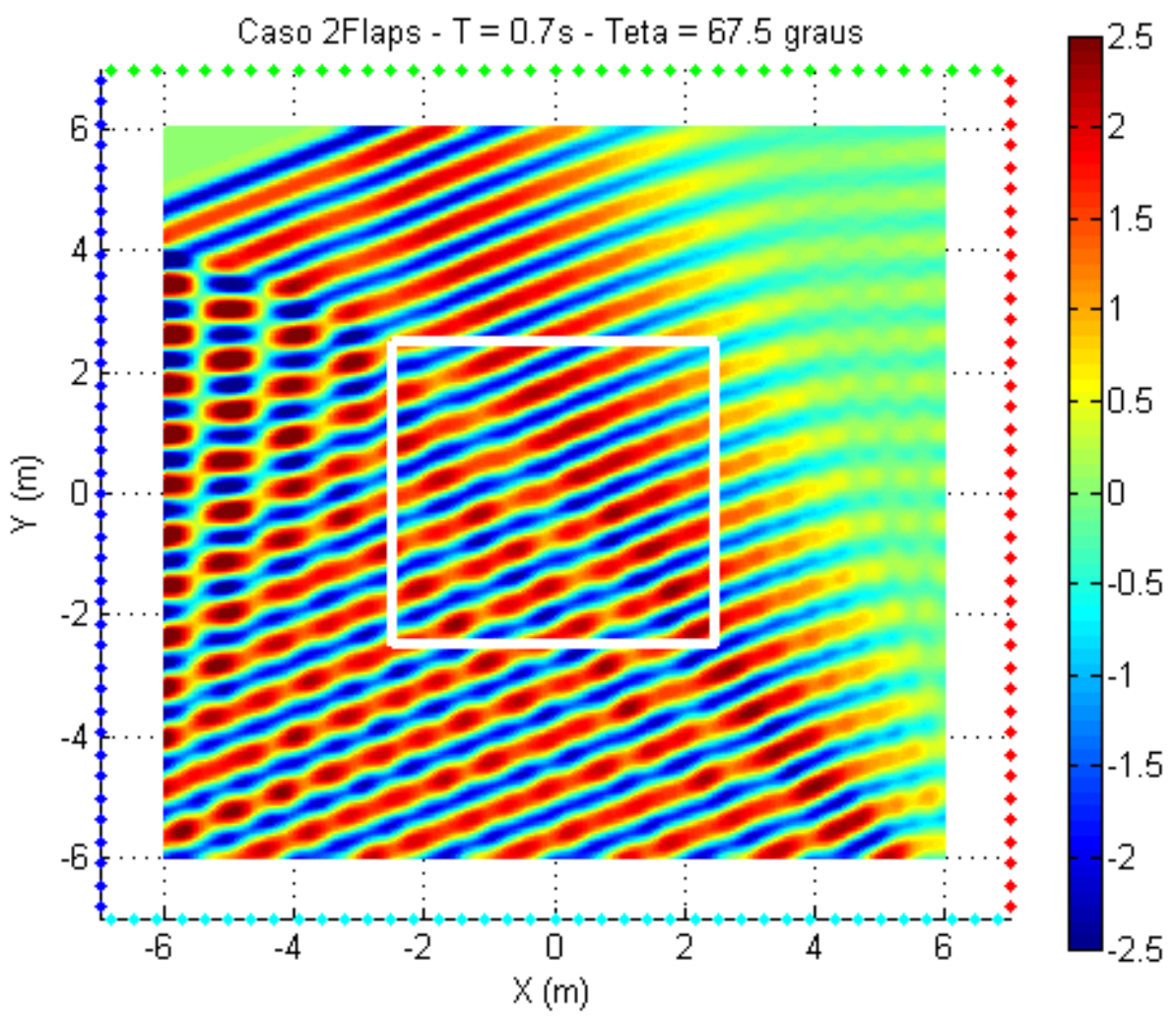

Figura 5.15: Superfície livre para o caso 2Flaps, com direção 67.5 e período $0.7 s$ s.

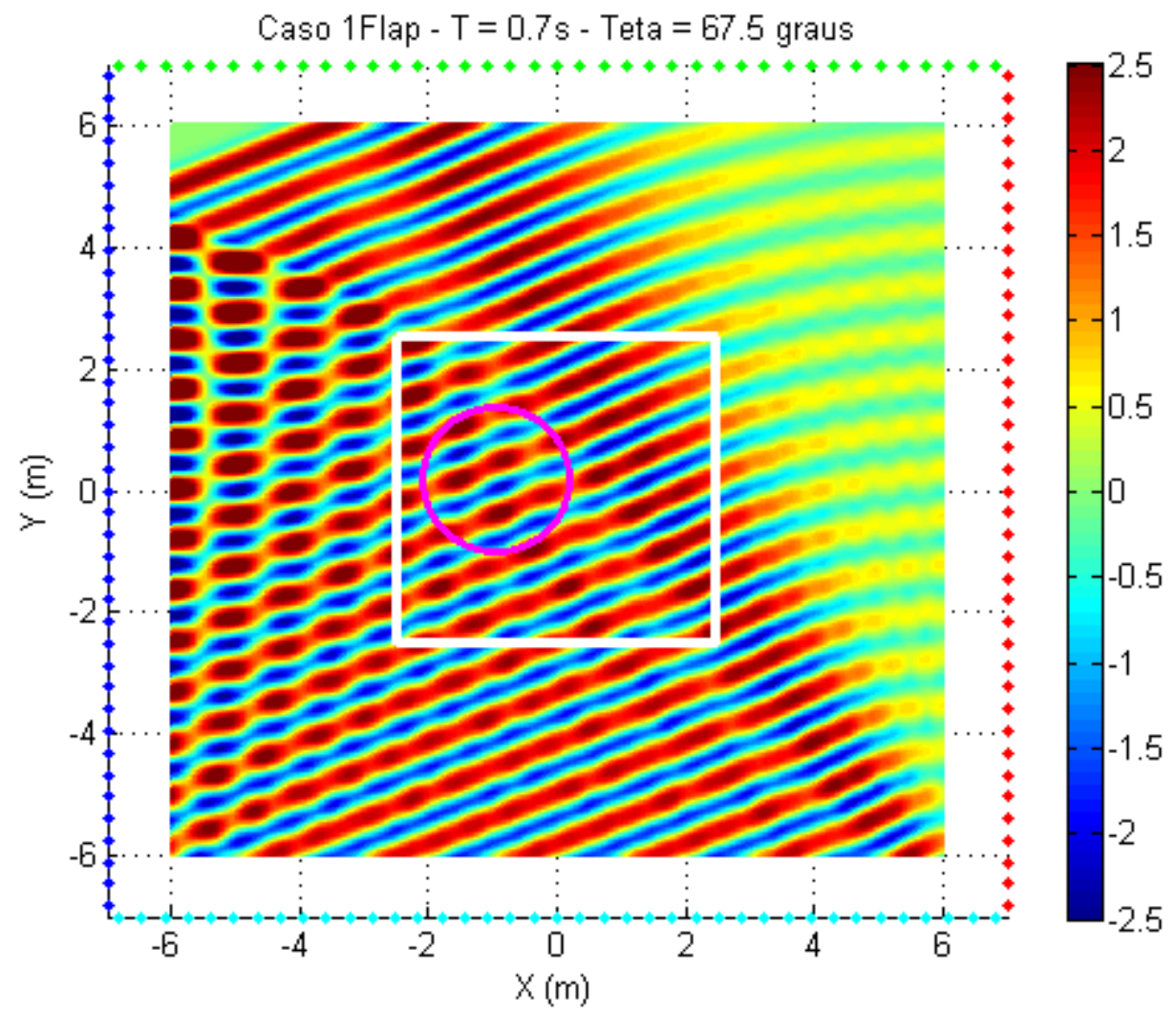

Figura 5.16: Superfície livre para o caso 1Flap, com direção 67.5 e período $0.7 \mathrm{~s}$. 


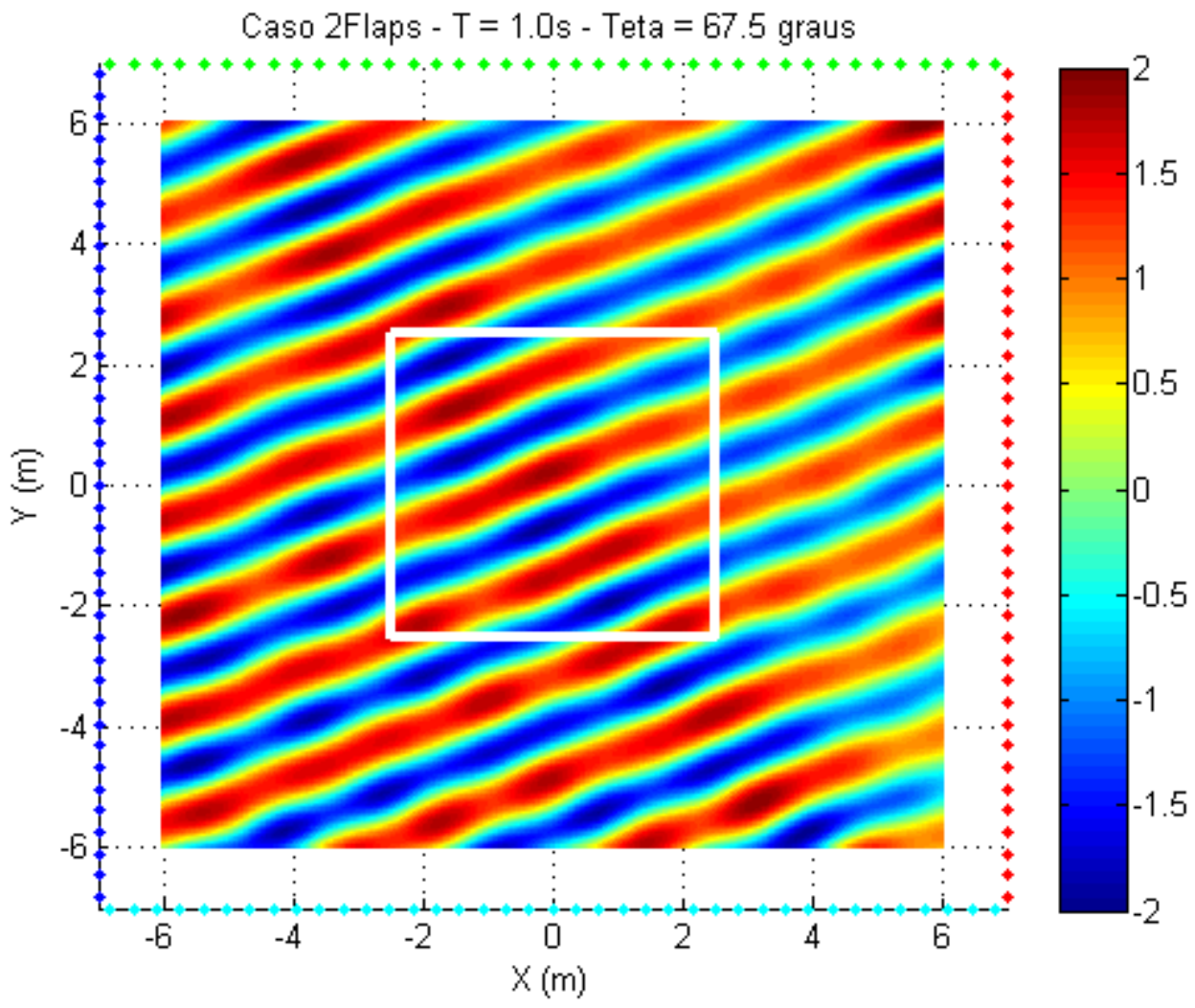

Figura 5.17: Superfície livre para o caso 2Flaps, com direção 67.5 e período $1.0 s$.

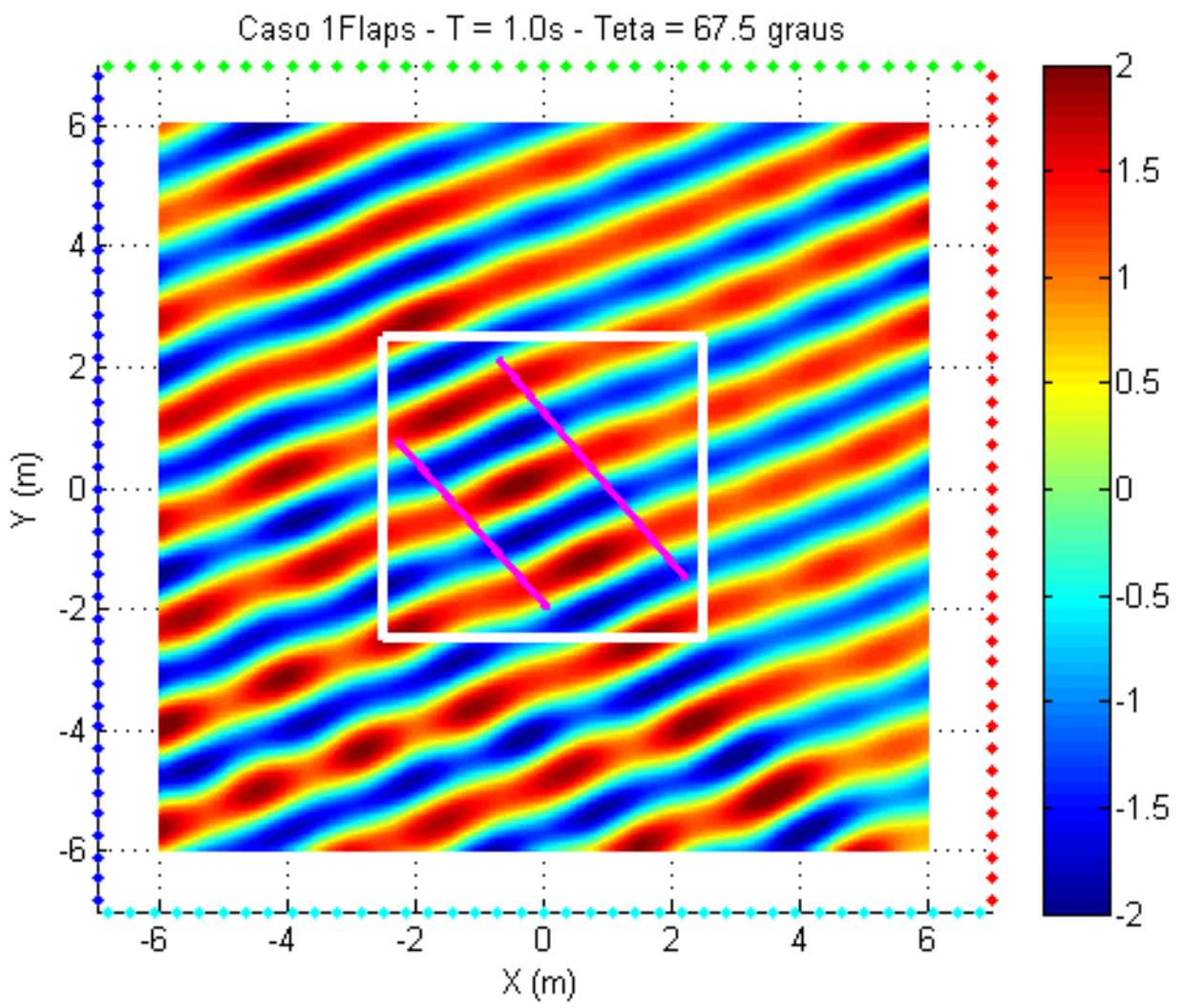

Figura 5.18: Superfície livre para o caso 1Flaps, com direção 67.5 e período 1.0s. 
Por fim temos a direção de 90 graus, onde surgiram resultados diferenciados. Nesta direção, a parede com flaps travados do caso 2Flaps passa a gerar a onda sozinha e, pelo fato dela operar com apenas 35 flaps, contra 37 flaps do caso 1Flap, era esperado que o desvio padrão fosse maior para todos os períodos de onda, fato não observado nos resultados. Entre os períodos de 2.0 até aproximadamente 1.1 segundos, essa previsão se mostrou correta. Contudo, para períodos menores, houve uma inversão, com o caso 1Flap apresentando piores resultados que o caso 2Flaps abaixo de 1.1 segundos.

Outro ponto de destaque são os alto valores de desvio padrão apresentados para o período de 1.5 segundos. Com a falta das ondas irradiadas pelos flaps travados ocorrem combinações de onda em certas regiões do tanque que causam uma grande variação na superfície livre. Isto pode ser compreendido de maneira mais fácil ao analisar a figura 5.19. O gráfico da esquerda representa a elevação da superfície livre gerada pelos 35 flaps da parede e o gráfico da direita representa a onda que seria gerada pelos flaps que estão travados que, se somada ao gráfico da esquerda, resultaria na onda gerada pela parede toda, com desvio padrão igual ao caso com todos os flaps. Pode-se observar que as duas figuras são complementares e, quando somadas, resulta na geração feita com a parede completa. Esta soma pode ser conferida na figura 5.20.
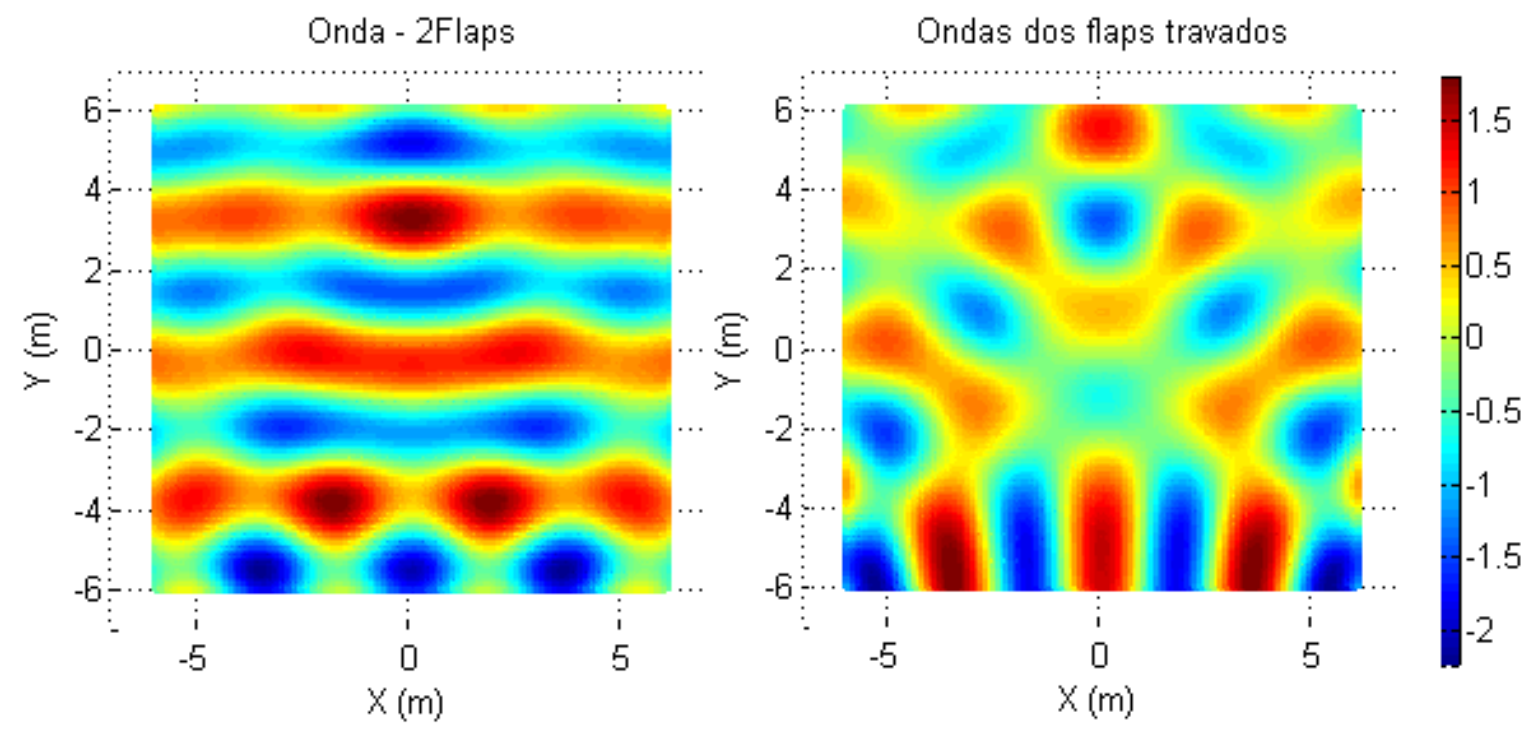

Figura 5.19: Onda do caso 2Flaps (esq.) e onda que seria gerada pelos flaps travados. 


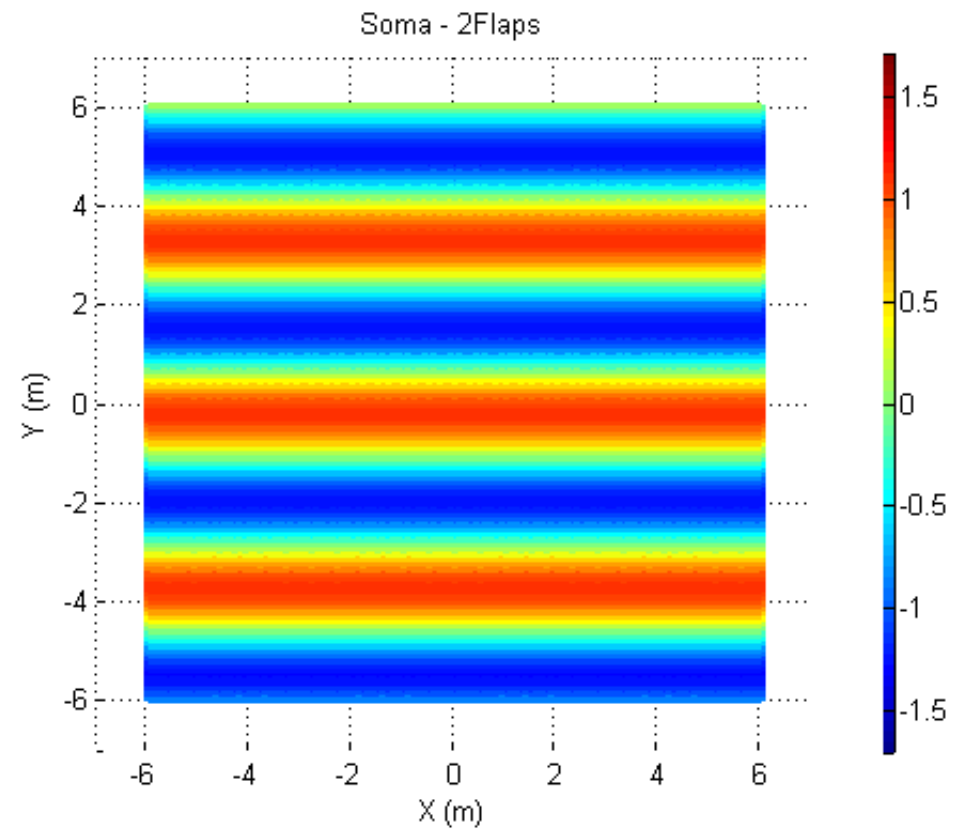

Figura 5.20: Soma das ondas geradas por todos os flaps funcionando.

De modo geral, os resultados obtidos nesta seção deixam claro que não há uma configuração possível que a melhor para todos os períodos e direção de propagação. Do ponto de vista da geração a melhor opção seria uma combinação dos casos 1FLap e 2Flaps, escolhendo qual delas irá operar em cada condição. No entanto, para tornar isso possível, é necessário realizar uma alteração no modo de funcionamento do tanque, fazendo com que o travamento dos flaps possa ser alterado sem comprometer a operação do tanque e a discussão sobre a aplicação desta possibilidade fica além do escopo deste trabalho. 


\section{Conclusões e Recomendações de Trabalhos Futuros}

O desenvolvimento do simulador como um método simplificado de representar o campo de ondas em um tanque utilizando a solução da teoria linear de geração de ondas foi capaz de reproduzir com boa precisão a elevação da superfície livre para ondas regulares, tanto no caso bidimensional, quando foi realizada a comparação com resultados obtidos em ensaios em canal de ondas, quanto no caso tridimensional, que teve resultados comparados com o programa Wamit, que resolve o problema potencial utilizando o método dos elementos de contorno.

O simulador também tornou possível a realização de estudos sobre a eficiência das diferentes configurações de funcionamento do tanque pensadas durante a sua fase de projeto, inclusive sobre alterações previstas em sua geometria, mostrando que a ferramenta pode ter aplicações relevantes não apenas na fase de projeto do tanque, mas também no que tange a sua operação.

A utilização de fontes pontuais na representação dos geradores de onda mostrou-se bastante eficaz, tanto na representação dos geradores quanto na representação das imagens responsáveis por criar os efeitos de reflexão em paredes do tanque.

Com a ausência das limitações físicas existentes no tanque real, foi possível estudar o caso ideal de geração para um tanque quadrado, com todos seus flaps em funcionamento. Apesar de não ser possível sua aplicação na prática, este caso serve como referência de comparação para as análises dos outros casos, pois mostra nível mínimo de flutuação do campo esperado para uma zona de ensaios pré-definida, desvio este que é diferente de zero mesmo para o caso ideal, principalmente na geração de ondas oblíquas.

A configuração atual do tanque, denominada "caso 2Flaps" neste trabalho, apresentou os menores valores de desvio padrão gerando ondas com direção perpendicular à parede que tem todos os seus flaps operacionais, definida pela direção 0 graus, e também quando a direção de propagação é inferior ou igual à 45 
graus, com exceção do período 0.7 segundos e direção de propagação 45 graus. Para ângulos superiores a 45 graus, a influência dos flaps travados na área de ensaio aumenta, causando o aumento do desvio padrão.

Uma configuração pensada para o tanque, tratada neste trabalho como o "caso 1Flap", apresentou performance inferior ao caso 2Flaps para os ângulos inferiores a 45 graus. Em contrapartida, houve um ganho de desempenho para a maioria das combinações de períodos e ângulos acima de 45 graus analisadas. Os ganhos mais significativos são para a geração de ondas com períodos altos, na direção de 90 graus, para os quais o caso 2Flaps tem uma performance inadequada.

A terceira configuração testada recebeu o nome "Arredondado" devido ao arredondamento realizado nas quinas do tanque. A maior vantagem desta configuração está, em teoria, na absorção de ondas irradiadas por modelos no centro do tanque, porém, neste trabalho apenas a geração de ondas for analisada. O arredondamento dos cantos resultou em desvios padrão maiores para a maioria das combinações de direção e períodos do que aqueles correspondentes aos dois outros casos analisados, com exceção da direção 90 graus com período 1 segundo. Do ponto de vista da geração, este foi o caso com resultados mais pobres em termos da qualidade do campo de ondas na zona de ensaios.

Com base nos resultados obtidos, a melhor opção de geração seria a combinação dos menores desvios padrão obtidos para os casos 2Flaps e 1Flap. Para colocar isso em prática, é necessário criar meios de alterar os flaps que ficarão imobilizados de forma prática, seja mecanicamente ou por software. A discussão sobre a exeqüibilidade deste procedimento está além do escopo deste trabalho e fica como uma sugestão para ser analisada pela equipe responsável pelo tanque.

Outro ponto interessante, mas que não foi abordado, é a possibilidade de reduzir os efeitos de ponta na onda causados pela ausência de alguns flaps com variações no stroke dos outros, como citado por O'Dea e Newman (2007). O simulador poderia ser empregado com este propósito, aspecto que voltará a ser discutido a seguir. 


\subsection{Recomendações para futuras pesquisas}

O principal propósito deste trabalho foi o de criar uma ferramenta simplificada que seria útil na fase de projeto de tanques que dispõe de geradores de onda segmentados. Durante os testes com o simulador, este demonstrou-se útil também no estudo das ondas geradas na área de ensaio, podendo ser então utilizado para testar variações no procedimento de atuação dos geradores.

A primeira sugestão é a realização de comparações de resultados providos pelo simulador com resultados experimentais que podem ser obtidos no $\mathrm{CH}$-TPN. Até o momento, o simulador só foi comparado com resultados numéricos e a comparação com medições obtidas em ensaios no tanque é uma grande oportunidade de pesquisa.

Outra aplicação interessante seria a utilização do simulador para realizar um estudo sobre a variação na amplitude de cada gerador com o objetivo de gerar uma onda mais uniforme, conforme foi discutido por O'Dea e Newman (2007). Neste trabalho, mostraram que, com a diminuição gradativa da amplitude dos geradores de acordo com a sua proximidade da parede, foi possível obter uma diminuição considerável nas variações de amplitude ao longo da crista das ondas. Pode-se imaginar, inclusive, a aplicação de um processo de otimização para este tipo de problema. O método teria como objetivo minimizar as flutuações do campo de ondas em área pré-deteriminada através da escolha da melhor combinação de amplitudes e fases para as diferentes fontes geradoras e usaria o simulador ora apresentado como ferramenta para a avaliação dos resultados de cada uma destas combinações.

Por fim, fica a sugestão da modelagem da absorção de onda no simulador. A absorção ativa de ondas pode ser considerada como a geração de ondas com fase e direção opostas à da onda incidentes e é baseada em estimadores de freqüência e amplitude através da leitura de ondógrafos posicionados na frente dos flaps. O simulador é capaz de reproduzir a elevação de onda nestes pontos e, assim, simular a leitura feita pelos ondógrafos dos flaps, tornando possível a aplicação da teoria de absorção para calcular a resposta necessária em cada um dos flaps para gerar a 
onda responsável por eliminar a reflexão. Uma vez calculada a resposta de cada flap (em termos de intensidade e fase da fonte) através do sistema de controle da absorção, recai-se novamente no problema de geração de ondas, para o qual o simulador já se encontrada preparado. Com isso, seria possível emular os movimentos de cada flap e a interferência entre o campo de ondas incidente e aquele gerado pelos absorvedores, inclusive com a modelagem do efeito das ondas evanescentes. Com esta extensão da ferramenta, verificações experimentais mais abrangentes se tornam possíveis, com a comparação de medidas obtidas em ensaios que envolvam a operação dos absorvedores ativos de ondas. 


\section{Referências}

[1] Biesel F., Suquet F. et al., - "Laboratory Wave-Generating Apparatus" - Project Report $n^{\circ}$ 39, St. Anthony Falls Hydraulic Laboratory, University of Minessota, 1954.

[2] Biesel F. - "Wave Machines." - Neyrpic Hydraulic Laboratory - Genoble, France, 1954.

[3] Carneiro, M. L., "Desenvolvimento de dispositivo de geração e absorção ativa de ondas para tanque de ensaios de estruturas oceânicas", Dissertação apresentada à Escola Politécnica da USP, 2007.

[4] Carneiro, M.L.; de Mello, P. C.; Labate, F.; Araújo, A. A .M.; Simos, A.N.; Tannuri, E. A., "USP Wave Basin: Active wave absorption and generation algorithms", 4th International Workshop on Applied Offshore Hydrodynamics, 2009, Rio de Janeiro.

[5] de Mello, P. C. ; Carneiro, M.L. ; Tannuri, E. A. ; Nishimoto, K. . "USP Active Absorption Wave Basin: From Conception to Commissioning", Proceedings of the ASME 29th International Conference on Ocean, Offshore and Arctic Engineering, 2010.

[6] Dean, R.G., Dalrymple, R.A, "Water wave mechanics for engineers and scientists”World Scientific., 1991.

[7] Hirayama, T., "Generation and Simulation of Multi-Directional Transient Water Waves in a Longitudinal Towing Tank.", Japan Kansai Society of Naval Architeture, № 222, pp 203-209, 1994.

[8] Hyun, Jae Min, "Theory for Hinged Wavemakers of Finite Draft in Water of Constant Depth”, Journal Hydronautics, Vol.10, NO.1, 1976 
[9] Ito, K., Katsui, H., Mochizuki, M., Isobe, M. "Non-reflected multi directional wave maker theory and experiments verification." Proc., Wave Generation 95, Yokohama, pp. 106-125, 1996

[10] Maeda, K., Hosotani, N., Tamura, K., Hirotomo, A, "Wave making properties of circular basin." Int. Symp. Und. Tech.., Taipei, pp. 349 - 54, 2004.

[11] Michima, Paula Suemy dos Santos., "Estudo de um absorvedor de ondas ativo para tanque didático". Dissertação (Mestrado em Engenharia Naval e Oceânica) - Universidade de São Paulo, 2007.

[12] Naito, S., "Wave Generation and Absorption, Theory and Application." Proceedings of the Sixteenth International Offshore and Polar Engineering Conference, 2006

[13] Newman, J.N. "Marine Hydrodynamics." MIT Press, Cambridge, Massachusetts, 1977.

[14] Newman, J. N., "Analysis of wave generators and absorbers in basins", Unpublished Manuscript, 2008 (consultado em www.wamit.com em dezembro de 2009).

[15] O'Dea, J.F, Newman, J.N., "Numerical Studies of Directional Wavemaker Performance." 28th American Towing Tank Conference, Ann Arbor, Michigan 2007

[16] Schaffer, H. A., Klopman, G., "Review of multidirectional active wave absorption methods." Journal of Waterway, Port, Coastal and Ocean Engineering, 2000. 


\section{APÊNDICE A. Dispositivos de Geração}

Diversos dispositivos foram desenvolvidos com o objetivo de gerar ondas. Todos eles têm como idéia principal induzir o mesmo perfil de velocidades presente em uma onda plana progressiva.

Cada um deles tem características que os fazem mais ou menos adequados para determinada situação de geração. A seguir serão apresentados os principais dispositivos criados, as idéias envolvidas e seus pontos fortes e fracos.

\section{- $\quad$ Flap Flexível}

Baseando-se na teoria de onda, este tipo de flap foi concebido sobre o perfil de velocidades horizontal das partículas fluidas. O objetivo era fazer um flap capaz de copiar exatamente o perfil de velocidades presente sob a onda, ou seja, a velocidade do flap deve decair exatamente como decaem as velocidades no fluido.

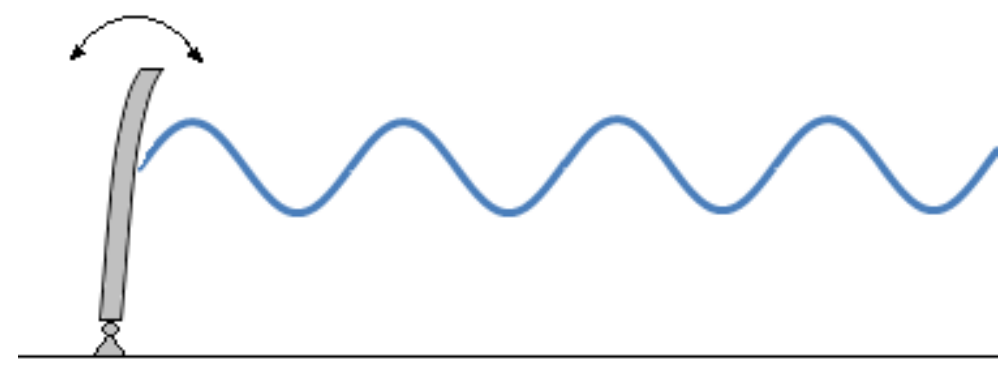

Figura 21: Gerador tipo flap Flexível.

Este pode ser considerado o flap ideal, não gerando perturbações indesejadas, como as ondas evanescentes, as quais serão discutidas adiante. Estas surgem por causa da incompatibilidade entre as velocidades do flap e as velocidades do fluxo sob uma onda progressiva. Porém, para atingir este objetivo, o mecanismo de atuação do flap, bem como sua estrutura flexível, 
tornaram-se bastante complexos e, conseqüentemente, caros para utilização em grande escala.

\section{- $\quad$ Flap bi-articulado}

É um dispositivo composto por dois flaps ligados por barras rígidas, porém, apenas um deles em contato com a água. $O$ flap traseiro, que não está em contato com a água, tem uma articulação posicionada no fundo do tanque e um mecanismo atuador em sua parte superior, conforme pode ser visto na figura 2.

O flap dianteiro, em contato com a água, tem sua base correndo em uma guia, posicionada ao fundo do tanque, existindo velocidade inclusive na região próxima ao fundo.

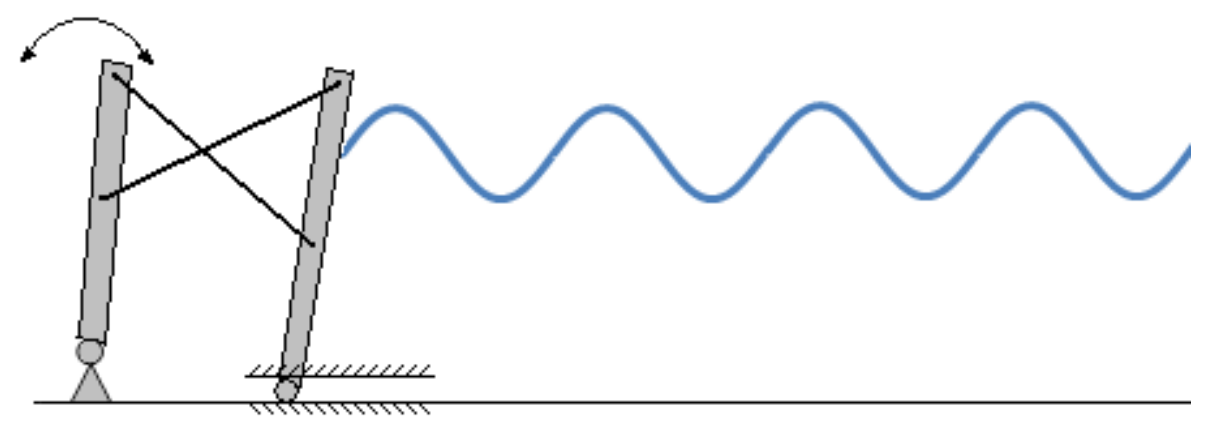

Figura 22: Gerador tipo flap Bi-Articulado.

Este dispositivo foi desenvolvido com o objetivo de melhor reproduzir o perfil de uma onda longa em profundidade finita, caso em que as velocidades horizontais próximas ao fundo do tanque não são desprezíveis. Seu mecanismo também é um tanto complexo e necessita de ajustes para cada freqüência de onda, dificultando sua aplicação prática.

- Tipo cunha 
É composto por uma cunha que se movimenta na vertical, assim gerando ondas. Os primeiros geradores deste tipo utilizavam uma seção triangular que, posteriormente, foi substituída por uma seção parabólica, por esta melhorar a qualidade da onda gerada. A figura 3 apresenta um esquema deste tipo de sistema.

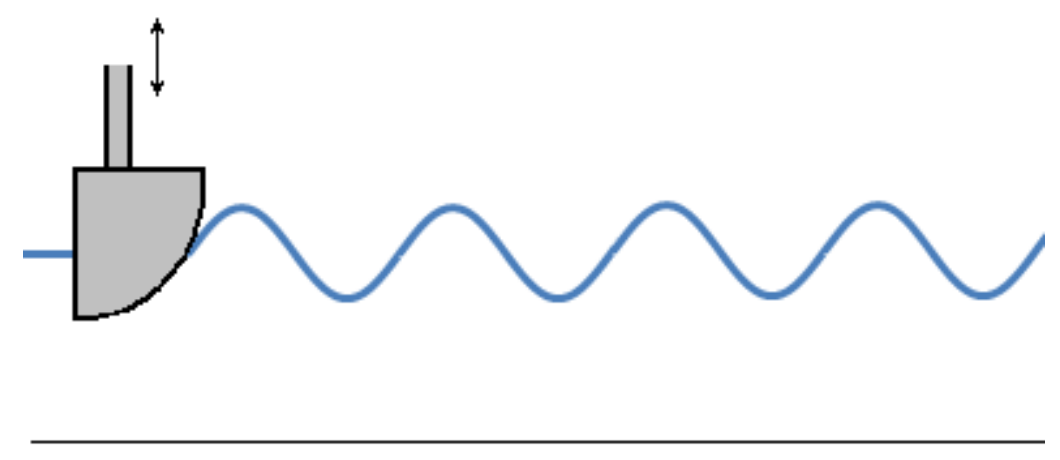

Figura 23: Gerador tipo cunha.

Um exemplo de aplicação deste dispositivo sendo utilizado como gerador e absorvedor é o Amoeba (Naito, 2006), um tanque acadêmico circular com 1,6 metros de diâmetro, desenvolvido na Universidade de Osaka.

- $\quad$ Tipo Pistão

Consiste em uma parede móvel, que se movimenta apenas na horizontal, conforme mostra a figura 4 . O sistema é bastante simples, porém não é muito utilizado. Seu rendimento é muito bom em geração de ondas longas em pequenas profundidades, onde vale a teoria de profundidade finita e, portanto, existem velocidades consideráveis na proximidade com o fundo. Contudo, a maioria dos tanques opera em condições de profundidade infinita, ou seja, o perfil de velocidade do fluido tem decaimento exponencial com a profundidade enquanto o deste gerador tem velocidade constante com a profundidade. Esta diferença entre os perfis de velocidade próximo ao fundo gera perturbações ${ }^{[1]}$ com amplitudes significativas na onda gerada. 


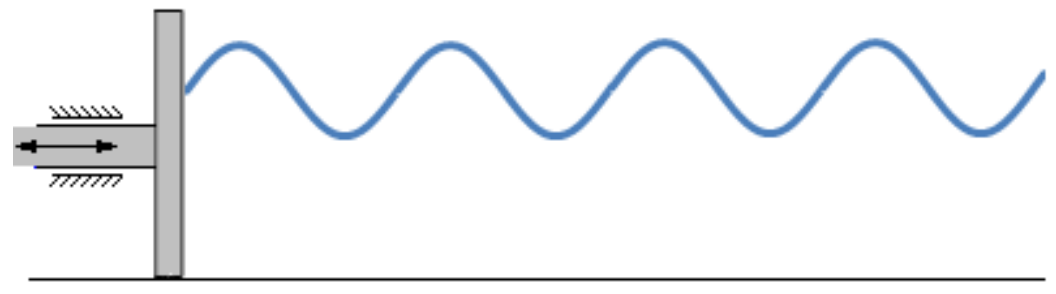

Figura 24: Gerador tipo Pistão.

- $\quad$ Tipo Flap

Este é o sistema mais utilizado em tanques na atualidade. A simplicidade do sistema aliada aos bons resultados na geração de ondas é responsável por esta larga utilização.

Consiste basicamente de uma chapa rígida, articulada no fundo do tanque, com o acionamento na parte superior, acima da água, conforme pode ser visto na Figura 25. O perfil de velocidades em sua parede tem decaimento linear com a profundidade, sendo sempre nulo no fundo.

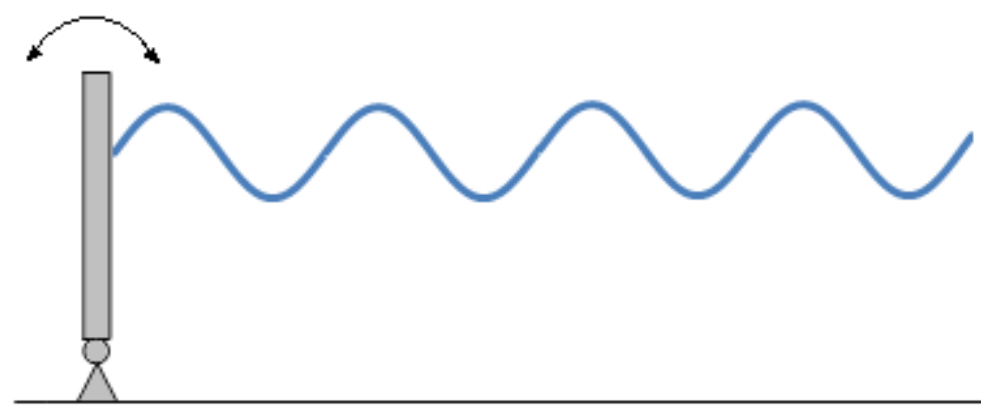

Figura 25: Gerador tipo flap.

Como é de se esperar, existem perturbações resultantes da incompatibilidade entre os perfis de velocidade. Porém, quando opera em condições nas quais é válida a teoria de águas profundas, estas perturbações têm amplitudes pequenas em relação à amplitude da onda gerada. Apesar de pequenas, estas perturbações devem ser consideradas na vizinhança do gerador, onde elas têm sua amplitude máxima. A ordem de grandeza destas perturbações será discutida quando for apresentada a função de transferência do flap. 
A partir de agora, será desenvolvida a teoria de geração e absorção de ondas, sempre mantendo o foco em geradores do tipo flap, gerador escolhido para utilização no Calibrador Hidrodinâmico. 